\title{
Implicit measures of association in psychopathology research
}

Citation for published version (APA):

Roefs, A., Huijding, J., Smulders, F. T. Y., MacLeod, C. M., de Jong, P. J., Wiers, R. W., \& Jansen, A. T. M. (2011). Implicit measures of association in psychopathology research. Psychological Bulletin, 137(1), 149-193. https://doi.org/10.1037/a0021729

Document status and date:

Published: 01/01/2011

DOI:

10.1037/a0021729

Document Version:

Publisher's PDF, also known as Version of record

Document license:

Taverne

Please check the document version of this publication:

- A submitted manuscript is the version of the article upon submission and before peer-review. There can be important differences between the submitted version and the official published version of record.

People interested in the research are advised to contact the author for the final version of the publication, or visit the DOI to the publisher's website.

- The final author version and the galley proof are versions of the publication after peer review.

- The final published version features the final layout of the paper including the volume, issue and page numbers.

Link to publication

\footnotetext{
General rights rights.

- You may freely distribute the URL identifying the publication in the public portal. please follow below link for the End User Agreement:

www.umlib.nl/taverne-license

Take down policy

If you believe that this document breaches copyright please contact us at:

repository@maastrichtuniversity.nl

providing details and we will investigate your claim.
}

Copyright and moral rights for the publications made accessible in the public portal are retained by the authors and/or other copyright owners and it is a condition of accessing publications that users recognise and abide by the legal requirements associated with these

- Users may download and print one copy of any publication from the public portal for the purpose of private study or research.

- You may not further distribute the material or use it for any profit-making activity or commercial gain

If the publication is distributed under the terms of Article $25 \mathrm{fa}$ of the Dutch Copyright Act, indicated by the "Taverne" license above, 


\title{
Implicit Measures of Association in Psychopathology Research
}

\author{
Anne Roefs \\ Maastricht University \\ Fren T. Y. Smulders \\ Maastricht University \\ Peter J. de Jong \\ Groningen University
}

\author{
Jorg Huijding \\ Erasmus University Rotterdam \\ Colin M. MacLeod \\ University of Waterloo \\ Reinout W. Wiers \\ University of Amsterdam
}

\author{
Anita T. M. Jansen \\ Maastricht University
}

\begin{abstract}
Studies obtaining implicit measures of associations in Diagnostic and Statistical Manual of Mental Disorders (4th ed., Text Revision; American Psychiatric Association, 2000) Axis I psychopathology are organized into three categories: (a) studies comparing groups having a disorder with controls, (b) experimental validity studies, and (c) incremental and predictive validity studies. In the first category, implicit measures of disorder-relevant associations were consistent with explicit beliefs for some disorders (e.g., specific phobia), but for other disorders evidence was either mixed (e.g., panic disorder) or inconsistent with explicit beliefs (e.g., pain disorder). For substance use disorders and overeating, expected positive and unexpected negative associations with craved substances were found consistently. Contrary to expectation, implicit measures of self-esteem were consistently positive for patients with depressive disorder, social phobia, and body dysmorphic disorder. In the second category, short-term manipulations of disorder-relevant states generally affected implicit measures as expected. Therapeutic interventions affected implicit measures for one type of specific phobia, social phobia, and panic disorder, but not for alcohol use disorders or obesity. In the third category, implicit measures had predictive value for certain psychopathological behaviors, sometimes moderated by the availability of cognitive resources (e.g., for alcohol and food, only when cognitive resources were limited). The strengths of implicit measures include (a) converging evidence for dysfunctional beliefs regarding certain disorders and consistent new insights for other disorders and (b) prediction of some psychopathological behaviors that explicit measures cannot explain. Weaknesses include (a) that findings were inconsistent for some disorders, raising doubts about the validity of the measures, and (b) that understanding of the concept "implicit" is incomplete.
\end{abstract}

Keywords: implicit measures, psychopathology, validity

Over the past decade, indirect measurement procedures such as the Implicit Association Test (IAT; Greenwald, McGhee, \& Schwartz, 1998) and the affective priming paradigm (APP; Fazio, Sanbonmatsu, Powell, \& Kardes, 1986) have become increasingly popular in psychopathology research. No doubt their popularity rests on their potential for extending measurements of disorder- relevant psychological attributes beyond what direct selfassessment can reveal. Traditionally, psychopathology researchers had relied largely on self-assessment questionnaires to obtain measures of patients' beliefs and feelings, measures that therefore were necessarily explicit. An important limitation of explicit measures is that they depend on patient introspection although we
Anne Roefs and Anita T. M. Jansen, Department of Clinical Psychological Science, Faculty of Psychology and Neuroscience, Maastricht University, Maastricht, the Netherlands; Jorg Huijding, Clinical Psychology Program, Institute of Psychology, Erasmus University Rotterdam, Rotterdam, the Netherlands; Fren T. Y. Smulders, Cognitive Neuroscience Department, Faculty of Psychology and Neuroscience, Maastricht University; Colin M. MacLeod, Department of Psychology, University of Waterloo, Waterloo, Ontario, Canada; Peter J. de Jong, Clinical Psychology, Department of Psychology, Faculty of Behavioural and Social Sciences, Groningen University, Groningen, the Netherlands;
Reinout W. Wiers, Developmental Psychology, University of Amsterdam, Amsterdam, the Netherlands.

We thank Jessie Beerthuyzen for locating all of the doi information, Wilhelm Hofmann for critical reading of sections of the article, Jan De Houwer for his valuable advice as a reviewer, and Nnamdi Pole for careful editing and advice concerning the article.

Correspondence concerning this article should be addressed to Anne Roefs, Department of Clinical Psychological Science (UNS40), Faculty of Psychology and Neuroscience, Maastricht University, P.O. Box 616, 6200 MD, Maastricht, the Netherlands. E-mail: A.Roefs@maastrichtuniversity.nl 
know that people do not have introspective access to all of the mechanisms that underlie their behavior (Nisbett \& Wilson, 1977). Indeed, this limitation featured centrally in early approaches to psychopathology (Freud, 1901/1914). Explicit measures are also subject to other criticisms, including their sensitivity to socially desirable answering tendencies and the fact that people sometimes may dismiss as irrelevant cognitions that actually are relevant (Schwarz, 1999; Schwarz \& Oyserman, 2001).

To complement these explicit measures of psychological attributes, researchers have designed procedures such as the IAT and the APP to obtain implicit measures. De Houwer, TeigeMocigemba, Spruyt, and Moors (2009a) defined an implicit measure as "a measurement outcome that is causally produced by the to-be-measured attribute in the absence of certain goals, awareness, substantial cognitive resources, or substantial time" (p. 350). It is important to keep in mind that implicitness is not an all-ornone feature of a measure (Moors \& De Houwer, 2006). For example, a measure can be labeled as implicit in the sense that people are unaware of (the origin of) their association or cannot control the process that leads to the measurement outcome. Thus, not all implicit measures possess the same features of implicitness. De Houwer and colleagues (De Houwer, 2006, 2009; De Houwer et al., 2009a) provide extensive reviews of the degree to which various implicit measures meet the criteria for implicitness.

To the extent that implicit measures reflect uncontrollable, unaware, fast mechanisms, they could provide information that augments that from explicit measures. This is important in psychopathology research where self-presentation strategies are always of concern. For example, when in a clinic, some patients with alcohol dependence may have difficulty admitting their strong positive attitude toward alcohol. To the extent that implicit measures cannot be controlled (faked), they can provide important information. In addition, measures that are implicit in the sense that they are produced by attributes of which the person is unaware could reveal insights beyond those of conscious (explicit) measures. Moreover, measurement procedures that are implicit in the sense that they are based on rapid processing (notably involving speeded response times) are more likely to capture automatic effects of psychological attributes than are self-paced measures (cf. MacLeod, 2008, regarding distinguishing implicit from explicit memory).

The distinction between implicit and explicit measures originally gave rise to a debate about which measure reflects a person's true attitude, a debate that Fazio and Olson (2003) facetitiously characterized as "Will the real attitude please stand up?" (p. 304). Current thinking treats implicit and explicit measures as complementary rather than as competitors, with neither paramount. As reflected in dual-process models (e.g., Fazio \& Towles-Schwen, 1999; Smith \& DeCoster, 2000; Strack \& Deutsch, 2004), both types of measures are true in the sense that both have predictive validity. These models specify the conditions under which each type of measure is theorized to be predictive of behavior: Explicit measures are expected to be predictive when resources used for cognitive control are high, whereas implicit measures are expected to be predictive when these resources are low. Thus, when resources are limited either because of time constraints or competing cognitive demands, people have no time to deliberate and therefore behavior is best predicted by implicit measures.

In psychopathology research, an implicit measure is often assumed to reflect the strength of association between a disorder- relevant target (e.g., the self in depression) and an attribute (e.g., negative). These targets and attributes have been derived from two possible sources, both related to the dysfunctional beliefs held by those with the disorder. The first concerns dysfunctional beliefs (e.g., a patient suffering from depression typically holds the dysfunctional belief "I am worthless"), as specified in the principal cognitive theories, often based on Beck's cognitive approach to psychopathology (e.g., Beck \& Clark, 1997; Beck, Freeman, \& Davis, 2004; Beck, Rush, Shaw, \& Emery, 1979). The second concerns dysfunctional beliefs that are apparent either from the main characteristics of the disorder as specified in the Diagnostic and Statistical Manual of Mental Disorders (4th ed., Text Revision [DSM-IV-TR]; American Psychiatric Association, 2000; e.g., a patient with social phobia is afraid of humiliation or of a negative evaluation in social situations) or from clinical observation (e.g., craving in substance use disorders). Therefore, implicit measures are taken to reflect associations between disorder-relevant targets and particular focal attributes. As a result, they have the potential to reveal aspects of the dysfunctional beliefs that explicit measures cannot reveal and to predict behaviors that explicit measures do not predict.

To help achieve conceptual clarity with respect to the term implicit measure, we note the usefulness of distinguishing between measurement procedures and measurement outcomes (De Houwer, 2006; De Houwer et al., 2009a). A measurement procedure (e.g., IAT) is simply the specific experimental methodology, the set of guidelines followed that lead to an outcome. A measurement outcome is the result of the measurement procedure. We prefer to reserve the term measure for the measurement outcome, so in this article, we use the term implicit measure to refer to the outcome of a measurement procedure such as the IAT or the APP. This is also a good point at which to note that the theory for a particular disorder as described in this review is often not the only cognitive theory for the disorder. We chose to describe those theories that inspired the work using implicit measures.

With this background, we can now state our goal for this article: to provide an integrative review of studies that obtained implicit measures of disorder-relevant associations. In the service of this goal, the article is structured as follows. First, the various measurement procedures that have been used in psychopathology research are explained, along with a brief discussion of the reliability and validity of each. This review includes studies with indirect measurement procedures, such as the IAT (Greenwald et al., 1998) and variants on this test, the APP (Fazio et al., 1986), the Affective Simon Task (De Houwer, Crombez, Baeyens, \& Hermans, 2001; De Houwer \& Eelen, 1998), the Extrinsic Affective Simon Task (De Houwer, 2003b), and approach and avoidance tasks (De Houwer et al., 2001; Rinck \& Becker, 2007). For the approach and avoidance tasks, because approach is related to positive valence and avoidance to negative valence, performance on these tasks is theorized to reflect affective associations. Although memory and attentional biases likely will also contribute to our understanding of dysfunctional beliefs, they are not included in this review because they have been extensively reviewed elsewhere (Harvey, Watkins, Mansell, \& Shafran, 2004; Williams, Mathews, \& MacLeod, 1996). Second, the convergent and discriminant validity of implicit measures is discussed. These set the stage for the third and major part third and major part-a review of research using implicit measures in psychopathology. 


\section{Organizing the Research}

The studies included in this review are structured into three categories (see De Houwer et al., 2009a) as follows.

\section{Studies Comparing Groups Having a Disorder With Controls}

In this quasi-experimental approach, a disordered group is compared to a healthy group. The typical expectation is that there will be a disorder-congruent association in the disordered group but that this association will be weaker or absent in the healthy control group. An example would be an implicit measure that reflects a negative association with spiders that is specific to individuals with spider phobia (see, e.g., Watts, McKenna, Sharrock, \& Trezise, 1986). Somewhat less consistent with dysfunctional beliefs is an implicit measure that reflects a disorder-incongruent association that is weaker in a disordered group than in a healthy control group. For example, finding reduced positive implicit self-esteem in depressed patients as compared with healthy controls is not fully in line with the negative dysfunctional belief of depressed individuals regarding the self (D. A. Clark, Beck, \& Alford, 1999) but does show that the self-esteem of depressed patients is relatively negative compared with that of healthy controls.

\section{Experimental Validity Studies}

In this category, there are two types of experimental studies. The first involves manipulating an aspect of the psychopathology to study its effect on the implicit measure. For example, deprivational state in nicotine-dependent people could be manipulated to affect craving (Sherman, Rose, Koch, Presson, \& Chassin, 2003). In the second type of study, the effect of clinical treatment on implicit measures is examined. In these two types of study, if the manipulation or the treatment affects the implicit measure, that outcome is taken as evidence that the cognitive process indexed by the implicit measure plays a role in that type of psychopathology. This approach rests on two assumptions: (a) that the psychological attributes of interest are amenable to change and (b) that observed changes in an implicit measure are due to changes in the psychological attribute of interest rather than in some other process (De Houwer et al., 2009a). If these assumptions are satisfied, then these types of studies can yield stronger causal inferences than the quasi-experimental known-groups approach, because the risk of unrecognized confounds is reduced.

\section{Incremental and Predictive Validity Studies}

The third kind of study asks whether an implicit measure can predict a pathological behavior and, if so, whether it can do so beyond what can be explained by analogous explicit measures (e.g., study whether implicit measures of associations with alcohol have incremental validity for explaining alcohol use; Houben \& Wiers, 2006b). The dependent variables in such studies have been either self-reported or actually observed behavior. They have also varied in the extent to which they motivated behavioral control or demanded cognitive resources, which is relevant because dualprocess models of information processing (e.g., Fazio \& Towles-
Schwen, 1999) state that the accurate prediction of behavior with implicit and explicit measures depends on these factors.

\section{Measurement Procedures}

In each of the measurement procedures, participants are presented with single picture or word stimuli representing disorderrelevant targets (e.g., spider) and attributes (e.g., afraid). Participants are instructed to respond as quickly and as accurately as possible to these stimuli. Response latency and accuracy are the main dependent variables; ordinarily, latency is the variable of primary interest. The general idea behind the use of these paradigms is that a certain pattern of response latencies and error percentages can serve as an index of the strength of target-attribute associations in memory. We describe four paradigms (and variations) widely used in psychopathology research, and we discuss the validity and reliability of their outcomes. As is so often true with empirical measures throughout psychological research, information on reliability is limited and thus is described only when it is available. A more extensive review of the validity and reliability of some of these measures can be found in De Houwer et al. (2009a).

\section{The Implicit Association Test}

The task in the IAT (Greenwald et al., 1998) is to categorize each presented stimulus as quickly and accurately as possible according to a target dimension (e.g., high-fat foods vs. low-fat foods) or an attribute dimension (e.g., positive vs. negative). For example, chocolate should be categorized as a high-fat food, whereas happy should be categorized as positive. In the critical combination phases of the IAT, participants perform a doublecategorization task. In one of these combination phases, they are instructed to make a binary decision for stimuli from two dimensions simultaneously: one from the target dimension and one from the attribute dimension (e.g., press the left button for high-fat foods and positive words; press the right button for low-fat foods and negative words). In the other combination phase, the response assignment is reversed for the target dimension (e.g., press the left button for low-fat foods and positive words; press the right button for high-fat foods and negative words).

The IAT effect is typically calculated as the difference in average response latency (and/or percentage of errors) between these two combination phases. The logic behind the IAT is that people perform better when two associated targets/attributes share a response key than when two nonassociated targets/attributes share a response key. As used here, "associated" means that these targets/attributes are connected in the participant's mind. Therefore, if participants are better at responding when the combination is high fat and positive versus low fat and negative than when the combination is reversed, the conclusion would be that the participants have a more positive association with high-fat foods than with low-fat foods, even though this is an association that they might well not admit to were they directly queried.

Evidence for the validity of the IAT effect as an index of affective associations was first described in the seminal article by Greenwald et al. (1998). Their experiment tested affective associations to concepts to which people are expected to have relatively uniform associations: flowers and insects. Participants were faster 
in the compatible phase (flowers-positive and insects-negative) than in the incompatible phase (flowers-negative and insectspositive), clearly showing that the IAT can capture affective associations. Since then, many studies have replicated and extended the basic paradigm and finding of Greenwald et al.

Converging support comes from studies in which novel affective associations were created for previously unknown stimuli with a classical conditioning procedure. Both IAT results and an analogous explicit measure reflected these newly created attitudes despite participants showing no awareness that the conditioned stimulus (CS) and unconditioned stimulus (US) were contingently paired (Olson \& Fazio, 2001). Because affective associations appear to be the only likely source of the IAT effect, this constitutes strong evidence that the IAT can capture affective associations. On the basis of these studies and the evidence reviewed elsewhere (De Houwer et al., 2009a), it is now generally accepted that IAT effects can reflect affective associations, although other potential sources of IAT effects have also been identified (Dasgupta, McGhee, Greenwald, \& Banaji, 2000; De Houwer, Geldof, \& De Bruycker, 2005; Fiedler, Messner, \& Bluemke, 2006; Mierke \& Klauer, 2003; Rothermund \& Wentura, 2001, 2004).

Research has shown that IAT measures are indeed less controllable than are explicit measures, which is good news for the claim that IAT measures are implicit. For example, when instructed to appear either conscientious or not conscientious, participants were less able to do so on an IAT measure than on a self-report measure (Steffens, 2004). However, at least some studies have shown that IAT measures are not implicit in the sense that people are unaware of the associations that a particular IAT aims to assess. For example, in a racial attitude IAT, a considerable proportion of Caucasian participants felt the IAT effect, in that they realized that they were slower in the black-positive/white-negative block than in the black-negative/white-positive block. More than one third of these participants attributed this slowness to racial associations (Monteith, Voils, \& Ashburn-Nardo, 2001), which shows that participants often are aware of what the IAT is intended to assess. Note that the IAT effect did not itself depend on such awareness. In general, both the internal consistency $(r / \alpha=.7$ to .9$)$ and the test-retest reliability (median $r=.56$ ) for the IAT are moderately good (see De Houwer et al., 2009a; Nosek, Greenwald, \& Banaji, 2007).

\section{Variants on the Implicit Association Test}

Variants on the IAT have been designed, some of which have had the goal of solving limitations of the original IAT. In all of these variants, the basic task and the type of stimuli are similar to the original IAT: Participants are asked to sort single word or picture stimuli into predefined categories. The logic and computation of effect scores are also the same as in the original IAT. These variants derive some superficial validity from their structural similarities with the original IAT, but in some cases studies with normatively positive and negative stimuli provide formal evidence of their validity (e.g., Nosek \& Banaji, 2001). We consider five such variants.

Personalized Implicit Association Test. The goal of this modification was to make more direct reference to the self. To achieve this, the personalized IAT differs from the original IAT in two main ways: (a) It uses as attribute labels "I like" and "I dislike" instead of the more normative "positive" and "negative" and (b) it does not provide error feedback. Target categories (e.g., high-fat foods vs. low-fat foods) are the same as in the regular IAT. The personalized IAT was intended to focus on the individual, thereby reducing the influence of extrapersonal associations, such as those that are part of a culture, on the original IAT (Olson \& Fazio, 2004; Olson, Fazio, \& Han, 2009). Note, however, that Nosek and Hansen (2008) argued against culture as a contaminating influence on the IAT and additionally pointed to the futility of attempting to separate cultural from personal influences on responses to the IAT.

Single-Category Implicit Association Test (SC-IAT). The SC-IAT uses only one target category (e.g., alcohol; Karpinski \& Steinman, 2006). The measure was developed to achieve a measure of absolute (rather than relative) strength of association between a target category and attribute categories. As Greenwald and Farnham (2000) acknowledged, the original IAT can yield only relative strength measures. For example, the standard self-esteem IAT assesses associations between me-other and positivenegative, indicating whether a person has more positive/negative associations with me than with other but not indicating the strength of the evaluation of either me or other. This need not be a weakness, considering that many categories have a naturally opposing contrast category, but for research questions where no such contrast category exists (e.g., for cocaine or spiders), it is preferable to have an IAT-like task that does not require a contrast category. The SC-IAT contains two combination blocks. In one, the target category shares a response key with positive attributes; the other key is pressed for negative attributes. In the other critical block, the target key assignment is shared with negative attributes. Note that the SC-IAT is essentially identical to the single-target IAT (ST-IAT; Bluemke \& Friese, 2008). Initial studies reported that the SC-IAT had comparable internal consistency (.69) to the original IAT (Karpinski \& Steinman, 2006).

Unipolar Implicit Association Test. As discussed, the original IAT is limited in yielding relative - not absolute-attribute information. For example, it can only be concluded that certain associations are more positive than negative. However, for some attitude objects (e.g., chocolate), it may be relevant to assess the negative (e.g., unhealthy) and positive (e.g., palatable) associations independently (de Liver, van der Pligt, \& Wigboldus, 2007). Therefore, the unipolar IAT was developed, in which an attribute category of interest (e.g., positive) is contrasted with neutral (see, e.g., Jajodia \& Earleywine, 2003). For example, positive and negative associations with the target alcohol versus the target soft drinks can be assessed independently by contrasting positive with neutral and negative with neutral associations in separate unipolar IATs. Note that a single-category variant of the unipolar IAT has also been used (see, e.g., Houben \& Wiers, 2008a). The reported internal consistency of the unipolar IAT has ranged rather widely from .29 to .77 (Houben \& Wiers, 2009).

Go/no-go Implicit Association Test. The go/no-go IAT (Nosek \& Banaji, 2001), like the SC-IAT, has the advantage that it can assess attitudes toward a single target category. Participants are required to respond on go trials: In one condition, participants respond to the target category (e.g., fruit) and one attribute category (e.g., positive). In another condition, they respond to the same target category and an alternative attribute category (e.g., negative). On no-go trials in both conditions, participants withhold 
responses to stimuli that do not belong to one of these categories. In this example, associations with fruit should be reflected in the difference in the ease of responding between the two conditions. Manipulating what is presented on no-go trials can influence the context in which an attitude is assessed. For example, the target category fruit can be assessed in isolation, that is, without stimuli from a contrasting target category being presented on no-go trials. In this case, only negative or positive stimuli would be presented on no-go trials. If the researcher desires to assess associations with a target category in comparison to a contrast category (e.g., snacks), stimuli from this contrast category should be included among the no-go trials as well. The reported internal consistency of the go/no-go IAT has varied from low (.20; Nosek \& Banaji, $2001)$ to considerably higher (.50 to .82; Boldero, Rawlings, \& Haslam, 2007; Leeuw, Peters, Wiers, \& Vlaeyen, 2007).

Affective Simon Task. In a typical Affective Simon Task (De Houwer et al., 2001; De Houwer \& Eelen, 1998), the person responds to each stimulus by saying a positive or a negative word aloud. The interesting element of the task is that the person is instructed to ignore the affective meaning of the stimulus, responding instead on the basis of a nonaffective property of the stimulus, such as grammatical category or lettercase. For example, an individual might be asked to say "positive" when he or she sees a noun and to say "negative" when he or she sees an adjective. The validity of this measure as an index of affective associations is supported by De Houwer and Eelen's (1998) finding that participants responded faster when the task-irrelevant valence of a stimulus and the required response were congruent. For example, for the stimulus SUNSHINE, people were faster when told to say "positive" than when told to say "negative" in response to uppercase words.

De Houwer (2003b) introduced a useful variant on the Affective Simon Task - the Extrinsic Affective Simon Task (EAST). In this version, the participant responds using buttons associated with a certain affective value during the task (hence, extrinsic) rather than with an actual affective response such as "positive" or "negative" (hence, intrinsic). In the initial version of the EAST, white, blue, and green words were presented. The white words were either positive or negative, and participants classified these words as such by pressing one key for positive words and another key for negative words (e.g., left for positive, right for negative). The colored words were the target concepts (e.g., spiders). Participants categorized these words on the basis of their color (e.g., left for blue, right for green). In the critical blocks, white and colored words were mixed. In this example, it should be easier for an individual with spider phobia to respond to spider words in green than to those in blue because green words and negative words have been assigned a common response key. A virtue of the Affective Simon Task and the EAST is that computation of its effect does not depend on comparing two separate trial blocks as is the case in the IAT, the SC-IAT, and the go/no-go IAT (combination vs. reversed combination); instead, the effect can be assessed in a single block, avoiding complicating order effects.

Variants of the EAST include a pictorial version (Huijding \& de Jong, 2005a, 2005b) and the identification-EAST (ID-EAST), in which participants are instructed to process the meaning of the target stimuli (De Houwer \& De Bruycker, 2007). The validity of the EAST is supported by studies showing that it can assess affective associations with normatively positive and negative stim- uli (De Houwer, 2003b). Although the EAST has generally shown quite low internal consistency ( $r=.12$ to .55 ; De Houwer, 2003b; Leeuw et al., 2007; Teige, Schnabel, Banse, \& Asendorpf, 2004), the internal consistency of the ID-EAST has been considerably better ( $\alpha=.60$ to .66; De Houwer \& De Bruycker, 2007).

\section{The Affective Priming Paradigm}

The APP (Fazio et al., 1986; Klauer \& Musch, 2003) is the other very popular technique. In this task, two stimuli are presented in quick succession: a prime followed by a target. Prime stimuli represent the concepts of interest (e.g., spiders vs. butterflies) and target stimuli represent the attribute categories (e.g., positive vs. negative). No response is required to the prime, but participants must respond to the target by evaluating it as being positive or negative or by just naming it. The purpose of the priming paradigm is to determine the extent to which the presentation of the prime influences the response to the target. The critical idea is that affectively congruent prime-target pairs (e.g., spider-awful) should lead to shorter response latencies to the target word than should affectively incongruent prime-target pairs (e.g., spiderhappy) (Bargh, Chaiken, Govender, \& Pratto, 1992; Fazio et al., 1986; Hermans, De Houwer, \& Eelen, 1994, 2001). To the extent that such a pattern of affective priming is observed, it is taken to reflect the person's evaluation of the prime (e.g., spiders).

The validity of the APP is supported by studies showing that it can capture affective associations with stimuli that most people normatively evaluate negatively (e.g., disaster) or positively (e.g., holidays; e.g., Fazio, 2001) and with stimuli for which novel affective associations were created experimentally (e.g., Olson \& Fazio, 2002). Research has shown that APP effects (a) are based on fast and relatively efficient processes, (b) can be found in the absence of awareness of the prime or of the origin of the attitude toward the prime, and (c) can be obtained without the intention to evaluate the prime (see De Houwer et al., 2009a, for a review). These findings all support the view that the APP yields valid implicit information. Some studies, however, have reported low internal consistency (e.g., Bosson, Swann, \& Pennebaker, 2000: $\alpha=-.16$ to .49; Olson \& Fazio, 2003: $r=.04$ ) and test-retest reliability (.08 to .28; Bosson et al., 2000). Studies conducted with latent variable analyses (Cunningham, Preacher, \& Banaji, 2001), which correct for measurement error, have shown substantially improved interitem consistency $(\alpha=.64)$ and test-retest reliability (stability estimate $=.68$ ).

Cunningham et al. (2001) noted that response-latency measures are vulnerable to low reliability because individual response latencies fluctuate over trials. Of course, this is more true, the fewer the number of trials there are per condition, so investigators should be careful to include as many trials per condition as is feasible. Note, too, that this criticism should apply to any response-time-based measure but that it may particularly apply to measurement procedures, such as the APP, in which the person does not need to categorize stimuli into predefined categories. This freedom leaves more room for different interpretations of the presented stimuli (Olson \& Fazio, 2003), which necessarily promotes variability over trials. 


\section{Approach and Avoidance Tasks}

Approach and avoidance have long been at the heart of work on animal motivation and learning, so it is not surprising that these concepts are also of interest in studying human behavior. Consider one variant of an approach and avoidance task-the stimulusresponse compatibility task (De Houwer et al., 2001; Mogg, Bradley, Field, \& De Houwer, 2003; Mogg, Field, \& Bradley, 2005). Participants are instructed to move a mannequin figure on the computer monitor toward one category of pictures and away from another category of pictures. For example, in one of the two critical phases, the mannequin is to be moved toward smokingrelated pictures and away from neutral pictures. In the other critical phase, the assignment of mannequin responses is reversed. The difference score between the two phases is taken to indicate the relative approach-avoidance tendency toward the focal category of pictures (i.e., those related to smoking).

Several other variants of the approach-avoidance task (Chen \& Bargh, 1999) have been introduced (e.g., Fishbach \& Shah, 2006; Rinck \& Becker, 2007). One such variant is similar to the stimulus-response compatibility task except that participants have to pull a joystick toward themselves for one category of pictures (e.g., smoking) and push it away from themselves for another category of pictures (e.g., neutral). In a further clever variant (Rinck \& Becker, 2007), pushing makes the picture increasingly smaller (which is considered an index of avoidance) and pulling makes the picture increasingly bigger (which is considered an index of approach). In some types of approach-avoidance task, the participant's response is based on the picture contents (e.g., push spider pictures and pull neutral pictures), which could be seen as more direct and possibly not as implicit. In other types, responding is based on an aspect of the stimulus not related to its content (e.g., push landscape-oriented pictures and pull portrait-oriented pictures). The task would appear to be more indirect and therefore possibly more implicit when the participant's response is based on the more unobtrusive content-irrelevant aspect, and this procedural difference might influence measurement outcomes.

Some variants of the approach-avoidance task have shown evidence of validity. The stimulus-response compatibility task has successfully assessed approach and avoidance tendencies toward normatively valenced stimuli (De Houwer et al., 2001), and a version of the approach-avoidance task has done so for stimuli about which participants held strongly positive or negative attitudes (Chen \& Bargh, 1999). Other variants of the approachavoidance task (Rinck \& Becker, 2007) have shown fairly good internal consistency (.71 to .80$)$.

\section{Convergent and Discriminant Validity With Explicit Measures and Other Implicit Measures}

Some might assume that implicit measures should show convergent validity with explicit measures assessing the same construct-that implicit-explicit correspondence should be high. If this were the case, however, then the added value of implicit measures would be questionable. In fact, it has consistently been found that implicit and explicit measures are related but also are distinct and that their variance is often best represented by two latent factors (Nosek \& Smyth, 2007). Moreover, the strength of the correspondence between implicit and explicit measures has been shown to vary as a function of the research domain (Hofmann, Gawronski, Gschwendner, Le, \& Schmitt, 2005; Nosek, 2005). To illustrate, a large Internet study on implicit measures of preferences conducted with the IAT showed the average implicitexplicit correspondence over 57 domains to be $r=.36$, with correlations ranging from $r=-.05$ (females-males) to $r=.70$ (prochoice-prolife) depending on the target categories (Nosek, 2005).

Several moderators have been identified that explain the variability in implicit-explicit correspondence (Hofmann et al., 2005; Nosek, 2005). For the IAT, implicit-explicit correspondence was higher (a) when self-presentation concerns were weak (e.g., Coke vs. Pepsi) as opposed to when they were strong (e.g., thin vs. overweight people); (b) when the research topic elicited more spontaneity on the explicit measure (e.g., self-report measures on spider phobias vs. morality); (c) for explicit measures that reflected affective evaluations (e.g., feeling thermometers) rather than cognitive evaluations (e.g., semantic differentials), consistent with the view that implicit measures reflect affective evaluations; (d) for explicit measures that contain the same type of relativity as the IAT (e.g., self vs. other), as opposed to those that reflect absolute evaluations (e.g., self-esteem); (e) for stronger evaluations (e.g., prochoice vs. prolife) than for weaker evaluations (e.g., short people vs. tall people); and (f) for evaluations perceived as unique, as more distinct from the norm (e.g., veganism vs. chocolate). Although these moderating factors have been well established only for the IAT, it is possible that some of them affect implicit-explicit correspondence for other measurement procedures as well, which would provide reassuring convergence across the measures. For the APP, the motivation to hide prejudice was a moderating factor, in that implicit-explicit correspondence was only observed for participants who were rather unmotivated to hide their prejudice (Fazio, Jackson, Dunton, \& Williams, 1995).

One general reason for a low correlation between implicit and explicit measures could be that they are obtained with very different procedures (method variance). In support of this, the correlation between these two types of measures greatly increased when the measurement procedures were made as similar as possible, by using the same response metric and the same type of stimuli in both measurement procedures, with the only remaining difference being that one was a direct assessment and the other an indirect assessment of evaluations (Payne, Burkley, \& Stokes, 2008). In addition, a low implicit-explicit correlation can be the result of a low reliability of one or both measures. This has also been a key issue in the cognitive literature on implicit versus explicit memory, with some evidence that implicit measures are sometimes unreliable (Buchner \& Wippich, 2000).

Although one might expect two implicit measures reflecting similar associations to correlate strongly, this has not been the case either in psychopathology research (e.g., nicotine dependence: Sherman et al., 2003; alcohol abuse: Thush et al., 2007) or in other types of research (Bosson et al., 2000; Cunningham et al., 2001). This lack of convergent validity may be partly explained by the inconsistency in procedures used to obtain implicit measures. Indeed, when using a latent variable approach, which corrects for this inconsistency, IAT and APP effects were found to correlate substantially ( $r=.63$; Cunningham et al., 2001). In addition, IAT and APP effects corresponded more strongly when the APP procedures were modified to more closely match those of the IAT, in 
that participants were told to focus on the categories (e.g., Black vs. White) rather than the exemplars (e.g., individual Black and White faces; Olson \& Fazio, 2003). These findings are reassuring with regard to the coherence of the implicit concepts they seek to measure. To increase the chance for meaningful correlations to emerge, future research should limit method variance and either use reliable measures or correct for measurement error.

With the preceding discussion on convergent validity in mind, in the review section on psychopathology research that has used implicit measures, the degree of implicit-explicit correlation in each reviewed form of psychopathology is briefly addressed, and all implicit-explicit correlations are listed in Tables 1 through 12. Note that the sign of the correlations was recoded where necessary so that the values could be interpreted in the same way across and within studies. A positive correlation indicates that the directions of the implicit and explicit measure were the same; a negative correlation indicates that the two measures had opposite directions. Overall, a fair degree of implicit-explicit correspondence was observed, although correlations generally were not very high.

\section{Psychopathology Research Conducted With Implicit Measures}

Following a sketch of each disorder, we describe characteristic dysfunctional beliefs and provide a brief discussion of the empirical support for these beliefs. Where possible, we also provide implicit-explicit correlations. Relevant research is discussed according to the three approaches, omitting sections where no studies were available within an approach for a particular disorder. Summaries are included where there is a sufficiently large literature.

\section{Specific Phobia}

Table 1 presents results of studies on specific phobia. Individuals with a specific phobia experience intense distress when confronted with a specific stimulus or situation, ranging from heights to blood to public speaking. Exposure to the phobic stimulus or situation is therefore avoided or endured with extreme distress (American Psychiatric Association, 2000). People with specific phobias have been shown-not surprisingly-to hold explicit threat-related beliefs, such as "the spider will suddenly approach me" (e.g., Arntz, Lavy, Van der Berg, \& Van Rijsoort, 1993; Thorpe \& Salkovskis, 1995). Implicit measures are therefore expected to reflect negative associations with these objects of fear (de Jong \& Muris, 2002). For pragmatic reasons-the high prevalence of this phobia (American Psychiatric Association, 2000) and the ready availability of the object of fear for behavioral measures-research with implicit measures involving specific phobias has focused exclusively on spider phobia.

For spider phobia, implicit-explicit correlations range from $r=$ -.21 to .67 , with most studies reporting the expected positive implicit-explicit correlations. Correlations are stronger for approach and avoidance tasks and for implicit measures that tested for associations with more specific spider-related attributes such as disgust and danger as opposed to less specific attributes such as positive and negative. The highest correlations ( $r s=.50$ to .67$)$ were observed in a study (Teachman, Gregg, \& Woody, 2001) in which the explicit and implicit measures made the same kind of relative comparisons (spiders vs. snakes), in line with the point just made about the importance of minimizing method variance.

Studies comparing having a disorder with controls. Several studies have shown that spider-fearful individuals have a characteristic pattern of affective associations to spiders. In Teachman et al. (2001), individuals with spider versus snake phobias performed four IATs, with spiders and snakes as the target categories and good-bad, danger-safety, disgusting-appealing, and afraid-unafraid as the attribute categories. Each of the IAT measures clearly differentiated the two phobic groups and, when combined into one variable, correctly classified $92 \%$ of the individuals as suffering from snake or spider phobia. Further research showed that IAT measures of spider associations also differentiated between highly fearful participants and nonfearful controls (Ellwart, Rinck, \& Becker, 2006; Huijding \& de Jong, 2007; Teachman \& Woody, 2003) and even spider enthusiasts (Ellwart et al., 2006).

Using a pictorial version of the EAST, Huijding and de Jong (2005b) found that both high- and low-fearful students had negative associations with spider stimuli, an effect more pronounced in the high-fearful participants. In a later study, this EAST measure significantly differentiated between treatment-seeking spiderfearful individuals and nonfearful controls (Huijding \& de Jong, 2009). In addition, a go/no-go IAT measure was also successful in distinguishing between high and low spider-fearful participants (Teachman, 2007). Converging evidence was found with an approach-avoidance task: In each of three experiments, spiderfearful individuals showed more avoidance of spider pictures than did healthy controls, whereas no such difference emerged for neutral pictures (Rinck \& Becker, 2007).

In contrast, high and low spider-fearful individuals showed similar negative affective associations with spiders on an IAT (where spiders were contrasted to the neutral category) ${ }^{1}$ as well as on an Affective Simon Task (de Jong, van den Hout, Rietbroek, \& Huijding, 2003). One explanation for this contrasting finding could be that de Jong et al. used verbal stimuli (i.e., words such as web and legs), whereas other researchers (Ellwart et al., 2006; Huijding \& de Jong, 2007; Teachman et al., 2001; Teachman \& Woody, 2003) used pictures of spiders. Words may provide an insufficiently strong threat cue to differentiate between high- and lowfearful individuals (cf. Foa \& Kozak, 1986; Huijding \& de Jong, 2005b).

Experimental validity studies. Although specific negative beliefs are assumed to be generally associated with certain forms of psychopathology, it is important to realize that these beliefs may become more or less salient depending on the context (Williams, Watts, MacLeod, \& Matthews, 1997). Ellwart, Becker, and Rinck (2005) tested this idea in a study in which participants completed

\footnotetext{
${ }^{1}$ The IAT used by de Jong and colleagues (de Jong, 2002; de Jong et al., 2001, 2003) was, in fact, a learning task: Participants were instructed to determine for themselves what the correct key assignments were. Consequently, no category labels were displayed during the task. Additionally, the task consisted of only four phases, with the combined sorting of targets and attributes using the reverse response requirement following directly after the initial combined sorting task, without a practice phase. The idea was that one would learn a particular target-attribute combination (and unlearn the other) faster when that combination was congruent with the preexisting memory structure.
} 


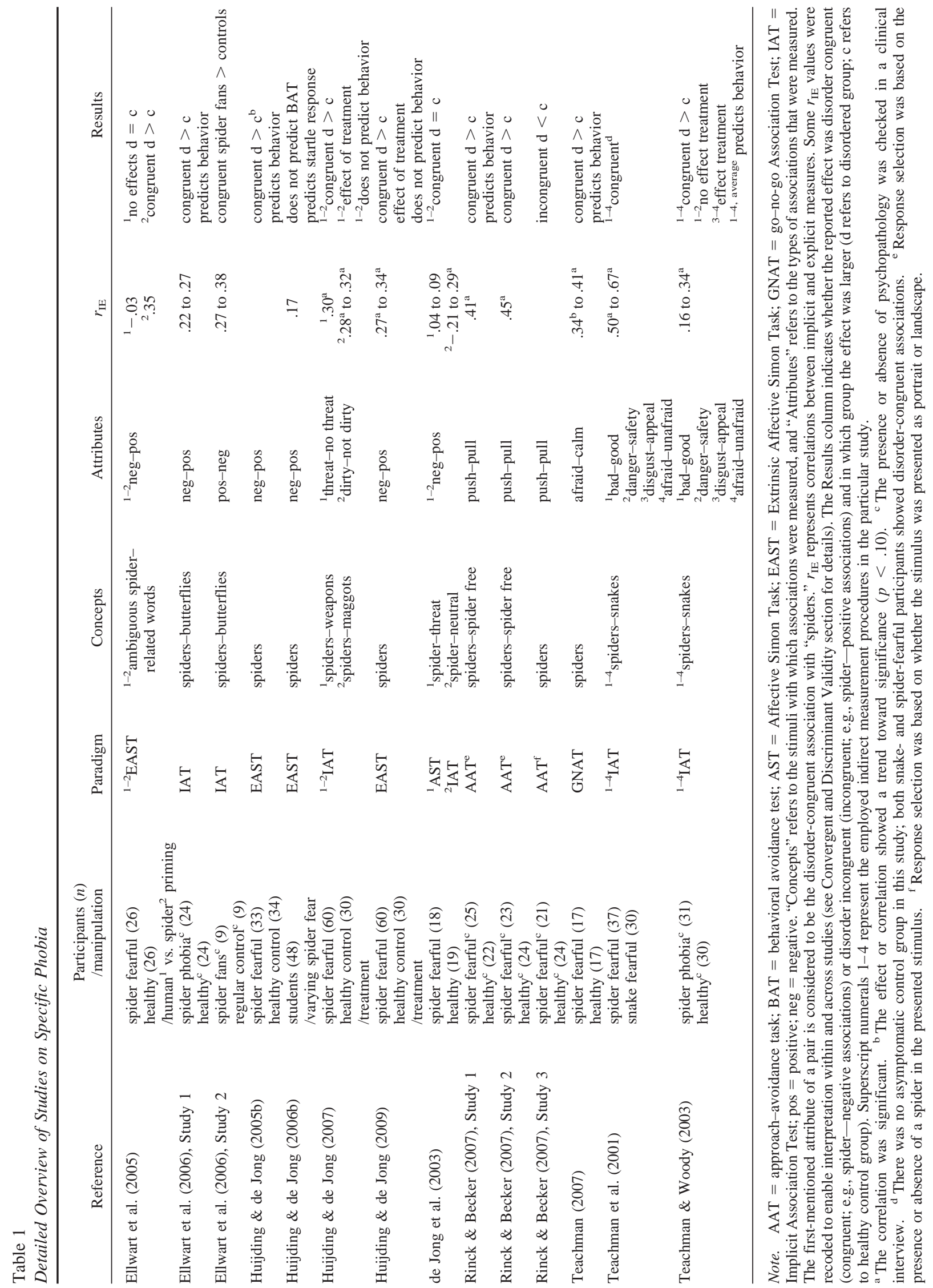


two identical EAST procedures with ambiguous target words (e.g., crawl, legs, hairy). The first EAST was preceded by a series of human adult and baby pictures. The second EAST was preceded by a series of spider pictures. After the human-picture priming, there was no evidence of negative spider associations in either spider-fearful or nonfearful participants. However, spider-fearful participants did show negative spider associations after spiderpicture priming, whereas there was no such effect in nonfearful controls. Thus, the ambiguous target words evoked negative associations in individuals with spider phobia only when these words were put into a spider-related context. Context dependency makes intuitive sense, so it is good to see it occur.

Apart from this contextual influence, a clinically relevant question is whether implicit measures of spider associations can change during treatment. This question goes back at least to the study by Watts et al. (1986), where the emotional Stroop effect was administered to spider-phobic individuals pre- and posttreatment. To test the effect of a three-session exposure therapy, Teachman and Woody (2003) compared a treatment group of spider-phobic participants and a nontreatment control group of nonphobic participants. Both groups performed four spider-related IATs and two spider-unrelated control IATs at three intervals: at pretest, at posttest, and at a two-month follow-up. Results showed that the afraid-unafraid and the disgusting-appealing IAT effects remained stable from pretest to posttest in the nonphobic control group but changed significantly in the successfully treated phobic group. At posttest, these IAT measures no longer differed between the two groups. Furthermore, these IAT effects remained stable at the two-month posttherapy follow-up, suggesting that the treatment was successful in decreasing the strength of spider-afraid and spider-disgust associations.

Although Teachman and Woody (2003) included a nonfearful control group and two control IATs, the changes observed on the fear-relevant IATs could still have been the result of testing, not treatment, effects. Testing effects could arguably be different for phobic and nonphobic participants. This possibility was addressed in later treatment studies (Huijding \& de Jong, 2007, 2009) that included: (a) a high-fearful group that received a single session of exposure, which was successful; (b) a high-fearful delayedtreatment control group that received treatment after study completion; and (c) a low-fearful control group. In high-fearful participants, implicit measures of spider associations were obtained either before and after a single session of exposure or before and after a 2-hr pause (Huijding \& de Jong, 2007: two IATs; Huijding $\&$ de Jong, 2009: EAST). The treatment group and the delayedtreatment control group showed a similar decrease on the IAT measures from pretest to posttest, suggesting that changes were the result of test-retest effects rather than being treatment-specific effects. Although the effect was small at best, the EAST measure showed a marginally significant treatment-specific reduction of negative spider associations.

Incremental and predictive validity studies. Most studies have used a behavioral avoidance task as the to-be-predicted behavior. In this task, participants are asked to approach a live spider. The dependent variables of interest are how close and how fast the participant approaches the spider. Implicit measures of negative spider associations derived from the IAT (Ellwart et al., 2006; Teachman \& Woody, 2003; but see: Huijding \& de Jong,
2007), the pictorial EAST (Huijding \& de Jong, 2005b; but see: Huijding \& de Jong, 2009), the go/no-go IAT (Teachman, 2007), and the approach-avoidance task (Rinck \& Becker, 2007) predicted variance in behavioral avoidance task performance beyond what was predicted by self-reported spider fear.

Cognitive models of anxiety (e.g., Beck \& Clark, 1997) and dual-process models of information processing (e.g., Fazio \& Towles-Schwen, 1999) both propose that implicit and explicit measures of associations are differentially related to spontaneous versus more strategically generated fear responses. In line with this, Huijding and de Jong (2006b) found that whereas a verbal EAST measure was the main predictor of spontaneous fear responses (startle reflex), self-reported spider fear was the only predictor of relatively controllable fear responses (i.e., behavioral avoidance task performance). Yet, as noted above, other studies have found associations between implicit measures and behavioral avoidance task performance (e.g., Teachman \& Woody, 2003). Interpretation of these results will have to await further empirical clarification.

Summary. Generally, implicit measures have confirmed the theoretically expected negative associations with spiders. That is, several implicit measures of spider associations have successfully differentiated between high and low spider-fearful individuals. In addition, implicit measures have predicted phobia-related behavior beyond what explicit measures have predicted and, in one case, even more so for relatively spontaneous fear responses. Finally, implicit measures of spider fear-related affective associations have appeared to be malleable by contextual factors and possibly also by treatment.

\section{Social Phobia}

Table 2 presents results of studies on social phobia. Patients with social phobia experience significant, enduring fear of social or performance situations in which they can feel embarrassment (American Psychiatric Association, 2000). From a cognitive perspective, symptoms are a result of dysfunctional beliefs regarding danger of rejection and failure in social situations and a negative sense of self-esteem (e.g., D. M. Clark \& Wells, 1995; Rapee \& Heimberg, 1997). In support of this view, individuals with social phobia (a) score higher on self-report measures of fear of negative evaluation than do healthy and clinical control groups (e.g., Heimberg, Hope, Rapee, \& Bruch, 1988), (b) underestimate the quality of their social performance (Alden \& Wallace, 1995), and (c) tend to evaluate even positive social situations as threatening (Alden, Taylor, Mellings, \& Laposa, 2008). Therefore, implicit measures should reflect negative associations with the self and with social situations. Implicit-explicit correlations ranged from $r=-.05$ to .41 .

Studies comparing groups with a disorder to controls. de Jong, Pasman, Kindt, and van den Hout (2001) found an IAT association between social interactions (e.g., date, presentation) and negative outcomes (e.g., blunder) in socially fearful students. ${ }^{1}$ However, IAT self-esteem effects were not specific to socially fearful students, in that both high and low socially fearful students associated self with positive, although this self-favoring effect was significantly weaker in the anxious group than in the nonanxious group (de Jong, 2002). ${ }^{1}$ Moreover, these results were replicated by 


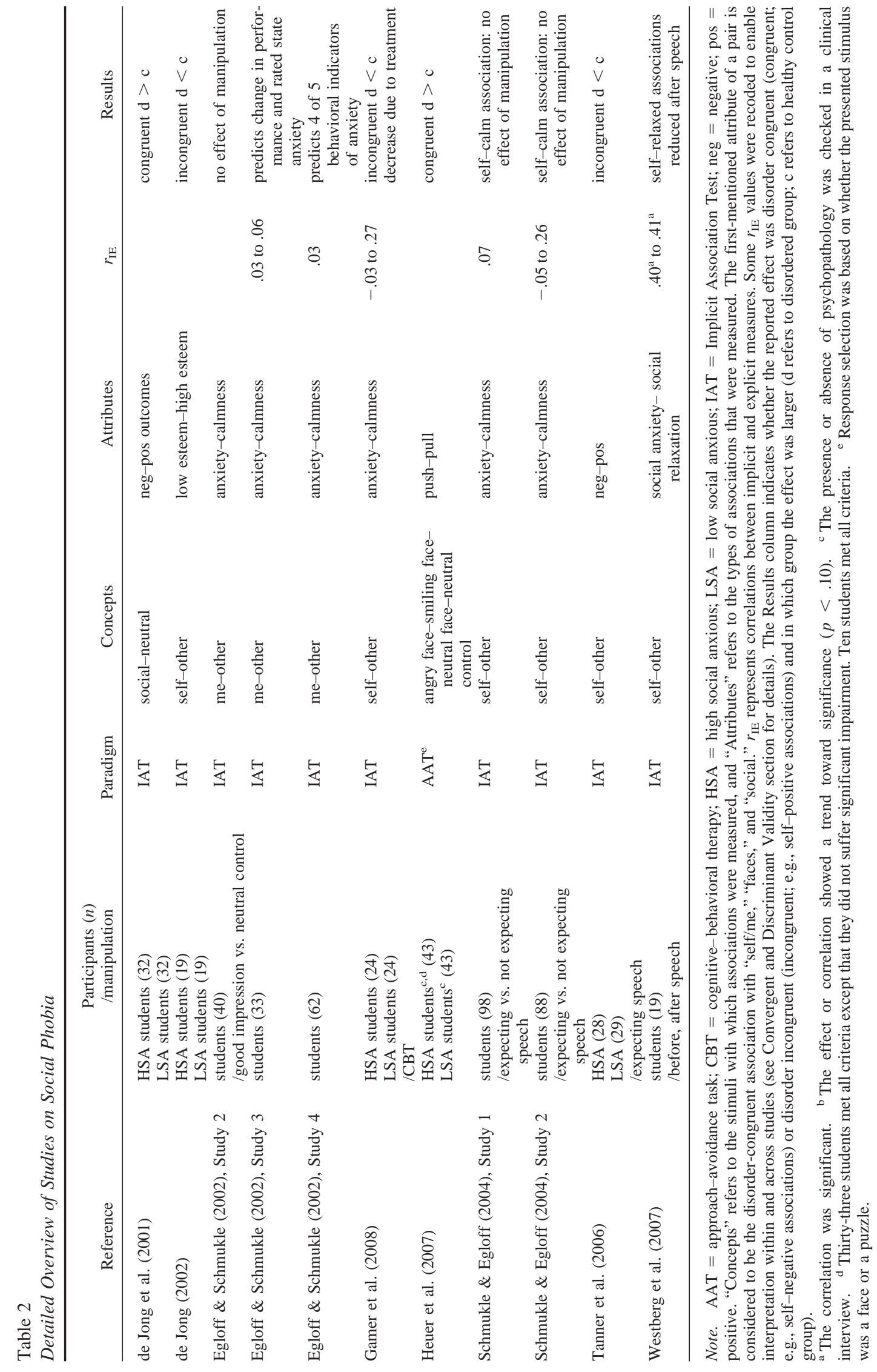


Tanner, Stopa, and De Houwer (2006) when an implicit measure was obtained after participants gave a speech (note, however, that they did not contrast this group to either a no-speech premeasurement group or a no-speech control group). In still another study, high socially anxious individuals had weaker self-calmness associations than did low socially anxious individuals (Gamer, Schmukle, Luka-Krausgrill, \& Egloff, 2008). Because social phobia patients are hypervigilant to cues of possible negative evaluations by others, human facial expressions are a particularly important source of information for them. A study conducted with an approach-avoidance task found that, as expected, socially fearful students showed stronger avoidance responses to angry faces but unexpectedly also showed stronger avoidance responses to smiling faces than did their counterparts with low social fearfulness. No differences emerged between these groups in response to neutral faces or neutral control stimuli (Heuer, Rinck, \& Becker, 2007).

Experimental validity studies. Patterns of findings can be difficult to align with intuition. In one study, scores on an anxiety IAT (target dimension: self-other; attribute dimension: anxietycalmness) did not differ between students expecting compared with those not expecting to give a speech (Schmukle \& Egloff, 2004). Yet, in another study self-calmness associations on a similar IAT decreased after student participants gave a speech that was intended as an anxiety induction (Westberg, Lundh, \& Jönsson, 2007). Possibly expectation was too weak an induction compared with actual performance. In a third study-illustrating the difficulty in faking responses to the IAT_Egloff and Schmukle (2002) found that healthy participants who were instructed to make a good impression for a job application could not manipulate their anxiety IAT scores and performed virtually identically to control participants who did not receive specific instructions on how to perform the IAT.

Consistent with clinical expectations, Gamer et al. (2008) found that self-calmness associations increased significantly on an IAT over the course of a successful cognitive-behavioral therapy treatment in high socially anxious individuals. Nonanxious controls, who did not receive treatment but who were assessed at the same time points, showed no changes. At posttest, the IAT scores of the high socially anxious individuals no longer differed from those of the low socially anxious individuals. Although encouraging in terms of the use of implicit measures to evaluate treatment efficacy, it is unclear whether this effect can be attributed to repeated testing, because this study did not include a waiting-list control group.

Incremental and predictive validity studies. Egloff and Schmukle (2002; Study 3) found that, following a stress task, an anxiety IAT was predictive of change in cognitive performance and experimenter-rated state anxiety over and above explicit measures. Moreover, a follow-up experiment showed that this IAT measure was also predictive of four of five behavioral indicators of anxiety (Egloff \& Schmukle, 2002, Study 4).

Summary. Findings are partly consistent with explicit dysfunctional beliefs, but the pattern does not display the desired consistency. More comprehensive studies will be needed to determine how effective implicit measures are in the context of social phobia, both in terms of identifying affected individuals and in terms of measuring the influence of treatment.

\section{Panic Disorder}

Table 3 presents results of studies on panic disorder. Panic attacks are discrete periods of rapidly occurring or escalating fear or discomfort accompanied by a number of somatic and cognitive symptoms, such as palpitations, sweating, trembling, shortness of breath, and fears of dying or losing control. Individuals with panic disorder suffer from recurrent panic attacks and show persistent worry about future attacks and the consequences of such attacks (American Psychiatric Association, 2000). A cognitive perspective on panic assigns a crucial role to the misinterpretation of bodily sensations as indicating catastrophic consequences in the onset and maintenance of the disorder (e.g., D. M. Clark, 1986). Indeed, patients with panic disorder are more likely to interpret ambiguous bodily sensations as threatening than are healthy and clinical control groups (e.g., D. M. Clark et al., 1997; Rosmarin, Bourque, Antony, \& McCabe, 2009). Implicit measures are expected to reflect associations between the self and panic, indicating a panic self-schema (Teachman, 2005), and between bodily sensations and catastrophic outcomes (D. M. Clark, 1986). Research on implicitexplicit correspondence is limited and correlations range from $r=$ .24 to $r=.37$.

Studies comparing groups having a disorder with controls. Two groups - students scoring high on a self-report measure of anxiety sensitivity (Teachman, 2005) and patients diagnosed with panic disorder (Teachman, Smith-Janik, \& Saporito, 2007)showed weaker IAT calm-me associations than did healthy control participants. Also supporting cognitive theories, using a semantic priming paradigm, ${ }^{2}$ Schneider and Schulte (2007) reported that patients with panic disorder reacted faster to catastrophic target words (e.g., "heart attack") following panic-related primes describing bodily sensations (e.g., "I feel dizzy") than did healthy control participants. Unexpectedly, however, no parallel group differences were found in IAT bodily changes-alarming associations (Teachman, 2005, 2007).

Experimental validity studies. Over the course of a 12-week program of cognitive-behavior therapy, the strength of IAT calm-me associations increased in panic disorder patients. A selfreport measure of panic disorder severity showed corresponding reductions. Moreover, additional prospective analyses showed that IAT change scores were predictive of later changes in panic disorder severity, but not the other way around. This outcome suggests that the cognitive change assessed by the IAT precedes panic disorder symptom reduction (Teachman, Marker, \& SmithJanik, 2008).

Incremental and predictive validity studies. Structural modeling has shown an IAT measure of calmness associations to be a unique predictor of panic symptoms (Teachman et al., 2007). A priming measure of associations between panic-related bodily sensations and catastrophic interpretations predicted the degree to which anxiety sensitivity decreased over the course of a single

\footnotetext{
${ }^{2}$ Although the semantic priming paradigm is not one of the measurement procedures included in this review, some highly relevant semantic priming studies are included. The difference between a semantic and an affective priming task is that the focus of the semantic priming paradigm is on the meaningful relation between a type of prime and a type of target, whereas in affective priming the focus is on the emotional associations between the primes and targets (De Houwer, 2003a).
} 
session of cognitive intervention, independent of what was predicted by an explicit measure of catastrophic cognitions. That is, the stronger the priming effect of panic-related bodily sensations for catastrophic targets, the less was the reduction in anxiety sensitivity during the single treatment session (Schneider \& Schulte, 2008).

\section{Other Anxiety Disorders}

Table 4 presents results of studies on other anxiety disorders. Two relevant studies were conducted on obsessive-compulsive disorder (OCD) and one on posttraumatic stress disorder (PTSD). OCD is characterized by the occurrence and recurrence of persistent thoughts, impulses, or images that are experienced as intrusive and inappropriate (obsessions) and/or repetitive behaviors aimed at preventing or neutralizing feared events (compulsions) (American Psychiatric Association, 2000). On the basis of early research on obsessions (Rachman \& De Silva, 1978), cognitive models of OCD (Rachman, 1997; Salkovskis, 1985) ascribe the major difference between healthy people and OCD patients not to the specific content of intrusive thoughts but to a dysfunctional interpretation of their meaning. Indeed, patients suffering from OCD interpret obsessive thoughts as signs that they are immoral, evil, and dangerous (Obsessive Compulsive Cognitions Working Group, 2001, 2003).

PTSD patients suffer from re-experiencing an extremely traumatic event, avoidance of stimuli related to the trauma, and increased arousal (American Psychiatric Association, 2000). It is thought that both pre- and posttrauma dysfunctional beliefs concerning the self, the world, and the future play a major role in the development of PTSD, and it is hypothesized that extreme beliefs about one's own vulnerability are associated with the development of PTSD symptoms (Engelhard, Huijding, van den Hout, \& de Jong, 2007). Thus, according to some cognitive models, OCD patients might be expected to associate the self with immoral and dangerous, and unwanted thoughts with important, whereas PTSD patients would be expected to associate the self with either very high or very low vulnerability on implicit measures. Research on implicit-explicit correspondence is limited, and correlations for OCD and PTSD hover around zero (for OCD, $r$ s range from -.18 to .17, and for PTSD, $r$ s range from .00 to .13).

Studies comparing groups with a disorder to controls. In student participants, the strength of self-reported OCD symptoms was not related to IAT measures of the associations self-danger, self-immoral, and unwanted thought-important (Teachman \& Clerkin, 2007; Teachman, Woody, \& Magee, 2006). With regard to PTSD, a curvilinear relation was expected between PTSD symptom severity and IAT self-(in)vulnerability associations. However, the strength of clinician-rated PTSD symptoms in soldiers showed a linear relation such that more severe PTSD symptoms were linked to weaker self-invulnerable associations (Engelhard et al., 2007). Thus, the picture emerging from these studies is not consistent with the proposed cognitive theories of these disorders.

Experimental validity studies. Manipulation of beliefs about the importance of intrusive thoughts (important vs. meaningless vs. no information) in an OCD study increased IAT unwanted thought-important associations but had no effect on selfdanger or self-immoral associations. However, those with more 


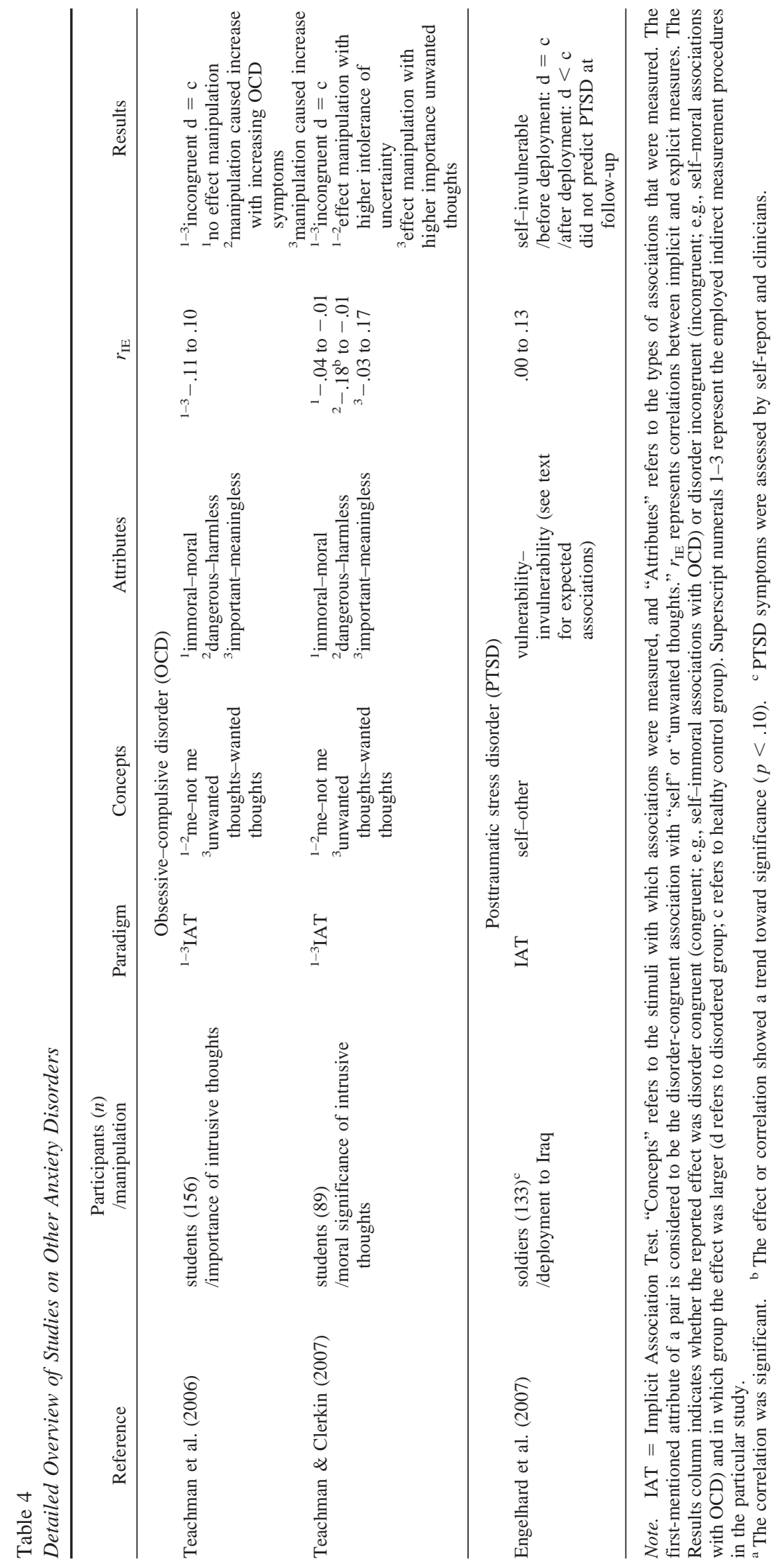


OCD symptoms before the manipulation were more sensitive to information that unwanted thoughts are important and thus more likely to show an increase in self-danger associations in that condition (Teachman et al., 2006). A subsequent study (Teachman \& Clerkin, 2007) showed that manipulation of beliefs about the moral significance of intrusive thoughts also had no effect on IAT measures of associations. However, structural modeling showed that higher self-reported intolerance of uncertainty before the manipulation was associated with greater decreases in self-danger and self-immoral associations in the group that was told that intrusive thoughts are meaningless. In addition, participants who reported prior to the manipulation that unwanted thoughts were highly important were more sensitive to the instruction that intrusive thoughts are morally significant (as evidenced by their tendency to show stronger associations of unwanted-thoughtsimportant on the IAT).

Incremental and predictive validity studies. One study on PTSD obtained IAT measures of self-vulnerability associations before deployment to Iraq and five months after deployment. These measures were not predictive of PTSD symptoms assessed 15 months after deployment (Engelhard et al., 2007).

\section{Depressive Disorder}

Table 5 presents results of studies on depressive disorder. A major depressive episode is a period of at least two weeks during which the patient either suffers from a depressed mood or has no interest or pleasure in almost all activities (American Psychiatric Association, 2000). According to a cognitive perspective on depression, the view of the self, the world, and the future is negatively biased in depressed patients (Beck et al., 1979; D. A. Clark et al., 1999). This has been confirmed in several studies with self-report measures of such dysfunctional beliefs (e.g., Hollon, Kendall, \& Lumry, 1986; Silverman, Silverman, \& Eardley, 1984). According to this notion, implicit measures are expected to display negative associations with the self. Implicit-explicit correlations range from $r-.41$ to $r=.25$.

Studies comparing groups having a disorder with controls. In contrast to theoretical expectations, several studies conducted with an IAT found evidence for positive self-esteem both in depressed patients and in healthy controls (De Raedt, Schacht, Franck, \& De Houwer, 2006; Franck, De Raedt, \& De Houwer, 2008; Franck, De Raedt, Dereu, \& Van den Abbeele, 2007; Gemar, Segal, Sagrati, \& Kennedy, 2001). An EAST measure of selfesteem was even more positive in depressed patients than it was in healthy controls (De Raedt et al., 2006). Somewhat consistent with cognitive theory, in two IAT studies, these positive self associations were smaller in former depressed patients (Meites, Deveney, Steele, Holmes, \& Pizzagalli, 2008) and in students at high risk of becoming depressed (Steinberg, Karpinski, \& Alloy, 2007) than in healthy controls. In addition, IAT self-esteem was neutral in a subgroup of depressed patients without suicidal ideation (Franck et al., 2007).

Experimental validity studies. Gemar et al. (2001) used an IAT to measure self-esteem before and after a negative mood induction in healthy controls and formerly depressed individuals. In an atypical analysis (see De Houwer, 2002), Gemar et al. eliminated the attribute trials and analyzed me and not-me trials separately, their goal being to have separate indices of associations with me and not-me. Whereas the me category was associated with positive, the not-me category was associated with negative. Moreover, the negative mood induction only reduced the positive bias in the me trials in formerly depressed individuals, not in healthy controls. The differential effectiveness of the mood induction may be explained by the exceptionally elevated me-positive bias premood induction in the formerly depressed participants who took part in this study.

Using standard IAT analysis procedures, Franck et al. (2008) replicated this exact result pattern. These researchers suggested that the higher self-esteem of the formerly depressed participants before mood induction could function as a buffer against threats to self-esteem. This idea, although provocative, seems to be contradicted by a study by Meites et al. (2008), in which a mood induction procedure reduced me-happy associations only in healthy controls, not in formerly depressed participants. Critically, in this study, formerly depressed participants did not show increased me-happy associations prior to the mood induction.

Incremental and predictive validity studies. In line with the dual-process models of information processing described earlier, Haeffel et al. (2007) found that an IAT measure of self-esteem interacted with the presence of an experimentally induced stressor to predict immediate affective reactions. Participants with lower implicit measures of self-esteem, when in the stressor condition, reported the highest immediate distress score. Moreover, an explicit measure of cognitive style interacted with a measure of stressful life events to predict depressive symptoms at a five-week follow-up: Participants with a negative cognitive style who reported more stressful life events also reported experiencing the most depressive symptoms. Correspondingly, Steinberg et al. (2007) found that the occurrence of negative events predicted depressive symptoms four months later in participants at risk for depression, but only when the implicit measure of self-esteem was relatively negative.

Summary. Unexpectedly, depressed individuals consistently were not characterized by negative implicit measures of selfesteem. This provocative outcome warrants further attention. A mood induction influenced IAT results, but evidence was equivocal regarding which group (healthy controls or formerly depressed participants) showed this effect and whether the effect resulted from elevated pre-induction IAT scores. Nonetheless, an IAT measure was predictive (in interaction with a stress manipulation) of the occurrence of depressive symptoms and immediate affective reactions.

\section{Body Dysmorphic Disorder}

Table 6 presents results of studies on body dysmorphic disorder (BDD). Patients suffering from BDD are preoccupied with either an imagined defect or a slight anomaly in their appearance (American Psychiatric Association, 2000). According to an influential cognitive-behavioral model of BDD (Veale, 2004), BDD patients misinterpret normal bodily features or minor appearance flaws, leading to excessive rumination, anxiety, and body checking. These patients are thought to have a distorted view of their own attractiveness and to hold dysfunctional beliefs about the importance of attractiveness. Thus, BDD patients, for example, hold the belief, "If my appearance is defective, I shall end up alone and isolated" (Veale et al., 1996). In addition, they have been shown to 


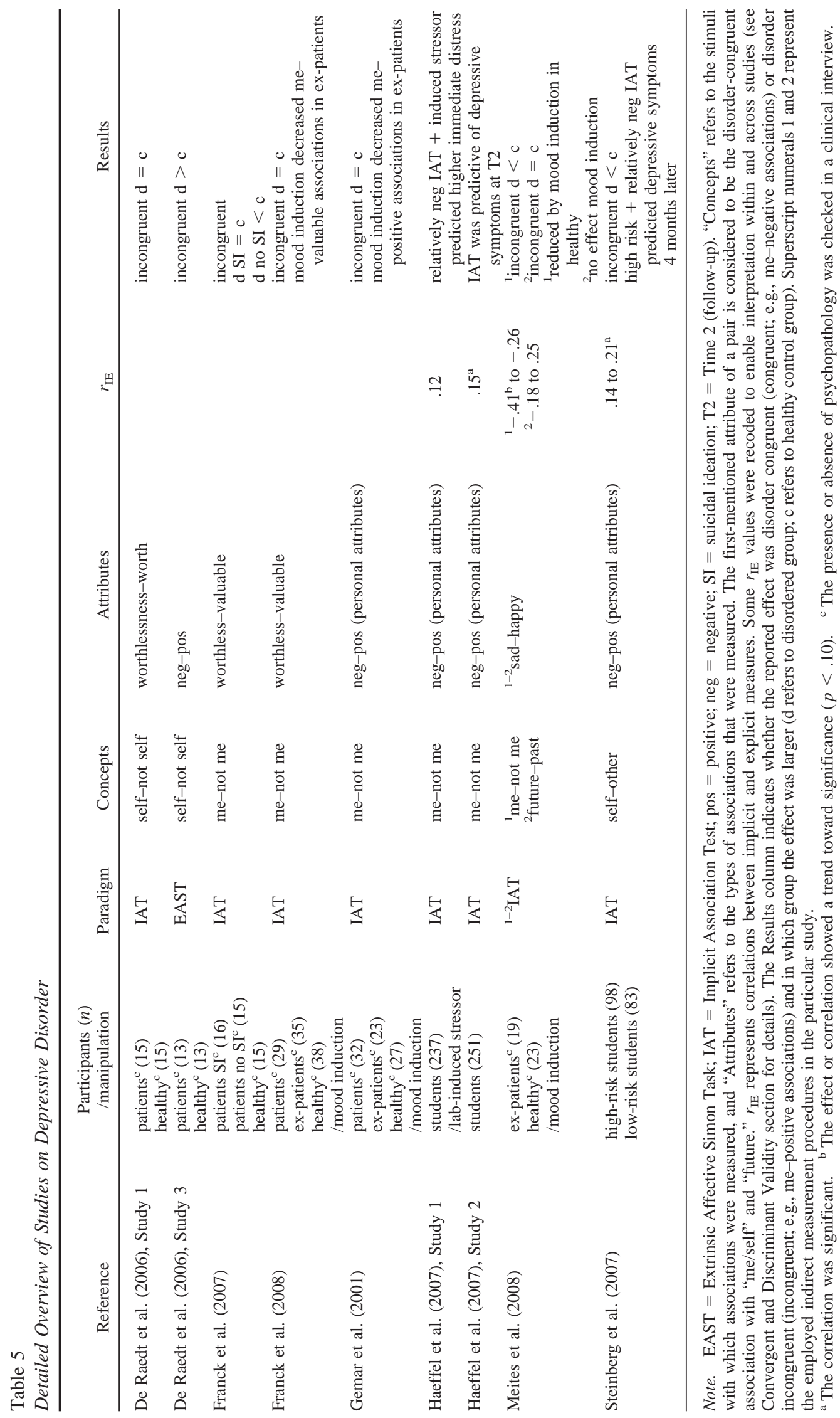


have a lower level of self-esteem (Biby, 1998). Accordingly, implicit measures should reflect positive associations between attractiveness and importance and negative associations with the self. Research on implicit-explicit correspondence is limited, and correlations range from $r=-.02$ to .48 .

Studies comparing groups having a disorder with controls. One study involving BDD patients found evidence for less positive self-esteem on an IAT, as compared with healthy controls (Buhlmann, Teachman, Gerbershagen, Kikul, \& Rief, 2008). However, another study, involving BDD symptomatic students rather than actual patients, failed to produce this same pattern (Clerkin \& Teachman, 2009). To date, no IAT study has found evidence of increased importance of attractiveness in BDD patients (Buhlmann et al., 2008; Clerkin \& Teachman, 2009), so progress in this realm has been minimal thus far.

Incremental and predictive validity studies. Despite this absence of evidence for an attractiveness-importance link, an IAT measure of the importance of attractiveness did predict behavioral avoidance of a mirror: Students who showed stronger IAT attractiveness-importance associations positioned themselves farther away from a mirror in the laboratory. Interestingly, explicit measures assessing the importance of attractiveness failed to predict this behavior (Clerkin \& Teachman, 2009).

Summary. There is minimal evidence that BDD patients are characterized by reduced self-esteem. One limitation that needs to be addressed is that many studies probably have examined patient groups with comorbidities (e.g., depressive symptoms), thereby complicating any conclusions by what amounts to disorder confounds. Of course, this criticism applies not just to BDD.

\section{Pain Disorder}

Table 7 presents results of studies on pain disorder. Patients with pain disorder present with pain that is of sufficient severity to warrant clinical attention (American Psychiatric Association, 2000). Psychological factors are seen as playing a major role in the pain symptoms (Linton, 2000). According to a cognitive perspective, appraisals and beliefs about pain have a large impact on emotional and behavioral responses to pain (Gatchel, Peng, Peters, Fuchs, \& Turk, 2007). Numerous studies have demonstrated that catastrophic thoughts concerning pain (e.g., "pain is the worst thing that could ever happen to me") are associated with increased pain and increased disability in both clinical and nonclinical populations (for a review, see Keefe, Rumble, Scipio, Giordano, \& Perri, 2004). In addition, pain disorder patients report avoidance of activities that they think will worsen their pain (Vlaeyen, KoleSnijders, Boeren, \& van Eek, 1995). Accordingly, implicit measures should reflect association between the self and pain, as well as negative and threat-related associations with pain-inducing activities and with pain itself. Research on implicit-explicit correspondence is limited and correlations range from $r=-.24$ to .40 .

Studies comparing groups with a disorder to controls. Goubert, Crombez, Hermans, and Vanderstraeten (2003) compared patients who had low back pain with healthy individuals. Unexpectedly, in the APP, only the healthy participants showed negative associations with activities that stress the back as compared with low-threat movements. Patients with low back pain actually showed a relatively positive association with backstressing activities. Complicating the picture, in a study involving 


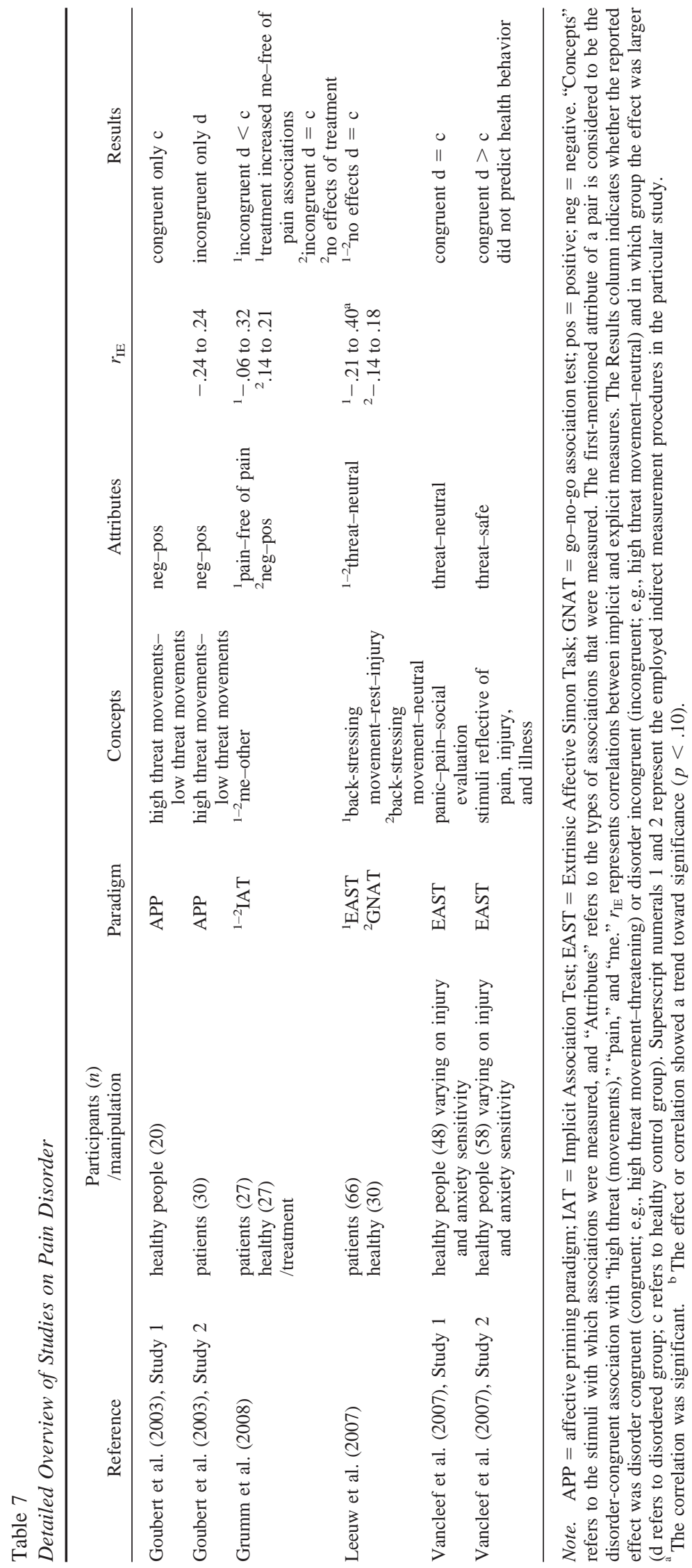


two tasks - both a go/no-go IAT and an EAST-no evidence emerged for associations between back-stressing activities and threat, either in patients with low back pain or in healthy controls (Leeuw et al., 2007).

In contrast, somewhat in line with expectations, Vancleef, Peters, Gilissen, and de Jong (2007) found stronger associations using the EAST for both panic and pain to threat than for either of these terms to neutral in a sample of healthy participants with varying degrees of anxiety and injury sensitivity. However, these EAST associations were not linked with anxiety sensitivity or injury sensitivity. Yet, in a second EAST study (Vancleef et al., 2007), pain-related stimuli were more strongly associated with threat than with safe, an effect that this time was positively correlated with injury sensitivity and anxiety sensitivity, but the latter relation only approached statistical significance. In addition, also to a certain extent in line with expectations, an IAT measure of associations between me-other and pain-free of pain did distinguish between chronic pain patients and healthy control participants. Patients had weaker me-free of pain associations than did healthy control participants (Grumm, Erbe, von Collani, \& Nestler, 2008).

Experimental validity studies and incremental and predictive validity studies. In line with expectations, IAT self-free of pain associations increased over the course of a four-week psychotherapy program in a sample of chronic pain patients (Grumm et al., 2008). Healthy control participants, who did not receive treatment but who were assessed at the same time intervals, showed no changes. At posttest, the IAT scores of the chronic pain patients no longer differed from the IAT scores of the healthy control participants. Unexpectedly, though, in another study, which included anxiety sensitivity and injury sensitivity in the model, pain-threat associations (as measured by the EAST) did not explain additional variance in either health-protecting behavior or use of health care services (Vancleef et al., 2007).

\section{Sexual Disorders}

Table 8 presents results of studies on sexual disorders. Only two studies obtained implicit measures in the context of sexual disorders, both fitting into the category of studies comparing groups having a disorder with controls. The first study focused on pedophilia. Individuals with pedophilia repeatedly experience strong sexually arousing fantasies, sexual urges, or behaviors involving sexual activity with children who have not yet reached puberty (American Psychiatric Association, 2000). Therefore, it is expected that implicit measures would show associations between children and sex. Gray, Brown, MacCulloch, Smith, and Snowden (2005) obtained implicit measures of associations in pedophilia, with the rationale that such individuals ordinarily are motivated to hide their sexual preferences. The participants of that study showed a stronger IAT association between sex and children than between sex and adults, whereas other-offender control participants showed evidence of the opposite association. In addition, the IAT score was somewhat successful in predicting group membership: With an IAT effect of 0 as the threshold for classification, $78 \%$ of the pedophilic individuals were correctly identified (but $42 \%$ of the other-offender control participants were misclassified as pedophiles). For pedophilia, implicit-explicit correspondence has not been studied.

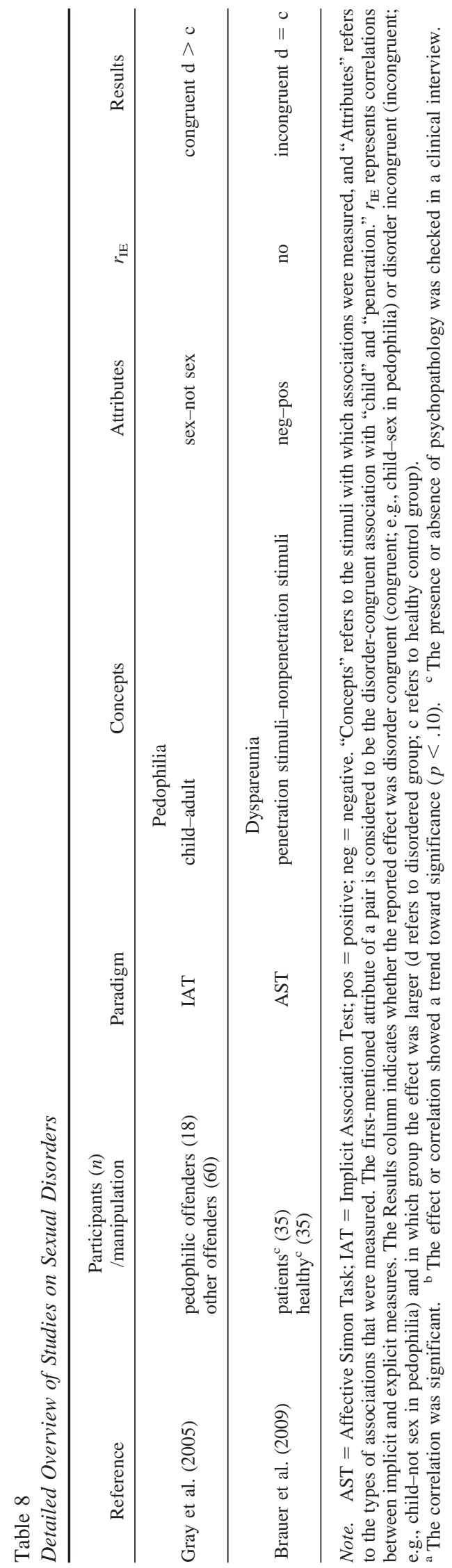


The other relevant study (Brauer, de Jong, Huijding, Laan, \& ter Kuile, 2009) focused on dyspareunia. Patients with dyspareunia experience genital pain during sexual intercourse (American Psychiatric Association, 2000). According to a cognitive perspective, fear of pain results in sexual problems (Barlow, 1986). In line with this, women with dyspareunia reported more negative affect than control women when presented with erotic stimuli either with or without the threat of pain (Brauer, ter Kuile, Jansen, \& Laan, 2007). Therefore, implicit measures would be expected to reflect negative associations with sexual stimuli. In fact, women with and without dyspareunia did not differ in implicit measures of affective reactions to sexual stimuli: Both groups displayed positive associations with sexual stimuli (Brauer et al., 2009). For dyspareunia, no evidence was found for implicit-explicit correspondence ( $r$ not specified).

\section{Eating Disorders}

Table 9 presents results of studies on eating disorders. The two best known eating disorders are anorexia nervosa and bulimia nervosa. Patients with anorexia nervosa refuse to maintain a minimally healthy body weight, are afraid of gaining weight, and have a disturbed body image. Patients with bulimia nervosa suffer from eating binges and use inappropriate compensation methods such as purging; they also overvalue the importance of body shape and weight (American Psychiatric Association, 2000). Insights into bulimia can be gleaned from studying people who lack the fullblown disorder but who suffer from restrained eating or obesity. Like bulimic patients, restrained eaters "exhibit periods of restraint punctuated by episodes of disinhibited overeating" (Heatherton, Herman, Polivy, King, \& McGree, 1988, p. 19). A substantial number of obese people also suffer from eating binges (Bruce \& Agras, 1992; de Zwaan \& Mitchell, 1992). Restrained eating has been hypothesized to be related to a perception of high-caloric foods - often forbidden in diets - as being extra desirable (Gendall \& Joyce, 2001; Stice, 2002), consistent with a large literature suggesting that the consumption of a high-fat diet plays a major role in obesity (e.g., Bray \& Popkin, 1998; Jéquier, 2002). Indeed, obese people report a preference for high-fat foods (Gerding \& Weinstein, 1992; Rissanen et al., 2002), and restrained eaters have been found to fail regularly and to indulge in exactly those high-fat palatable foods that they normally consider forbidden (Herman \& Polivy, 2004).

Patients with bulimia, restrained eaters, and obese people would all therefore be expected to show strong positive implicit measures of associations with high-fat palatable foods. For anorexic patients, on the other hand, high-fat foods are hypothesized to have lost their incentive value (Jansen, 1998, 2001; Pinel, Assanand, \& Lehman, 2000). In support of this, anorexic patients of the restricting type reported a reduced desire for high-fat foods (Stoner, Fedoroff, Andersen, \& Rolls, 1996). Therefore, for anorexic patients, implicit measures of associations with high-fat palatable foods would be expected to be strongly negative. For obesity and restrained eating, implicit-explicit correlations range from $r=.02$ to .44; implicit-explicit correspondence has not been studied for anorexia.

Studies comparing groups having a disorder with controls

Obesity. Contrary to expectation, both obese participants and healthy-weight controls showed more negative associations with high-fat foods than with low-fat foods on an IAT. This effect was more pronounced in obese people (Roefs \& Jansen, 2002) and was stronger with increased reported dieting activity (Maison, Greenwald, \& Bruin, 2001; Roefs \& Jansen, 2002). These findings might be partially explained by the high-fat versus low-fat category labels, which might have made fat content salient and thereby elicited associations based on health concerns rather than palatability. But this explanation is insufficient because similar results were found in a study using the APP, a paradigm that does not require sorting of target stimuli into predefined categories. Regardless of weight status, all participants showed more positive associations with low-fat palatable foods than with high-fat palatable foods (Roefs, Stapert, et al., 2005). Providing further evidence for the idea that automatic associations are based on health concerns, Werrij et al. (2009) found, using a semantic priming paradigm, ${ }^{2}$ that both obese participants and healthy-weight controls associated palatable high-fat foods with restraint rather than with disinhibition).

Studies of obese children also yielded no evidence for positive associations with high-fat palatable foods. Obese children showed positive associations with both healthy and unhealthy foods on an EAST; for lean children, the effect was suggestive of neutral associations with both types of foods. Analyses of percentage of errors resulted in a different pattern, however, suggesting that all of the children had positive associations with healthy foods and neutral associations with unhealthy foods (Craeynest et al., 2005). A study conducted with a personalized version of the IAT (Olson $\&$ Fazio, 2004) produced evidence corroborating these latter EAST results: Both obese and lean children had more positive associations with healthy foods than with unhealthy foods. In addition, on another personalized IAT, both obese children and healthy controls showed no differential positive associations with palatable foods as compared with hobbies (Craeynest, Crombez, Haerens, \& De Bourdeaudhuij, 2007). However, one study contrasts with all of these studies suggesting that obese children do not show the expected associations. Craeynest, Crombez, De Houwer, Deforche, and De Bourdeaudhuij (2006) used a self-concept IAT to assess associations between self and high-fat foods and did find that lean children were more likely to associate themselves with nonfat foods than with high-fat foods. Obese children showed no such difference.

Restrained eating. Also in disagreement with theoretical expectations, Vartanian, Polivy, and Herman (2004) found that highrestrained eaters showed more negative IAT associations with high-fat foods than did low-restrained eaters. In further work with the APP and the EAST, participants showed a preference for palatable over unpalatable foods independent of their restraint status and the fat content of the stimuli (Roefs, Herman, MacLeod, Smulders, \& Jansen, 2005). However, on an EAST that included stimuli directly referring to caloric content (e.g., deep fried vs. steamed), instead of simply using food items as stimuli, restrained eaters showed stronger positive associations with high-caloric content than did unrestrained eaters (Hoefling \& Strack, 2008).

Somewhat in line with expectations, on a version of the stimulus-response compatibility task in which instructions focused on a feature not typically relevant to food, rather than on the food stimuli themselves (i.e., approach pictures photographed from above, avoid pictures photographed from the side), high restrained eaters displayed a stronger approach tendency toward both high- 


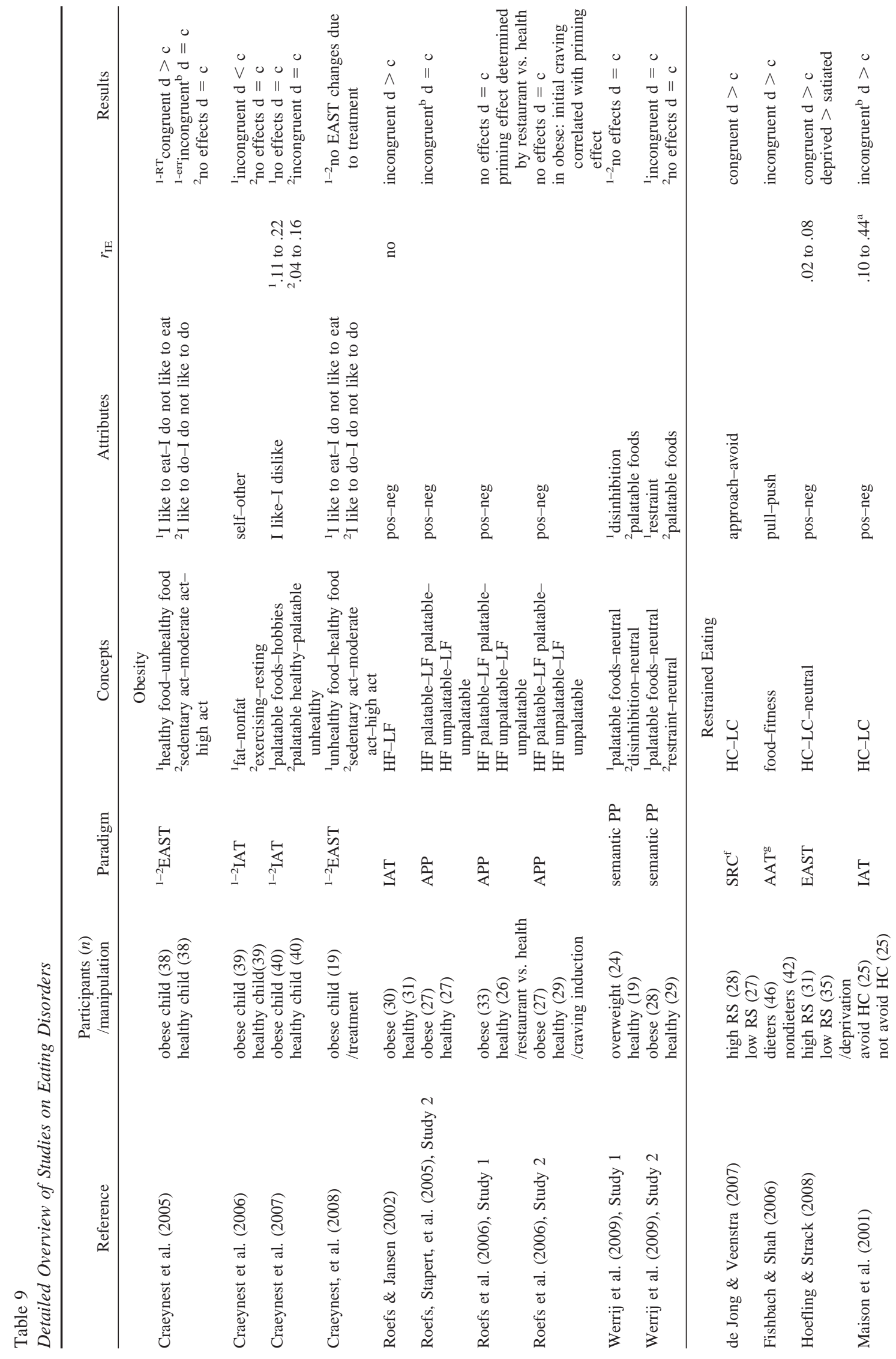




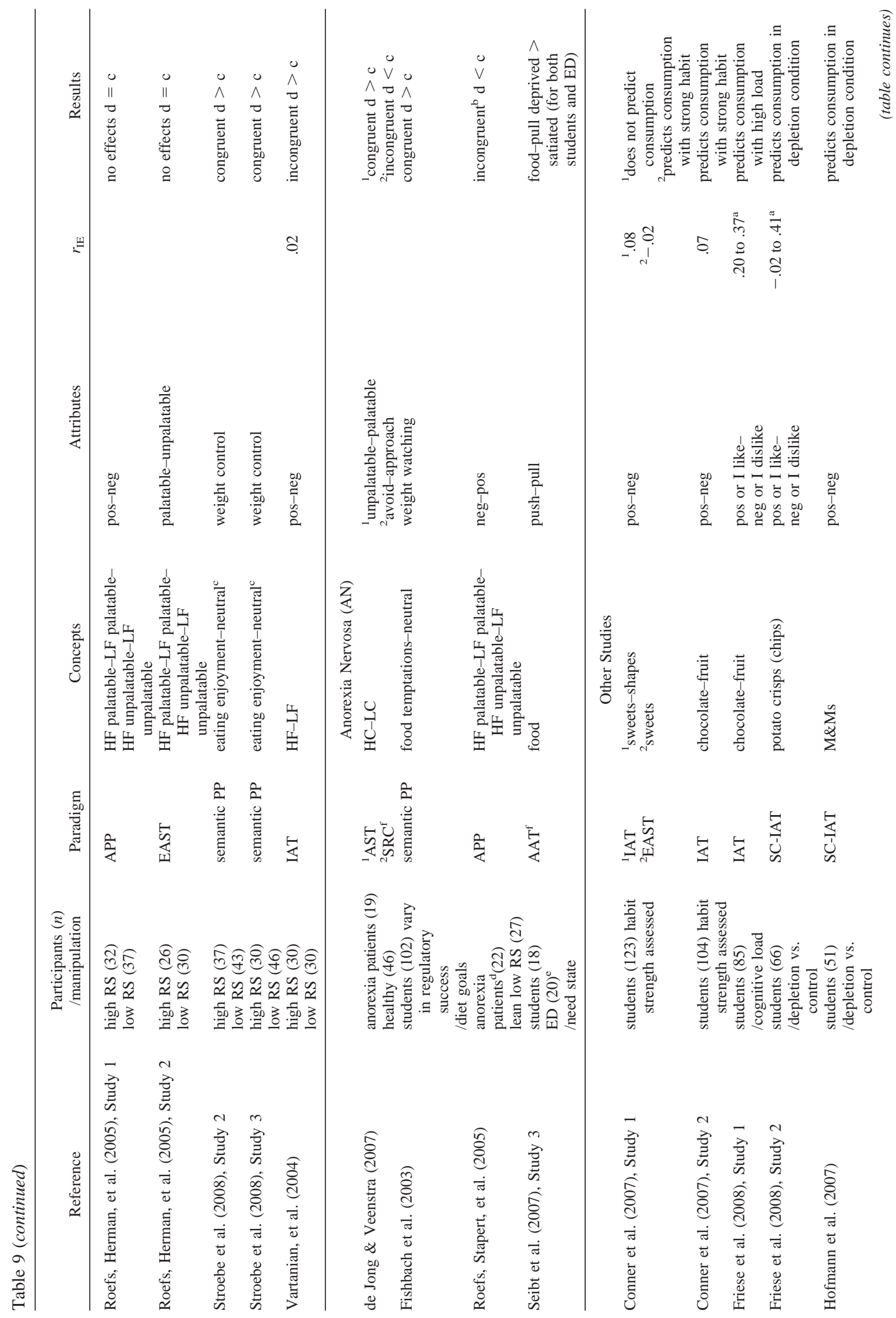




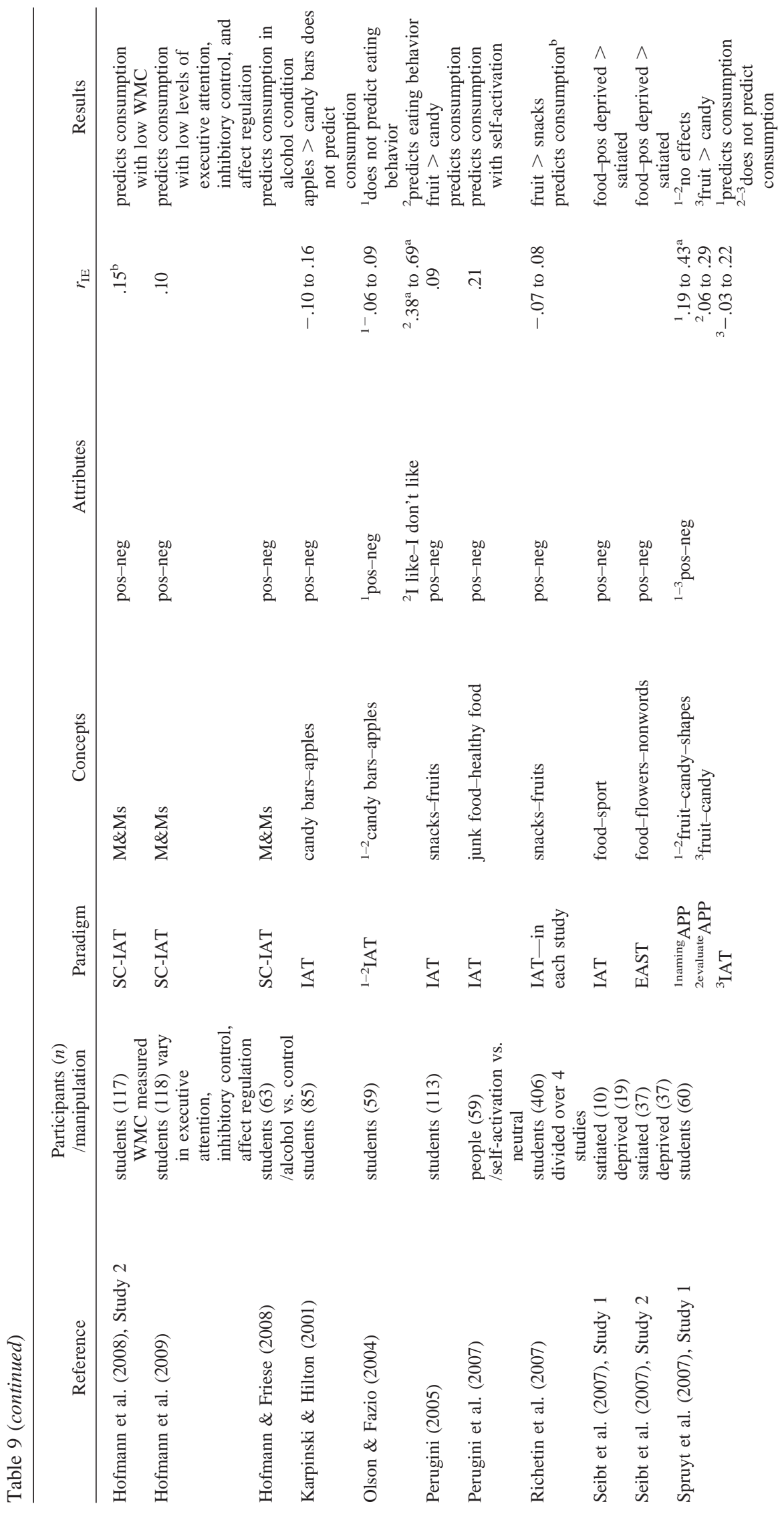






caloric and low-caloric foods than did low restrained eaters (de Jong \& Veenstra, 2007). In line with this approach tendency, Stroebe, Mensink, Aarts, Schut, and Kruglanski (2008) found that restrained eaters inhibited thoughts of weight control upon the presentation of "eating enjoyment" primes in a semantic priming paradigm. After neutral primes, restrained eaters were faster than unrestrained eaters in identifying weight-control targets. Yet quite opposite results emerged from a study using an approachavoidance task in which instructions to avoid or approach were based on whether the presented stimulus was or was not food. Dieters (selected based on the question: "Do you sometimes diet (yes or no)?," which correlated $r=.44$ with scores on the Restraint Scale) exhibited the ambivalent response of equally approaching and avoiding fattening food stimuli, unlike non-dieters, who exhibited approach responses toward fattening foods (Fishbach \& Shah, 2006).

Undereating. In line with theoretical expectations (e.g., Jansen, 1998, 2001), whereas healthy controls showed more positive APP associations with palatable than with unpalatable foods, AN patients showed no such priming effect (Roefs, Stapert, et al., 2005). Also in line with expectations, later research suggested that associations with food stimuli in AN patients may depend on caloric content. AN patients showed more positive associations with low-caloric foods and more negative associations with highcaloric food on an affective Simon task, as compared to healthy controls (de Jong \& Veenstra, 2007). These results were partly paralleled in results on a stimulus-response compatibility task in which response selection was based on a feature of the stimulus not typically relevant to food. Anorexic patients displayed a reduced approach response toward both high-caloric and low-caloric foods in comparison with healthy controls (de Jong \& Veenstra, 2007).

It is possible that patients with anorexia immediately associate tempting food with the dieting goal instead of with taste. Some studies have investigated the association between tempting foods and the goal of dieting, using a word-word semantic priming paradigm $^{2}$ (Fishbach, Friedman, \& Kruglanski, 2003). Results showed that participants who valued weight control and who were successful self-regulators were faster to recognize diet-related targets after the presentation of a tempting food prime, suggesting that presentation of temptations activated the goal of dieting (for a conceptual replication, see Papies, Stroebe, \& Aarts, 2008). To complicate the picture, however, similar findings have been obtained for unsuccessful dieters: They also associated high-caloric foods with restraint (Werrij et al., 2009).

Experimental validity studies. Roefs et al. (2006) specifically tested the role of context in food associations. In their first study, they manipulated the attention focus of obese and healthy-weight participants prior to performing an APP. Participants were focused either on the palatability of food or on the negative health consequences of eating fattening foods. In the palatability condition, participants showed more positive associations with high-fat and palatable foods; in the health condition, participants showed more positive associations with low-fat and unpalatable foods. Weight status (obese vs. healthy weight) did not influence these effects. In Roefs et al.'s second study, the level of craving was manipulated. For obese people, the level of initially experienced craving correlated positively with the palatability priming effect (i.e., with greater craving, obese people showed more positive associations 
with palatable foods than with unpalatable foods). This correlation was not significant for a healthy-weight control group. Converging with the results of the craving manipulation, further studies found that food deprivation elicited more positive associations with food on both an IAT and an EAST and more approach responses in both healthy participants and patients with eating disorder (Hoefling \& Strack, 2008; Seibt, Häfner, \& Deutsch, 2007; Stafford \& Scheffler, 2008).

One study investigated the question of whether implicit measures of eating associations change as a result of treatment (Craeynest, Crombez, Deforche, Tanghe, \& De Bourdeaudhuij, 2008). After a 12-month weight-loss treatment program in which obese children successfully achieved weight reduction, there was no change in implicit measures of associations with food and physical activity. Yet, greater weight reduction was related to more positive associations with healthy foods. On the other hand (and unexpectedly), these investigators found a relation between greater weight reduction and more negative associations with physical activity. Possibly, obese children who lost more weight became fed up with physical exercise, although we note that this study used only a small sample.

Incremental and predictive validity studies. The outcome of a naming variant of the APP was predictive of food-choice behavior (Snickers candy bar vs. apple), whereas this was not the case for the evaluative categorization variant of the APP and the standard IAT (Karpinski \& Hilton, 2001; Olson \& Fazio, 2004; Spruyt, Hermans, De Houwer, Vandekerckhove, \& Eelen, 2007). However, an IAT measure did prove to be predictive of food choice when participants chose between the general categories of snacks and fruits (Perugini, 2005; Richetin, Perugini, Prestwich, \& O'Gorman, 2007). A personalized IAT was found to be predictive of behavioral intention and past eating behavior (Olson \& Fazio, 2004).

In a series of experiments, Hofmann and colleagues showed that the prediction of eating behavior may depend critically on several moderating variables. A first moderator that they studied was the amount of self-regulatory resources (Hofmann, Rauch, \& Gawronski, 2007; see also Friese, Hofmann, \& Wänke, 2008, Study 2). In half of the participants, an emotion-suppression task temporarily depleted self-regulatory resources (depletion condition), whereas the other half of the participants were allowed to express their emotions normally (control condition). When self-regulation resources were low, a more positive SC-IAT measure of candy associations was related to greater consumption of candy. Such an association was not observed in the control condition.

Other studies on moderation found evidence corroborating that implicit measures are only predictive of eating behavior when resources are limited. These studies have varied in how they manipulated cognitive resources, and moderators include alcohol consumption (Hofmann \& Friese, 2008), cognitive capacity (Friese et al., 2008), working-memory capacity (Hofmann, Gschwendner, Wiers, Friese, \& Schmitt, 2008), executive attention, inhibitory control, and affect regulation (Hofmann, Friese, \& Roefs, 2009). In addition, implicit measures were predictive of eating behavior, with increased self-reported habit strength (Conner, Perugini, O'Gorman, Ayres, \& Prestwich, 2007) and with self-activation (i.e., activation of self-related knowledge; Perugini, O'Gorman, \& Prestwich, 2007).
Considering overeaters' implicit measures of food associations and context effects (i.e., attention, craving, deprivation), the overconsumption of high-caloric foods may be driven jointly by traitand state-positive associations with these foods, with the predictive validity of these implicit measures depending on moderator variables. Although obese people and restrained eaters did not display consistently more positive associations with high-fat foods, they may find themselves more frequently in situations in which the sensory aspects of food are emphasized, resulting in positive associations with high-caloric foods. This once again highlights the importance of contextual influences not only on explicit but also on implicit measures.

Summary. Evidence was equivocal for the idea that obese people and restrained eaters are characterized by stronger positive associations with high-caloric foods relative to normal, healthy eaters. Overeaters are almost certainly aware of the negative aspects of tempting high-caloric foods, which may have influenced their implicit measures of food associations. In line with expectations, food associations in anorexic patients were more negative than in healthy controls. Level of craving, hunger, and focus of attention (i.e., palatability vs. health) influenced implicit measures. However, implicit measures of associations with food and physical activity did not change over the course of a successful weightreduction treatment. Finally, implicit measures were mostly predictive of eating behavior when cognitive resources were limited, an intriguing finding worthy of further exploration.

\section{Alcohol Use Disorders}

Table 10 presents the results of studies on alcohol use disorders. Individuals with alcohol use disorders (subcategories of alcohol abuse and dependence) continue to drink alcohol despite significant alcohol-related problems (American Psychiatric Association, 2000). Alcohol-related expectancies-defined as anticipated outcomes of drinking (e.g., "drinking alcohol makes me more spontaneous")- have featured prominently in alcohol research (see Goldman, Del Boca, \& Darkes, 1999; Jones, Corbin, \& Fromme, 2001). Although the term dysfunctional beliefs is not used in this expectancy framework, expectancies arguably can be thought of as having a similar role to dysfunctional beliefs. Studies using multidimensional scaling have shown that these expectancies can be grouped not only as either positive or negative but also as relating to either arousal or sedation (Goldman et al., 1999; Rather, Goldman, Roehrich, \& Brannick, 1992). Typically, the expectancies of heavy drinkers reflect a combination of positive affect and arousal, whereas those of light drinkers reflect a combination of positive affect and sedation (Goldman et al., 1999). Research with implicit measures therefore has focused on both valence and arousal associations. Implicit-explicit correlations range from $r=-.36$ to .66 .

Studies comparing groups having a disorder with controls. Rather than specifying predefined groups (e.g., heavy vs. light drinkers) to study disorder-relevant associations, some studies have related the implicit measures of associations to a continuous measure of self-reported drinking behavior or alcohol-related problems, which is conceptually similar to comparing predefined groups. Associations between alcohol and positive/negative valence have been studied repeatedly, either contrasting negative with positive (e.g., Wiers, van Woerden, Smulders, \& de Jong, 2002) or assessing the two affective dimensions separately (e.g., 


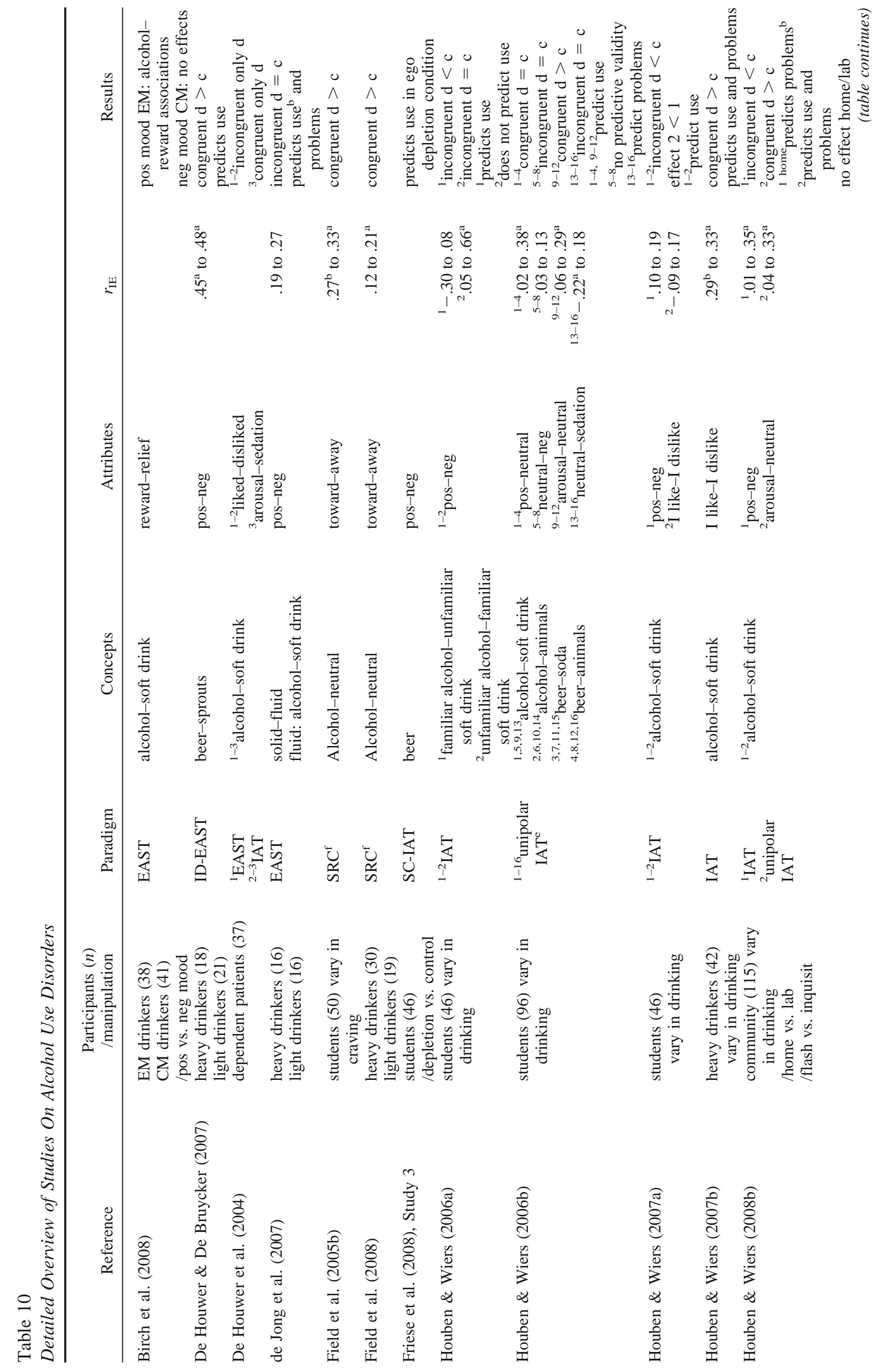




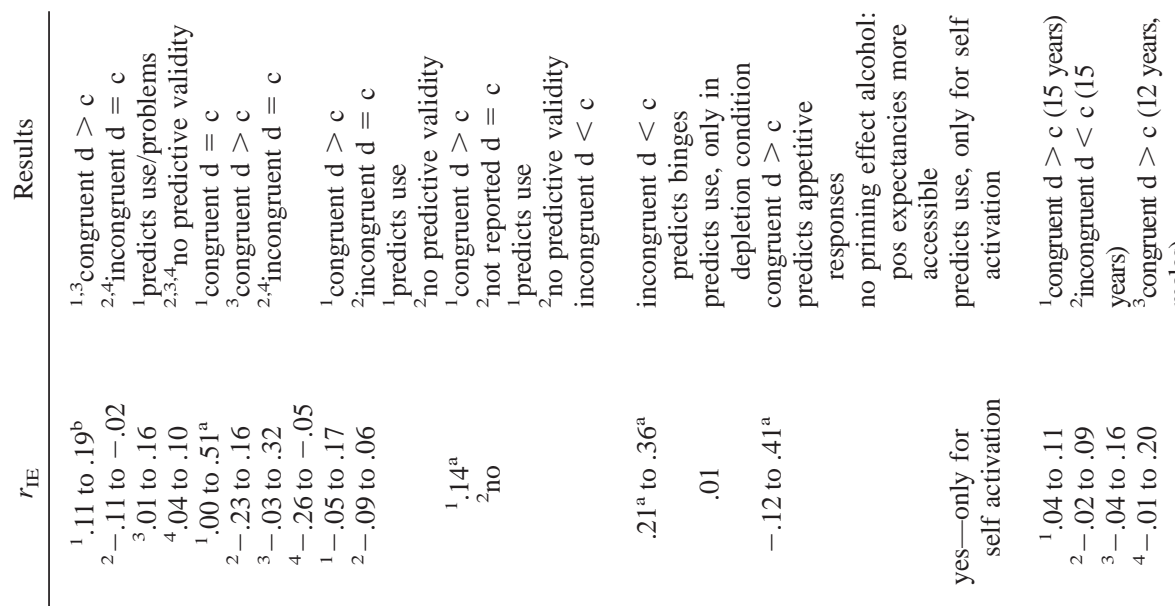





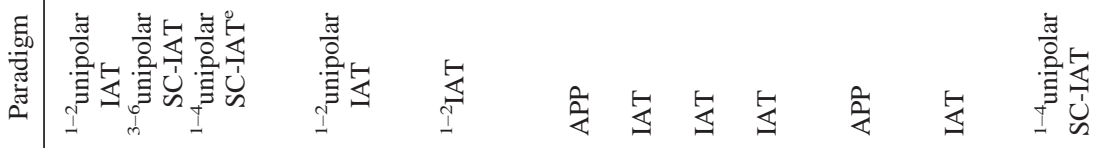

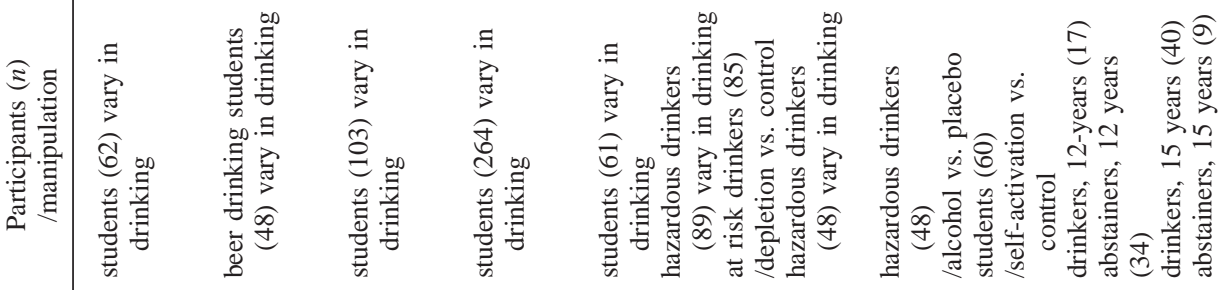

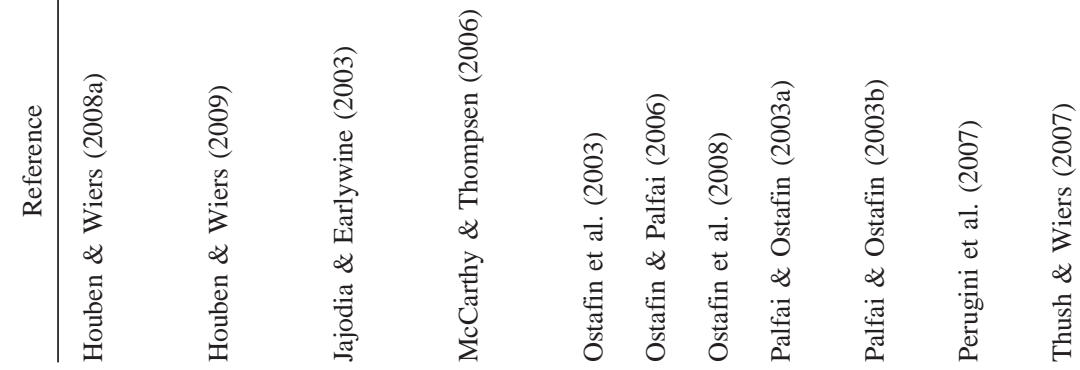






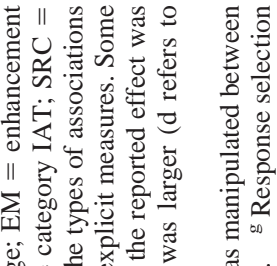



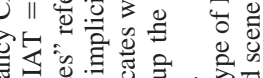

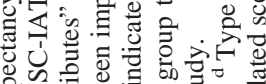

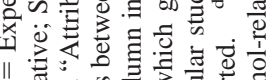

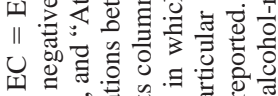

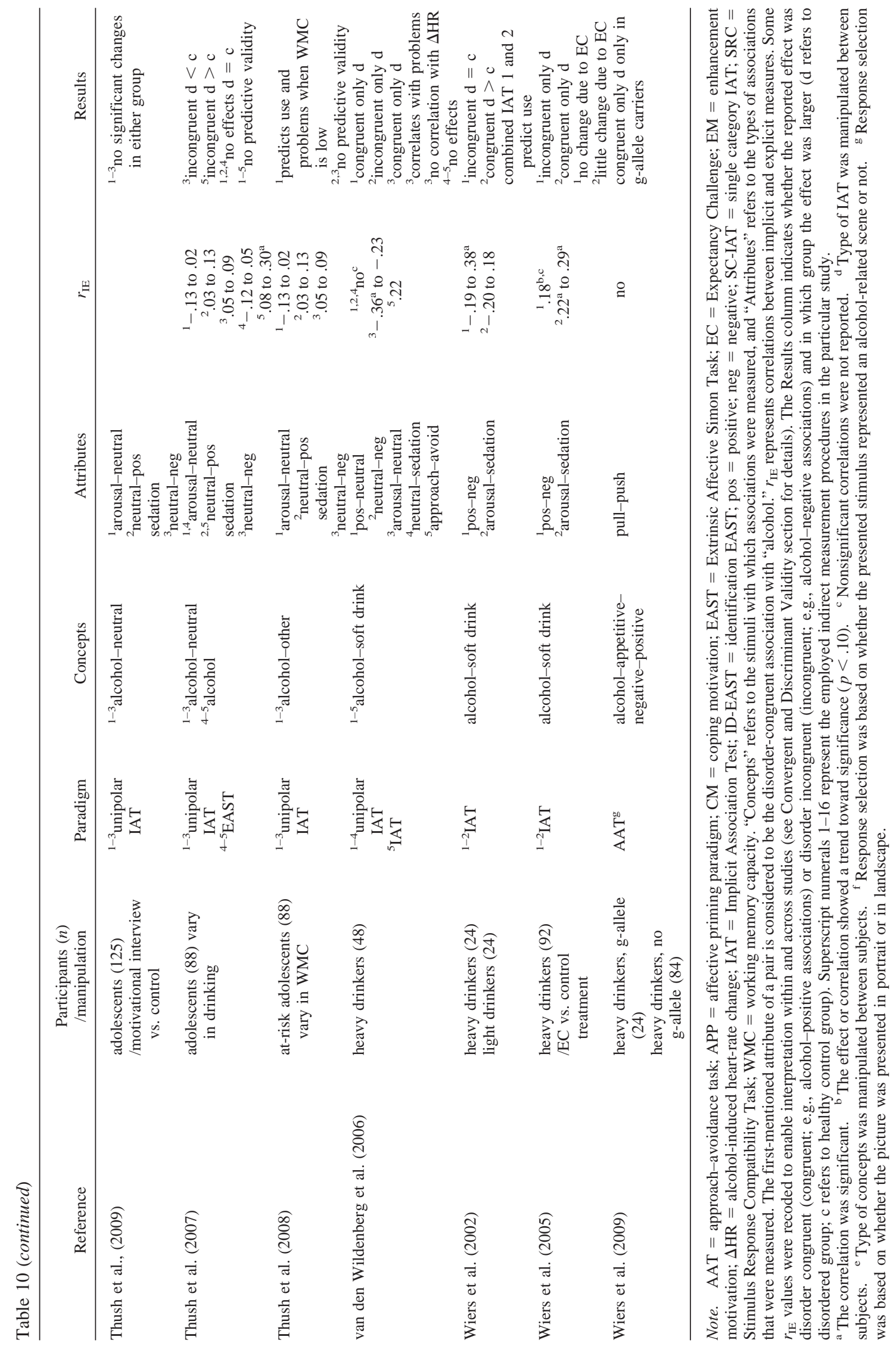


Jajodia \& Earleywine, 2003). A bipolar IAT contrasting alcohol versus soft drinks as positive versus negative in different samples - a randomly selected community sample (Houben \& Wiers, 2009), a sample of heavy and light drinkers (Wiers et al., 2002; Wiers, van de Luitgaarden, van den Wildenberg, \& Smulders, 2005), a sample of students varying in drinking behavior (Houben \& Wiers, 2006b), and a sample of alcohol-dependent patients (De Houwer, Crombez, Koster, \& De Beul, 2004)_unexpectedly showed stronger negative associations with alcohol than with soft drinks. Less negative alcohol associations on the bipolar IAT were correlated with increased self-reported drinking and alcohol problems (Houben \& Wiers, 2009).

The observed unexpected negative associations with alcohol may be partly explained by extrapersonal associations, most notably cultural knowledge about associations, knowledge that may not reflect one's own opinion. Such associations are known to affect IAT performance (Olson \& Fazio, 2004; but see Nosek \& Hansen, 2008) but may be addressed with a personalized version of the bipolar IAT (Olson \& Fazio, 2004). Compared with the traditional IAT, studies using this personalized IAT have found that drinking students showed less negative associations with alcohol as compared with the traditional IAT (Houben \& Wiers, 2007b) or even positive associations with alcohol (Houben \& Wiers, 2007a).

Another way to better understand the unexpected negative implicit measures of alcohol associations is to separate the positive/ negative dimension in unipolar IATs into positive-neutral and negative-neutral. When this is done, alcohol is related to both positive and negative valence in student samples (Houben \& Wiers, 2006a; Jajodia \& Earleywine, 2003). One study found stronger negative than positive associations (Houben \& Wiers, 2006a), whereas another found evidence only for negative associations (Houben \& Wiers, 2008a). Greater positive unipolar IAT associations were related to more self-reported drinking (Houben \& Wiers, 2008a; Jajodia \& Earleywine, 2003; McCarthy \& Thompsen, 2006) and to more alcohol problems (Houben \& Wiers, 2008a) but not consistently (Houben \& Wiers, 2006a; Jajodia \& Earleywine, 2003). Only one study found negative unipolar IAT associations to be related to less self-reported alcohol use and problems (Thush et al., 2007).

In studies involving the unipolar single-category IAT (SC-IAT), separate assessment of positive and negative dimensions is retained, but the comparison category (e.g., soft drinks) is omitted. Student participants showed both positive and negative associations with alcohol on unipolar SC-IATs (Houben \& Wiers, 2008a), but elevated self-reported drinking and alcohol problems were related only to the magnitude of positive SC-IAT associations. These effects were replicated and extended to associations with beer, because the alcohol category may have more negative cultural connotations than does the instance of beer. Positive and negative associations with both alcohol and beer were found. However, in this study, elevated self-reported drinking was related only to the magnitude of positive unipolar beer SC-IAT (Houben $\&$ Wiers, 2009). A different pattern of results was found for adolescents, who have less experience with drinking alcohol than do adults. Fifteen-year-old drinkers were both more positive and less negative toward alcohol than were abstainers, whereas no differences were found between 12-year-old drinkers and abstainers (Thush \& Wiers, 2007).
The EAST, like the SC-IAT, also obviates the need for a contrast category. On EAST measures of alcohol associations, alcohol-dependent patients (De Houwer et al., 2004) and both light and heavy drinkers (de Jong, Wiers, van de Braak, \& Huijding, 2007) showed positive associations with soft drinks, whereas alcohol was associated equally with positive and negative. Thus, the relatively negative associations with alcohol as compared with soft drinks on bipolar IAT measures (De Houwer et al., 2004; Wiers et al., 2002) may have been caused by positive associations with soft drinks rather than by negative associations with alcohol. In the ID-EAST, heavy drinkers had more positive associations with beer than did light drinkers (De Houwer \& De Bruycker, 2007). The existence of both positive and negative associations with alcohol on EAST, unipolar IAT, and SC-IAT measures (e.g., Houben \& Wiers, 2008a; Jajodia \& Earleywine, 2003) could suggest an ambivalent attitude toward alcohol, which is also evident on explicit measures (Conner \& Sparks, 2002).

Because approach is related to positive valence and avoidance, to negative valence, performance on these tasks is theorized to reflect affective associations. An APP study with alcohol and neutral words as primes and approach and avoidance words as targets found that an index of avoidance motivation-but not of approach motivation - was negatively related to the frequency of binge episodes and alcohol-related problems (Ostafin, Palfai, \& Wechsler, 2003). Thus, the fewer binge episodes and alcoholrelated problems that were reported, the stronger was the avoidance motivation. IAT effects depended heavily on the contrast category that was used. When alcohol was contrasted with electricity, at-risk drinkers associated alcohol more strongly with approach than with avoidance (Palfai \& Ostafin 2003b); when alcohol was contrasted with water, at-risk drinkers associated alcohol more strongly with avoidance than with approach (Ostafin \& Palfai, 2006), and when alcohol was contrasted with soft drinks, no difference was found between alcohol-approach and alcoholavoid associations in a group of heavy drinkers (van den Wildenberg, Beckers, van Lambaart, Conrod, \& Wiers, 2006). More in line with expectations, stronger IAT approach associations correlated positively with binge drinking in the past month (Ostafin \& Palfai, 2006; Palfai \& Ostafin, 2003b), quantity of drinking per occasion (but see Ostafin \& Palfai, 2006), difficulty controlling alcohol use, and greater sensitivity to positive incentives (Palfai \& Ostafin, 2003b).

Approach and avoidance tendencies have also been assessed with a stimulus-response compatibility task. Social drinkers scoring high on a subjective measure of alcohol craving showed stronger alcohol-approach tendencies compared with those scoring low on the craving measure (Field, Mogg, \& Bradley, 2005a). In line with these findings, heavy drinkers showed approach tendencies toward alcohol, whereas light drinkers did not. Moreover, this approach bias was significantly related to weekly alcohol consumption and to a measure of alcohol problems (Field, Kiernan, Eastwood, \& Child, 2008). Finally, another approachavoidance study tested associations with alcohol, general appetitive stimuli, and general positive and negative stimuli in heavy drinkers (Wiers, Rinck, Dictus, \& van den Wildenberg, 2009). This study also examined moderation by the OPRM1 gene because carriers of the g-allele of this gene have previously been found to demonstrate relatively strong cue-induced craving for alcohol (Ray \& Hutchison, 2004; van den Wildenberg et al., 2007). Heavy 
drinkers with this g-allele exhibited a stronger approach bias toward alcohol and to other appetitive stimuli than toward positive and negative stimuli. Heavy drinkers without this allele did not show an approach bias for any category of stimuli. The genebehavior connection clearly merits further study.

Because both valence expectancies and arousal expectancies play an important role in alcohol-use disorders (e.g., Goldman et al., 1999), it makes theoretical sense to obtain implicit measures of arousal associations as well. In an IAT contrasting alcohol with soft drinks and arousal with sedation, heavy-drinking students (Wiers et al., 2002, 2005) and alcohol-abuse patients (De Houwer et al., 2004) had stronger arousal associations than sedation associations with alcohol than they did with soft drinks. Consistent with this, a later study, with a student sample, involving unipolar IATs (Houben \& Wiers, 2006a) found strong IAT alcohol-arousal associations (see also Houben \& Wiers, 2009, with a community sample) and somewhat weaker IAT alcohol-sedation associations. Moreover, whereas alcohol-arousal associations were related to more self-reported alcohol use and problems (see also Houben \& Wiers, 2009), alcohol-sedation associations were related only to more alcohol problems.

Among 12-year-olds, male drinkers had stronger arousal associations than did abstainers, but female drinkers had both weaker arousal associations and stronger sedation associations than did abstainers (Thush \& Wiers, 2007). Lastly, a unipolar variant of the EAST assessing associations between alcohol and relaxed was associated with more self-reported drinking and alcohol problems (Thush et al., 2007). On the basis of findings of alcohol-induced heart-rate increases associated with feelings of arousal after drinking alcohol (Conrod, Peterson, \& Pihl, 2001), van den Wildenberg et al. (2006) tested the hypothesis that alcohol-arousal associations would correlate positively with heart-rate increases after alcohol consumption. In contrast with expectations, however, an as-yet unexplained negative association was found between these two variables.

Experimental validity studies. As predicted by alcoholexpectancy theory (Goldman et al., 1999), consumption of alcohol may make positive expectancies of alcohol more accessible. Unexpectedly, however, consumption of an alcoholic drink prior to performing the APP did not influence associations with alcohol (Palfai \& Ostafin, 2003a). Another study (Birch et al., 2008) addressed the influence of a mood manipulation on associations with alcohol, comparing people who drink to increase positive affect (enhancement motives, reward) with people who drink to decrease negative affect (coping motives, relief). These are the two motives that have been related to the development of alcohol use disorders (Cooper, Frone, Russell, \& Mudar, 1995). After a positive mood induction, enhancement-motive drinkers associated alcohol more strongly with reward than with relief. Unexpectedly, the reverse was not found: After a negative mood induction, coping-motive drinkers did not associate alcohol more strongly with relief than with reward (Birch et al., 2008).

In one study, therapy aimed at influencing alcohol expectancies had a short-lived effect on future alcohol use and only minimally changed the IAT associations (Wiers et al., 2005). As compared with a control intervention, this therapy did not lead to more changes on the valence IAT and produced only a little more reduction on the arousal IAT. It did, however, affect explicit arousal expectancies, and this change mediated the short-lived reduction in drinking. In a related study, a brief motivational interviewing intervention also did not lead to significant changes in implicit measures of associations or to reduced drinking (Thush et al., 2009).

Incremental and predictive validity studies. In most studies (except in Thush \& Wiers, 2007; Wiers et al., 2002, 2005), alcohol use and problems were assessed retrospectively. Therefore, no definite conclusions about the direction of the relation between implicit measures of associations and drinking/problems are possible. This is a drawback of research on this topic that would be good to remedy. Importantly, all reported associations of implicit measures of alcohol associations to measures of drinking behavior and drinking problems were controlled for the variance explained by explicit measures.

Stronger positive associations on the unipolar positive IAT, on (personalized versions of) the bipolar IAT, and on the ID-EAST, as well as stronger implicit measures of arousal associations, predicted more self-reported drinking (De Houwer \& De Bruycker, 2007; Houben \& Wiers, 2006a, 2006b, 2007a, 2007b, 2008b; Jajodia \& Earleywine, 2003; McCarthy \& Thompsen, 2006) and a combination of self-reported drinking and drinking problems (Houben \& Wiers, 2008a). Moreover, an implicit measure combining valence with arousal information was predictive of prospective alcohol use (Wiers et al., 2002). More research on the ability of implicit measures to predict the prospective use of alcohol would be particularly valuable.

Elevated alcohol problems were predicted by (a) elevation on a unipolar IAT measure of sedation associations (Houben \&Wiers, 2006a), (b) elevation on a unipolar IAT measure of arousal associations (Houben \& Wiers, 2008b), (c) elevation on a personalized bipolar IAT measure of positive associations (Houben \& Wiers, 2007a), and (d) reduction on an EAST measure of negative associations (de Jong et al., 2007). In most other studies, sedation associations (Thush \& Wiers, 2007; Thush et al., 2007, 2008), negative associations (Houben \& Wiers, 2008a; Jajodia \& Earleywine, 2003; McCarthy \& Thompsen, 2006; Thush et al., 2007, 2008), and approach associations (Ostafin \& Palfai, 2006) have not predicted alcohol use and/or problems. It is worthy of note, however, that an increased number of binge-drinking episodes was predicted by reduced alcohol-avoidance associations (Ostafin \& Palfai, 2006). In adolescent boys, increased binge drinking one year later was mainly predicted by increased alcohol-arousal and alcohol-positive associations (Thush \& Wiers, 2007). Taken together, support for incremental validity is strongest for implicit measures of both positive and arousal associations.

Apart from testing the incremental and predictive validity for self-reported alcohol use and problems, studies have addressed the predictive value for appetitive responses to alcohol. Increased IAT alcohol-approach associations were related to some appetitive responses when alcohol consumption was anticipated: increased urge to drink, more positive expected outcomes, and increased affective arousal responses (Palfai \& Ostafin, 2003b). Reduced IAT alcohol-avoid associations were related to alcohol desirability ratings, but this effect disappeared when controlling for explicit drinking motives (Ostafin \& Palfai, 2006).

Finally, as has been done in eating disorder research (e.g., Hofmann et al., 2007), moderating effects of variables related to the availability of cognitive resources have been examined. Working-memory capacity moderated the relation between im- 
plicit measures of positive arousal associations and a combined index of alcohol use and problems. These positive arousal associations were more strongly predictive of self-reported alcohol use and problems one month later in at-risk adolescents with low working-memory capacity than in those with high workingmemory capacity (Thush et al., 2008). Extending the results to a measure of actual beer consumption showed that an implicit measure of beer associations was predictive of beer consumption when self-regulatory resources were low but not when they were high (Friese et al., 2008, Study 3; cf. Hofmann et al., 2007). Similarly, an implicit measure of beer associations was only predictive of beer consumption in a so-called taste test in an ego-depletion condition (Ostafin, Marlatt, \& Greenwald, 2008). Finally, selfactivation had a similar moderating effect: A bipolar IAT was predictive only of self-reported alcohol consumption in a selfactivation condition (Perugini et al., 2007). Taken together, these findings can be interpreted as supportive of the hypothesis derived from the dual-process view that implicit measures of associations are predictive of behavior primarily when cognitive control is relatively weak (see also Wiers \& Stacy, 2010).

Summary. Although early studies with the regular IAT suggested negative associations with alcohol in drinking participants, later research with adaptations of the IAT and other paradigms showed that drinkers also have positive associations with alcohol. Importantly, the positive associations with alcohol were predictive of alcohol use. In addition, approach-avoid motivation and arousal associations also were related to self-reported drinking and appetitive responses. Two studies showed that implicit measures were mostly predictive of alcohol use in people with low cognitive resources. Finally, implicit measures of associations were influenced by mood and minimally by therapy.

\section{Nicotine Dependence}

Table 11 presents the results of studies on nicotine dependence. Characteristic of nicotine dependence is the fact that smoking is continued despite significant nicotine-related problems (American Psychiatric Association, 2000). As in alcohol use disorders, positive outcome expectancies are an important cognitive factor explaining smoking behavior. Expectancies related both to positive reinforcement (e.g., "smoking makes me feel good") and to negative reinforcement (e.g., "smoking helps me relax") are important predictors of smoking behavior (e.g., Brandon \& Baker, 1991; Hine, Honan, Marks, \& Brettschneider, 2007). Seemingly at odds with this notion, smokers' explicit measures of attitudes toward smoking are typically neutral at best, although they are less negative than those of nonsmokers (e.g., Chassin, Presson, Sherman, \& Edwards, 1991; Stacy, Bentler, \& Flay, 1994). In line with the importance of positive expectancies for explaining smoking behavior, implicit measures are expected to reflect positive associations with smoking. Implicit-explicit correlations range from $r=$ -.08 to .69 .

Studies comparing groups with a disorder to controls. On an IAT, smokers have repeatedly been shown to have negative associations with smoking relative to both positive (e.g., exercise) and neutral (e.g., shapes) contrast categories, with their negative associations being either not different from nonsmokers (Experiment 1 of Swanson, Rudman, \& Greenwald, 2001) or less negative than those of nonsmokers (Chassin, Presson, Rose, Sherman, \& Prost,
2002; Experiment 1 of Huijding, de Jong, Wiers, \& Verkooijen, 2005 Experiment 1 of Perugini, 2005). On a personalized IAT, smokers associated smoking more with negative than with positive social consequences (Kahler, Daughters, Leventhal, Gwaltney, \& Palfai, 2007). With a negative contrast category (i.e., stealing), both smokers and nonsmokers were relatively positive about smoking and did not differ in the strength of their associations (Experiment 2 of Robinson, Meier, Zetocha, \& McCaul, 2005; Experiment 2 of Swanson et al., 2001). Similar results were obtained on a self-identification IAT: Both smokers and nonsmokers identified more with smoking than with stealing, but this time the effect was more pronounced for the smokers (Experiment 2 of Swanson et al., 2001). Perhaps substituting a negative contrast category (e.g., lying) that is more morally ambiguous would be more revealing.

When nonsmoking was used as the contrast category, smokers either displayed negative associations (Experiment 3 of Swanson et al., 2001; Waters et al., 2007) or ambivalent associations (Experiments 1 and 2 of Robinson et al., 2005) with smoking. The strength of their negative associations with smoking decreased with higher levels of dependence (Waters et al., 2007). As expected, nonsmokers displayed more pronounced negative associations with smoking (Robinson et al., 2005; Experiment 3 of Swanson et al., 2001). On a self-identification IAT, smokers identified more strongly with smoking than with nonsmoking, whereas nonsmokers showed the reverse (Experiment 3 of Swanson et al., 2001). On a go/no-go IAT with neutral stimuli on the no-go trials, smokers also showed ambivalence toward smoking in that they associated smoking equally with good and with bad, whereas nonsmokers associated smoking more with bad (Bassett \& Dabbs, 2005). An alternative way to understand why unexpected relatively negative associations have frequently been found in smokers is, once again, to separate the positive and negative dimensions in unipolar IATs. A positive unipolar IAT with a neutral contrast category (i.e., smoking vs. birds) was positively correlated with self-reported smoking (McCarthy \& Thompsen, 2006). Thus, the more smoking behavior was reported, the more positive were the associations with smoking. A negative unipolar IAT was not related to self-reported smoking.

Of course, not all smoking cues are alike. Some may reflect the positive sensory aspects of smoking (e.g., a cigarette held in a hand); others might remind people of the negative health and economic aspects of smoking (e.g., the warning on the package). In one study, an APP was sensitive to the type of cue that was used as the prime in that smokers had negative associations with pictures showing smoking-related packaging information but positive associations with pictures depicting sensory aspects of smoking (Sherman et al., 2003). In that same study, the IAT showed no sensitivity to the type of cue, perhaps because of the overpowering effects of the category labels of the IAT (e.g., target dimension: smoking vs. cuddly animals; De Houwer, 2001). Consistent with the importance of distinguishing between types of smoking cues, on a SC-IAT measure with pictorial stimuli focusing on the sensory aspects of smoking, smokers had positive associations with smoking, whereas nonsmokers had negative associations (Huijding \& de Jong, 2006a). An alternative explanation for the lack of positive associations with smoking in smokers in IAT studies may be that the IAT reflects the negative (stigmatized) cultural connotation of smoking rather than a personal association (Karpinski \& 


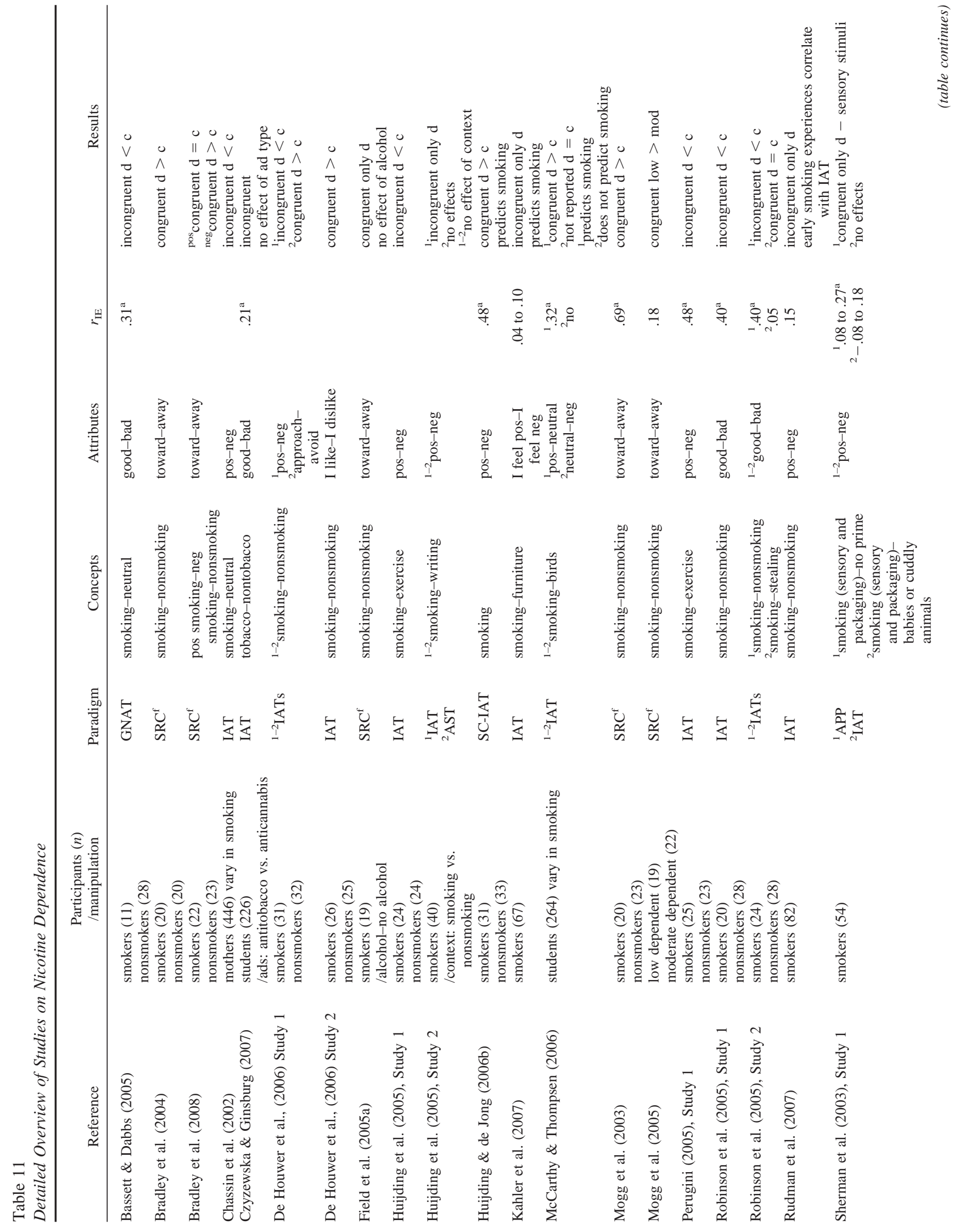







Hilton, 2001; Olson \& Fazio, 2004; but see Nosek \& Hansen, 2008). Indeed, on a personalized version of the IAT, smokers displayed clearly positive associations and nonsmokers displayed clearly negative associations for smoking pictures relative to nonsmoking pictures (De Houwer, Custers, \& De Clercq, 2006).

Findings with measures of approach and avoidance have frequently - but not always - been in line with expectations. Although smokers showed neutral or ambivalent associations with smoking pictures relative to nonsmoking pictures on a valence IAT, they showed approach associations on an approach-avoid IAT. Nonsmokers showed negative and avoid associations (De Houwer et al., 2006). Converging evidence was obtained with an SRC task: Although participants were faster overall to approach smoking pictures and avoid neutral pictures than vice versa, this approach bias was significantly stronger in smokers than in nonsmokers (Bradley, Field, Mogg, \& De Houwer, 2004; Mogg et al., 2003). Unexpectedly, the approach bias was stronger in low than in moderately dependent participants (Mogg et al., 2005). Finally, the valence of the smoking stimuli affected SRC results: Smokers showed a stronger approach bias toward negative smoking stimuli than did nonsmokers, whereas smokers and nonsmokers displayed an equally strong approach bias toward positive smoking stimuli (Bradley, Field, Healy, \& Mogg, 2008).

Experimental validity studies. In both a smoking setting and a neutral lab setting, participants showed a relatively negative association with smoking on the IAT and a neutral/ambivalent attitude on the AST (Study 2 of Huijding et al., 2005). Watching antitobacco ads (as compared with watching antimarijuana ads) did not significantly influence negative tobacco associations either (Czyzewska $\&$ Ginsburg, 2007). Because smoking is associated with alcohol consumption during social events, alcohol could activate positive associations with smoking. However, unexpectedly, the consumption of a small quantity of alcohol did not affect the strength of the approach bias in smokers (Field, Mogg, \& Bradley, 2005b), although it did increase the positive explicit rating of smokingrelated pictures.

Deprivational state in both heavy and light smokers affected implicit measures of associations with smoking (Sherman et al., 2003). In the APP, light smokers had more positive associations with smoking pictures when they had just smoked than when they were deprived. Conversely, heavy smokers had more negative associations with smoking pictures when they had just smoked than when they were deprived. As Sherman et al. (2003) suggested, heavy smokers may have displayed more negative associations with smoking when they had just smoked because of negative feelings about this socially undesirable behavior or about their dependence. In addition, less negative associations with smoking when deprived may be caused by increased craving. On the IAT, light smokers had more negative associations with smoking than did heavy smokers, and the deprivation manipulation did not affect the results.

As Waters et al. (2007) argued, the deprivation manipulation used by Sherman et al. (2003) may not have been long enough for an effect to occur on the IAT. Therefore, Waters et al. increased the deprivation duration to $12 \mathrm{hr}$ and additionally tested the effect of smoking a cigarette $40 \mathrm{~min}$ before completion of the IAT. The IAT effect was more negative when participants received a cigarette $40 \mathrm{~min}$ before the IAT and were allowed to smoke normally before the experiment than when they did not receive a cigarette and/or were asked to abstain before the experiment. This pattern of results is in accordance with the results for the heavy smokers in the Sherman et al. (2003) study. These heavy smokers $(>15$ cigarettes a day) likely resemble the participants in the study of Waters et al. (2007; $M=20.2$ cigarettes a day). Other research suggests that early childhood experiences with smoking, which are mostly negative, are also related to current associations with smoking as assessed by an IAT (Rudman, Phelan, \& Heppen, 2007), whereas recent experiences with smoking are unrelated to implicit measures of associations with smoking.

Incremental and predictive validity studies. A positive unipolar IAT measure predicted self-reported frequency of smoking over and above questionnaire expectancy measures (McCarthy \& Thompsen, 2006). Implicit measures of associations were also predictive of smoking abstinence at two and eight weeks after quit date and remained predictive when controlling for the number of smokers in the social environment and explicit expectancies (Kahler et al., 2007). Finally, more positive associations with smoking as indexed by the single-target IAT were significantly related to a higher level of craving at the end of the experiment (Huijding \& de Jong, 2006a). An IAT with nonsmoking as the contrast category was also related to self-reported craving but not to the startle response on smoking pictures compared with neutral pictures, a physiological measure of affective processing (Waters et al., 2007).

Summary. On the IAT, smokers' associations with smoking were mostly negative when compared with a positive or neutral contrast category, or they were at best ambivalent when compared to nonsmoking - although often less negative than in nonsmokers. Interestingly, when associations toward the specifically sensory aspects of smoking were assessed, or when a personalized version of the IAT was used, smokers showed positive associations with smoking. In addition, a substantial amount of support was found for approach associations with smoking in smokers. Deprivational state appeared to affect associations with smoking, but measurement context (smoking setting vs. neutral lab setting) and the consumption of alcohol did not. Implicit measures of associations were predictive of self-reported smoking, smoking abstinence, and self-reported craving. Implicit measures actually seem to have been quite informative in the domains of eating, drinking alcohol, and smoking, suggesting an important role in appetitive situations.

\section{Cannabis and Cocaine Dependence}

Table 12 presents the results of studies on cannabis and cocaine dependence. A characteristic of cannabis and cocaine dependence is that drug use continues despite significant drug-related problems (American Psychiatric Association, 2000). As with alcohol use disorders and nicotine dependence, expectancies regarding different types of reinforcement (e.g., social and emotional facilitation) have been shown to be important predictors of cannabis use (Alfonso \& Dunn, 2007; Mullens, Young, Dunne, \& Norton, 2010) and of cocaine use (Stacy, Newcomb, \& Bentler, 1995). In line with the expectancy literature, associations with cannabis and cocaine would be expected to be positive and arousal related. Reported implicit-explicit correlations are low $(r<.23)$.

Studies comparing groups with a disorder to controls. On an IAT, no clear positive association with cannabis has been found among cannabis users. Nonusers displayed a more negative asso- 
ROEFS ET AL.

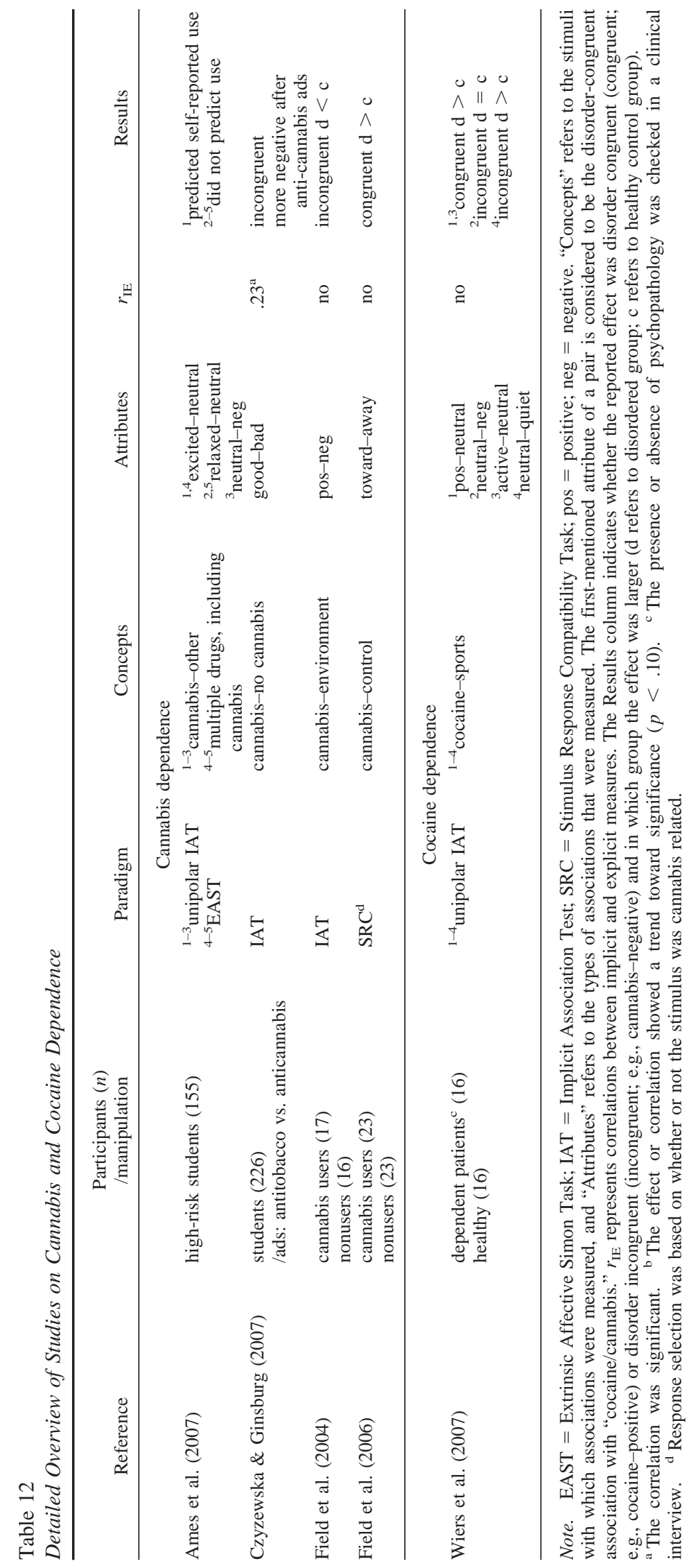


ciation with cannabis than with the neutral control category on the IAT, and their associations were more negative than those of cannabis users (Field, Mogg, \& Bradley, 2004). In line with research on nicotine dependence, results of an approach-avoidance measure (SRC task) confirmed expectations: Cannabis users, but not nonusers, were faster to approach than to avoid cannabis stimuli (Field, Eastwood, Bradley, \& Mogg, 2006). Only one study has reported implicit measures of cocaine associations (Wiers, Houben, \& de Kraker, 2007). Four unipolar IATs were used (positive, negative, arousal, and sedation; all relative to neutral), with cocaine versus sports as the concept categories. Cocainedependent participants displayed stronger arousal, positive, and sedation associations with cocaine than did controls, but no group difference was found for cocaine-negative associations.

Experimental validity studies. Implicit measures of associations with cannabis were negative in students. This effect was stronger when the IAT was administered after anticannabis ads than after antitobacco ads (Czyzewska \& Ginsburg, 2007). No such studies exist for cocaine, so this is a very meager experimental literature at present.

Incremental and predictive validity studies. Using a unipolar IAT measure, Ames et al. (2007) found that associations between cannabis and the attribute excited were predictive of self-reported cannabis use, after controlling for demographic variables and explicit beliefs. This pattern was not evident for unipolar IAT measures with the attributes relaxed or negative. In addition, two unipolar multiple-drug EAST measures (excited, relaxed; both compared to neutral) did not contribute to the explained variance.

\section{General Discussion}

We have covered the use of implicit measures with 12 categories of disorder, some with very limited literatures and some with quite extensive literatures. In the first part of the General Discussion, we integrate research findings over these various forms of psychopathology, organized according to the same three categories as used throughout the previous section: studies comparing groups with a disorder with controls, experimental validity studies, and incremental and predictive validity studies. In the second part, we address issues relating to the interpretation of implicit measures. In closing, we consider the bigger picture, including directions for future research.

\section{Integration of Findings}

Studies comparing groups having a disorder with controls. For specific phobia, pedophilia, and to some extent anorexia nervosa, the majority of findings were consistent with theoretical expectations. People with spider phobia and spider-fearful individuals showed the expected negative associations with spiders (e.g., Huijding \& de Jong, 2005b), and people with pedophilia had child-sex associations (Gray et al., 2005). Thus, the implicit measures of associations were disorder congruent and were strongest in or limited to the disordered group. For anorexia, the results were largely as expected: Implicit measures of food evaluations were either unaffected by the palatability and fat content of the foods (Roefs, Stapert, et al., 2005) or were negative for high-fat foods (de Jong \& Veenstra, 2007). However, instead of an avoidance of high-fat foods, only a reduced approach bias was found. Thus, findings with implicit measures for these disorders provide converging evidence for dysfunctional beliefs that are characteristic of these disorders.

Unexpected patterns of results emerged for depressive disorder, social phobia, and BDD. Although cognitive models of these disorders (e.g., D.A. Clark et al., 1999) predict negative selfesteem, implicit measures consistently have suggested positive self-esteem (e.g., De Raedt et al., 2006). Limited support for the cognitive models comes from the few studies (e.g., de Jong, 2002; Meites et al., 2008; Steinberg et al., 2007) that found weaker positive self-esteem in the disordered group than in healthy controls. Lower positive self-esteem may provide a weaker buffer against negative experiences, increasing vulnerability to onset and/or maintenance for those with disorders. Several explanations have been put forward for the unexpected finding of positive implicit measures of and negative explicit measures of self-esteem in these disorders. Franck et al. (2007) considered that this is either due to unstable self-esteem or to a discrepancy between high standards and negative perceived reality, both of which have been related to depressive symptomatology (Roberts \& Monroe, 1994; Weiner \& White, 1982). However, these are post hoc explanations, untested as yet.

Because self-esteem was almost always measured by the IAT rather than by other measurement procedures in these studies, it may be too soon to conclude that the role of negative self-esteem in cognitive models of psychopathology should be revised. In all studies, the comparison category was other or "not me," which may also yield biased results. Recall that the IAT is a relative measure that permits only the conclusion that the evaluation of the self is more positive than that of the other (see Pinter \& Greenwald, 2005). Thus, it could be that, even though disordered and healthy people show similar IAT effects, disordered people have more negative associations with both the self and the other than do healthy people. Interesting in this respect is a study in which the comparison category other was changed to friend or ingroup, both of which are obviously positive. Even with these comparison categories, evidence for positive self-esteem was found in a healthy sample (Yamaguchi et al., 2007). The use of these and other alternative comparison categories could be explored in future research on self-esteem in depressed, socially phobic, and BDD groups.

Future research should use paradigms that do not require a comparison category, such as the SC-IAT (Karpinski \& Steinman, 2006), to assess associations with the self without referring to the other. Additionally, unipolar variants of the IAT could be used in an attempt to assess the positive and negative associations independently. Finally, it would be interesting to study other potentially disorder-relevant associations as well. For example, given the association between mood disorders and suicide ideation and attempts, it could be informative to obtain implicit measures of self-injury associations. These measures have been shown to distinguish between nonsuicidal participants, suicide ideators, and suicide attempters and to predict future suicide ideation (Nock \& Banaji, 2007).

For panic disorder and social phobia, another unexpected association with the self emerged in the form of evidence for me-calm associations (e.g., Gamer et al., 2008; Teachman, 2005). These associations were reduced in a disordered group, but this pattern does not strictly fit the characteristic dysfunctional beliefs of these 
disorders. However, in a study involving the semantic priming paradigm (Schneider \& Schulte, 2007), evidence for disordercongruent associations was found for panic disorder patients; that is, bodily sensations were associated with catastrophic interpretations. Taken together, then, implicit measures were partly consistent with theoretical expectations.

Associations with craved substances (food, alcohol, nicotine, and drugs) reflected both the positive (e.g., high-fat foods taste good) and the negative (e.g., alcohol can give you a hangover) aspects of these substances. In research on nicotine dependence, the valence of the contrast category heavily influenced the direction of IAT effects: Whereas incongruent negative associations were generally found when a neutral (e.g., nonsmoking) or positive (e.g., exercise) contrast category was used (e.g., Chassin et al., 2002), congruent positive associations were found when negative (e.g., stealing) contrast categories or unipolar or single-category variants were used (e.g., Robinson et al., 2005). This pattern highlights an inherent limitation of the original IAT when no natural opposing category exists. In a similar vein, unexpected negative associations with craved substances have been found in alcohol and obesity research with the bipolar IAT (e.g., Roefs \& Jansen, 2002; Wiers et al., 2002). In alcohol research, this complexity has been resolved by assessing the positive and negative associations separately. Using this approach, clear evidence for both the expected positive and the unexpected negative associations with alcohol has been found (e.g., Houben \& Wiers, 2006a). In research on eating and nicotine dependence, many studies have found evidence for negative associations with the craved substances (e.g., Roefs \& Jansen, 2002). Interestingly, however, positive associations with the craved substances emerged when the sensory aspects-as opposed to the health consequences-were emphasized (e.g., Roefs et al., 2006).

Thus, the idea that substance users and overeaters would be characterized by implicit measures of positive associations with their craved substances is evidently too simplistic. Theories concerning overeating and alcohol and drug abuse need to accommodate the often-observed negative associations with craved substances, in addition to the expected positive associations. In substance users and overeaters, associations with the negative consequences of their use of alcohol, high-fat foods, nicotine, or drugs do appear to be present. This knowledge seems so accessible, in fact, that it even affects implicit measures of associations with these craved substances. Future research should carefully consider whether measures reflect associations with the sensory or the health-related aspects and preferably should assess positive and negative associations separately.

Finally, for dyspareunia, OCD, pain disorder, and PTSD, group differences were mostly inconsistent with theoretical expectations. For dyspareunia (Brauer et al., 2009) and OCD (e.g., Teachman et al., 2006), disorder-incongruent associations were found that did not differ between a disordered or symptomatic group and a healthy group. For pain disorder, only two studies (Goubert et al., 2003; Vancleef et al., 2007) found evidence for disorder-congruent associations specifically in disordered groups. The one relevant study on PTSD (Engelhard et al., 2007) unexpectedly found that self-invulnerable associations decreased with increasing PTSD symptoms. We hasten to emphasize, however, that research in these domains has been limited, so it is too early to draw firm conclusions from these unexpected findings.
It is striking that many findings for different disorders did not fit the theoretical expectations. Is this possibly because the theoretical expectations derive primarily from consideration of explicit factors only? For positive implicit self-esteem in depressive disorder, social phobia, and BDD, and negative associations with craved substances in food, alcohol, and drug-related disorders, these unexpected findings were so consistently reported that theories on these disorders should accommodate these findings. In other instances-OCD, dyspareunia, PTSD, pain disorder, and panic disorder-the number of studies is still too limited or the diversity of findings too large to argue for accommodation of the findings. In these instances, inconsistent findings may partly be explained by problems with the measurement procedures, such as low reliability or unsuitable stimuli, or by insufficient development of the theories themselves.

Experimental validity studies. As compared with the known-groups approach, relatively few experimental studies have been conducted. Those studies that have taken this approach have often found the expected effect of the manipulation on the implicit measures. For example, priming with spiders as opposed to humans elicited negative associations with ambiguous spider-related words in spider-fearful participants (Ellwart et al., 2005), a negative mood induction led to reduced self-positive associations in formerly depressed participants (e.g., Gemar et al., 2001), and inductions of craving and hunger affected associations with food positively in healthy and eating-disordered participants (e.g., Seibt et al., 2007). Although limited in number, these studies are consistent with the view that the processes indexed by the implicit measure play a role in the studied psychopathology. It is worth noting, however, that explicit measures would be expected to produce the same pattern, so the added value for the implicit measures will need to be carefully considered.

There are even fewer studies of treatment on implicit measures of associations. For specific phobia, social phobia, pain disorder and panic disorder, successful exposure therapy or CBT was associated with significant improvements on implicit measures of disorder-relevant associations (e.g., Grumm et al., 2008; Teachman \& Woody, 2003). Interestingly, for panic disorder, cognitive changes preceded symptom reduction (Teachman et al., 2008). For obesity, a successful weight-loss treatment did not lead to the predicted changes in implicit measures of associations with food and physical activity (Craeynest et al., 2008). Similarly, in the context of alcohol dependence, results showed no effect of motivational interviewing (Thush et al., 2009) and only a weak effect of an expectancy challenge intervention (Wiers et al., 2005) on implicit measures of alcohol associations. Note that these interventions either had no effect (motivational interviewing) or only a short-lived effect (expectancy challenge) on drinking behavior. One question that remains for further research is whether observed changes in implicit measures after treatment are causally related to symptom improvement or are merely an epiphenomenon. The study on panic disorder that showed that cognitive changes preceded symptom reduction (Teachman et al., 2008) is a first step in addressing this question. Another important question is whether certain implicit measures of associations are predictive of symptom onset. Of course, the holy grail would be to find an implicit measure that both predicts disorder onset and is sensitive to successful treatment of the disorder-and ideally is not coincident with explicit measures. 
Incremental and predictive validity studies. Importantly, implicit measures explained variance in a range of behavioral measures in addition to that explained by explicit measures. This was the case for performance on a spider behavioral-avoidance test (e.g., Teachman \& Woody, 2003), panic symptoms (e.g., Teachman et al., 2007), mirror avoidance (Clerkin \& Teachman, 2009), self-reported alcohol use (e.g., Jajodia \& Earleywine, 2003), and food choice (e.g., Perugini, 2005). In the context of alcohol abuse, increased alcohol-positive and alcohol-arousal associations predicted increases in drinking behavior and alcohol problems. Note that problem drinkers also consistently showed negative associations with alcohol, but these did not predict drinking behavior. In addition, in keeping with dual-process models of information processing (e.g., Fazio \& Towles-Schwen, 1999), some evidence was found for the idea that implicit measures are specifically predictive of spontaneous types of behavior, such as the startle response in the context of specific phobia (Huijding \& de Jong, 2006b) and immediate affective reactions in the context of depression (Haeffel et al., 2007). Implicit measures are potentially most valuable when they complement rather than coincide with explicit measures.

Finally, another interesting and promising approach has been the study of moderating variables of the relation between implicit measures and behavior in the context of eating behavior (e.g., Hofmann et al., 2009) and problem drinking (e.g., Thush et al., 2008). Generally, implicit measures of associations were predictive of behavior only when cognitive resources were limited either by an experimental manipulation or as an individual difference factor. We take this to be an important insight emerging from this review. Future research needs to address whether overeaters and problem drinkers more often suffer from conditions in which cognitive resources are limited. If this were true, then the behavior of these individuals would more often be guided by their implicit measures of associations with the craved substance, helping to explain their disordered behavior. Of course, the direction of causality must also be considered: Does the limitation on cognitive resources precede the problem behavior, or does focusing on the problem behavior itself result in limited resources?

This evidence for the predictive power of implicit measures fits the results of a recent meta-analysis by Greenwald, Poehlman, Uhlmann, and Banaji (2009), in which an average $r=.27$ was found between implicit measures and behavior, judgment, and psychophysiological measures. Implicit and explicit measures both explained unique variance, proving the value of both in the prediction of behavior. The predictive validity of explicit measures was reduced for socially sensitive topics, for which socially desirable answering tendencies may affect self-report measures. Thus, although we cannot draw conclusions about the uniqueness of implicit measures from (a lack of) implicit-explicit correlations, evidence for incremental predictive power demonstrates the added value of implicit measures. For a lively debate about the predictive validity of the IAT for discriminatory behavior, see Blanton et al. (2009); McConnell and Leibold (2009); and Ziegert and Hanges (2009).

\section{Interpretation Issues With Implicit Measures}

The aim of many of the reviewed studies was to use implicit measures to shed greater light on the dysfunctional beliefs that are characteristic for a disorder according to a cognitive perspective. Obviously, the conclusions of the studies depend on the validity of the implicit measures used. With an unexpected result involving an assessment tool, it may be difficult to determine whether the outcome of the measurement procedure was not valid or the theory is wrong. Several potential pitfalls accompany the translation of implicit measurement outcomes to psychological attributes and models of psychopathology. First, in principle, one cannot be certain "whether different attributes underlie explicit and implicit measures or whether both measures reflect the same attribute under different conditions" (De Houwer et al., 2009a, p. 351) Second, Blanton and Jaccard (2006) have expressed the position that it is not warranted to assume that the zero-point of the IAT (and probably of other implicit measures as well) corresponds to the true zero-point of the to-be-measured psychological attribute (but see Greenwald, Nosek, \& Siriam, 2006). This issue may, as Blanton and Jaccard argued as well, however, be less problematic when studying theoretical processes than when attempting to assess a psychological attribute of a person. Third, the extent to which implicit measures are informative for cognitive models of psychopathology is limited by the implicitness of these measures (i.e., the extent to which implicit measures reflect uncontrollable, nonconscious, and fast mechanisms) and our understanding of the processes by which psychological attributes cause the measurement outcomes (De Houwer et al., 2009a).

More research certainly is needed both on the implicitness of measures and on how psychological attributes express themselves in measurement outcomes. Researchers must realize that no measure is fully implicit or fully explicit (see Jacoby, 1991, for discussion of the impurity of tasks in terms of isolating unique processes). In an attempt to handle this problem, a modeling approach might be taken for estimating implicit and explicit components of measurement outcomes. An example would be the quadruple-process model (Conrey, Sherman, Gawronski, Hugenberg, \& Groom, 2005), the goal of which is to "quantitatively disentangle the influences of four distinct processes on implicit task performance: the likelihood that automatic bias is activated by a stimulus; that a correct response can be determined; that automatic bias is overcome; and that, in the absence of other information, a guessing bias drives responses" (Conrey et al., 2005, p. 469).

Still, as Nosek and Greenwald (2009) advocated, there is no need to wait until everything is known about implicit measures before these measures can be applied, the circularity of that idea notwithstanding. If the measurement outcomes show predictive validity and reliably distinguish between groups, then they are useful both in applied settings and potentially in theory refinement-at least to the extent that the implicit measures are not redundant with the explicit measures. Of course, to be able to make reasonable theoretical claims about what an implicit measure actually assesses, ongoing basic research is needed (De Houwer, Teige-Mocigemba, Spruyt, \& Moors, 2009b). What we have shown in this review is that implicit measures are at least partially distinct from explicit measures and that there is, for some disorders, convergence across implicit measures. This justifies the continuing application and exploration of these indices in the context of psychopathology. 


\section{Conclusion}

Implicit measures distinguished disordered from healthy people in several domains of psychopathology, similar to what has been achieved in the past by the emotional Stroop paradigm (Williams, Mathews, \& MacLeod, 1996), thereby providing converging evidence for the validity of the cognitive models of the dysfunctional beliefs in these types of psychopathology. However, we find it remarkable that often the observed implicit measure of association did not fit predictions from the cognitive model of the studied psychopathology. In two instances (self-esteem and negative associations with craved substances) findings were unexpected but so consistently reported that they have implications for the revision of cognitive theories of these disorders.

For future research, it is important to select the best paradigm for the research question (De Houwer et al., 2009a), taking into consideration, for example, (a) whether effects are expected on the category versus the exemplar level of the stimuli used; (b) whether a relative or an absolute measure of associations is suitable; (c) which stimuli best fit the psychological attribute of interest (e.g., idiographic stimuli, Schneider \& Schulte, 2007); (d) in what sense the expected effects are thought to be implicit; and (e) the reliability of the measure. In this regard, we call for stepping up efforts to measure - and indeed to find ways to increase- the reliability of implicit measures. In addition, we would like to see more studies where multiple implicit measures are included, so that their relative success and their convergence can be evaluated, ideally against that of explicit measures included in the same study. And we believe that circumstances of reduced cognitive resources warrant particular attention because it may be especially in these circumstances that implicit measures prove to be most informative.

The past decade has seen a dramatic increase in the use of implicit measures in psychopathology, just as in other domains of psychological inquiry. Despite ongoing debates about their interpretation and reliability, their possible independence from overt reports has made them highly attractive to many researchers in this field. In some areas, unexpected but consistent patterns in the results already call for theoretical modifications, whereas in other areas implicit measures provide converging evidence for the validity of the cognitive models for the disorders. In still other areas, factors related to task design or a low number of studies have hampered rapid progress. We concur with De Houwer et al. (2009a) that future research must seek to reveal the processes by which psychological attributes cause the measurement outcomes and to examine in what sense certain measures can (and cannot) be considered implicit. It has always been fundamental to our understanding of psychological processes that much lies beneath the surface: For this reason, implicit measures are especially intriguing.

\section{References}

Alden, L. E., Taylor, C. T., Mellings, T. M. J. B., \& Laposa, J. M. (2008). Social anxiety and the interpretation of positive social events. Journal of Anxiety Disorders, 22, 577-590. doi:10.1016/j.janxdis.2007.05.007

Alden, L. E., \& Wallace, S. T. (1995). Social phobia and social appraisal in successful and unsuccessful social interaction. Behaviour Research and Therapy, 33, 497-505. doi:10.1016/0005-7967(94)00088-2

Alfonso, J., \& Dunn, M. E. (2007). Differences in the marijuana expect- ancies of adolescents in relation to marijuana use. Substance Use \& Misuse, 42, 1009-1025. doi:10.1080/10826080701212386

American Psychiatric Association. (2000). Diagnostic and statistical manual of mental disorders (4th ed., Text Rev.). Washington, DC: Author. doi:10.1176/appi.books.9780890423349

Ames, S. L., Grenard, J. L., Thush, C., Sussman, S., Wiers, R. W., \& Stacy, A. W. (2007). Comparison of indirect assessments of association as predictors of marijuana use among at-risk adolescents. Experimental and Clinical Psychopharmacology, 15, 204-218. doi:10.1037/10641297.15.2.218

Arntz, A., Lavy, E., Van der Berg, G., \& Van Rijsoort, S. (1993). Negative beliefs of spider phobics: A psychometric evaluation of the Spider Phobia Beliefs Questionnaire. Advances in Behaviour Research and Therapy, 15, 257-277. doi:10.1016/0146-6402(93)90012-Q

Bargh, J. A., Chaiken, S., Govender, R., \& Pratto, F. (1992). The generality of the automatic attitude activation effect. Journal of Personality and Social Psychology, 62, 893-912. doi:10.1037/0022-3514.62.6.893

Barlow, D. H. (1986). Causes of sexual dysfunction: The role of anxiety and cognitive interference. Journal of Consulting and Clinical Psychology, 54, 140-148. doi:10.1037/0022-006X.54.2.140

Bassett, J. F., \& Dabbs, J. M., Jr. (2005). A portable version of the go/no-go association task (GNAT). Behavior Research Methods, 37, 506-512.

Beck, A. T., \& Clark, D. A. (1997). An information processing model of anxiety: Automatic and strategic processes. Behaviour Research and Therapy, 35, 49-58. doi:10.1016/S0005-7967(96)00069-1

Beck, A. T., Freeman, A., \& Davis, D. D. (Eds.). (2004). Cognitive therapy of personality disorders (2nd ed.). New York: Guilford Press.

Beck, A. T., Rush, A. J., Shaw, B. F., \& Emery, G. (1979). Cognitive therapy of depression. New York: Guilford Press.

Biby, E. L. (1998). The relationship between body dysmorphic disorder and depression, self-esteem, somatization, and obsessive-compulsive disorder. Journal of Clinical Psychology, 54, 489-499. doi:10.1002/(SICI)1097-4679(199806)54:4<489::AID-JCLP10< 3.0.CO;2-B

Birch, C. D., Stewart, S. H., Wiers, R. W., Klein, R. M., MacLean, A. D., $\&$ Berish, M. J. (2008). The mood-induced activation of implicit alcohol cognition in enhancement and coping motivated drinkers. Addictive Behaviors, 33, 565-581. doi:10.1016/j.addbeh.2007.11.004

Blanton, H., \& Jaccard, J. (2006). Arbitrary metrics in psychology. American Psychologist, 61, 27-41. doi:10.1037/0003-066X.61.1.27

Blanton, H., Jaccard, J., Klick, J., Mellers, B., Mitchell, G., \& Tetlock, P. E. (2009). Strong claims and weak evidence: Reassessing the predictive validity of the IAT. Journal of Applied Psychology, 94, 567-582. doi:10.1037/a0014665

Bluemke, M., \& Friese, M. (2008). Reliability and validity of the SingleTarget IAT (ST-IAT): Assessing automatic affect towards multiple attitude objects. European Journal of Social Psychology, 38, 977-997. doi:10.1002/ejsp.487

Boldero, J. M., Rawlings, D., \& Haslam, N. (2007). Convergence between GNAT-assessed implicit and explicit personality. European Journal of Personality, 21, 341-358. doi:10.1002/per.622

Bosson, J. K., Swann, W. B., \& Pennebaker, J. W. (2000). Stalking the perfect measure of implicit self-esteem: The blind men and the elephant revisited? Journal of Personality and Social Psychology, 79, 631-643. doi:10.1037/0022-3514.79.4.631

Bradley, B. P., Field, M., Healy, H., \& Mogg, K. (2008). Do the affective properties of smoking-related cues influence attentional and approach biases in cigarette smokers? Journal of Psychopharmacology, 22, 737745. doi: $10.1177 / 0269881107083844$

Bradley, B. P., Field, M., Mogg, K., \& De Houwer, J. (2004). Attentional and evaluative biases for smoking cues in nicotine dependence: Component processes of biases in visual orienting. Behavioural Pharmacology, 15, 29-36. doi:10.1097/01.fbp.0000113331.49506.b5 
Brandon, T. H., \& Baker, T. B. (1991). The Smoking Consequences Questionnaire: The subjective expected utility of smoking in college students. Psychological Assessment: A Journal of Consulting and Clinical Psychology, 3, 484-491. doi:10.1037/1040-3590.3.3.484

Brauer, M., de Jong, P. J., Huijding, J., Laan, E., \& ter Kuile, M. M. (2009). Automatic and deliberate affective associations with sexual stimuli in women with superficial dyspareunia. Archives of Sexual Behavior, 38, 486-497. doi:10.1007/s10508-008-9367-4

Brauer, M., ter Kuile, M. M., Janssen, S. A., \& Laan, E. (2007). The effect of pain-related fear on sexual arousal in women with superficial dyspareunia. European Journal of Pain, 11, 788-798. doi:10.1016/ j.ejpain.2006.12.006

Bray, G. A., \& Popkin, B. M. (1998). Dietary fat intake does affect obesity. American Journal of Clinical Nutrition, 68, 1157-1173.

Bruce, B., \& Agras, W. S. (1992). Binge eating in females: A populationbased investigation. International Journal of Eating Disorders, 12, 365373. doi:10.1002/1098-108X(199212)12:4<365::AID-EAT2260120404< 3.0.CO;2-M

Buchner, A., \& Wippich, W. (2000). On the reliability of implicit and explicit memory measures. Cognitive Psychology, 40, 227-259. doi: 10.1006/cogp.1999.0731

Buhlmann, U., Teachman, B. A., Gerbershagen, A., Kikul, J., \& Rief, W. (2008). Implicit and explicit self-esteem and attractiveness beliefs among individuals with body dysmorphic disorder. Cognitive Therapy and Research, 32, 213-225. doi:10.1007/s10608-006-9095-9

Chassin, L., Presson, C. C., Rose, J., Sherman, S. J., \& Prost, J. (2002). Parental smoking cessation and adolescent smoking. Journal of Pediatric Psychology, 27, 485-496. doi:10.1093/jpepsy/27.6.485

Chassin, L., Presson, C. C., Sherman, S. J., \& Edwards, D. A. (1991). Four pathways to young-adult smoking status: Adolescent socialpsychological antecedents in a midwestern community sample. Health Psychology, 10, 409-418. doi:10.1037/0278-6133.10.6.409

Chen, M., \& Bargh, J. A. (1999). Consequences of automatic evaluation: Immediate behavioral predispositions to approach or avoid the stimulus. Personality and Social Psychology Bulletin, 25, 215-224. doi:10.1177/ 0146167299025002007

Clark, D. A., Beck, A. T., \& Alford, B. A. (1999). Scientific foundations of cognitive theory and therapy of depression. New York: Wiley.

Clark, D. M. (1986). A cognitive approach to panic. Behaviour Research and Therapy, 24, 461-470. doi:10.1016/0005-7967(86)90011-2

Clark, D. M., Salkovskis, P. M., Breitholz, E., Westling, B. E., Öst, L. G., Koehler, K. A., \& Gelder, M. (1997). Misinterpretation of bodily sensations in panic disorder. Journal of Consulting and Clinical Psychology, 65, 203-213. doi:10.1037/0022-006X.65.2.203

Clark, D. M., \& Wells, A. (1995). A cognitive model of social phobia. In R. Heimberg, M. Liebowitz, D. A. Hope, \& F. R. Schneider (Eds.), Social phobia: Diagnosis, assessment, and treatment (pp. 69-93). New York: Guilford Press.

Clerkin, E. M., \& Teachman, B. A. (2009). Automatic and strategic measures as predictors of mirror gazing among individuals with body dysmorphic disorder symptoms. Journal of Nervous and Mental Disease, 197, 589-598. doi:10.1097/NMD.0b013e3181b05d7f

Conner, M. T., Perugini, M., O'Gorman, R., Ayres, K., \& Prestwich, A. (2007). Relations between implicit and explicit measures of attitudes and measures of behavior: Evidence of moderation by individual difference variables. Personality and Social Psychology Bulletin, 33, 1727-1740. doi:10.1177/0146167207309194

Conner, M. T., \& Sparks, P. (2002). Ambivalence and attitudes. European Review of Social Psychology, 12, 37-70. doi:10.1080/14792772143000012

Conrey, F. R., Sherman, J. W., Gawronski, B., Hugenberg, K., \& Groom, C. J. (2005). Separating multiple processes in implicit social cognition: The quad model of implicit task performance. Journal of Personality and Social Psychology, 89, 469-487. doi:10.1037/0022-3514.89.4.469

Conrod, P. J., Peterson, J. B., \& Pihl, R. O. (2001). Reliability and validity of alcohol-induced heart rate increase as a measure of sensitivity to the stimulant properties of alcohol. Psychopharmacology, 157, 20-30. doi: $10.1007 / \mathrm{s} 002130100741$

Cooper, M. L., Frone, M. R., Russell, M., \& Mudar, P. (1995). Drinking to regulate positive and negative emotions: A motivational model of alcohol use. Journal of Personality and Social Psychology, 69, 990-1005. doi:10.1037/0022-3514.69.5.990

Craeynest, M., Crombez, G., De Houwer, J., Deforche, B., \& De Bourdeaudhuij, I. (2006). Do children with obesity implicitly identify with sedentariness and fat food? Journal of Behavior Therapy and Experimental Psychiatry, 37, 347-357. doi:10.1016/j.jbtep.2006.02.003

Craeynest, M., Crombez, G., De Houwer, J., Deforche, B., Tanghe, A., \& De Bourdeaudhuij, I. (2005). Explicit and implicit attitudes towards food and physical activity in childhood obesity. Behaviour Research and Therapy, 43, 1111-1120. doi:10.1016/j.brat.2004.07.007

Craeynest, M., Crombez, G., Deforche, B., Tanghe, A., \& De Bourdeaudhuij, I. (2008). The role of implicit attitudes towards food and physical activity in the treatment of youth obesity. Eating Behaviors, 9, 41-51. doi:10.1016/j.eatbeh.2007.03.002

Craeynest, M., Crombez, G., Haerens, L., \& De Bourdeaudhuij, I. (2007). Do overweight youngsters like food more than lean peers? Assessing their implicit attitudes with a personalized Implicit Association Task. Food Quality and Preference, 18, 1077-1084. doi:10.1016/j.foodqual 2007.05.003

Cunningham, W. A., Preacher, K. J., \& Banaji, M. R. (2001). Implicit attitude measures: Consistency, stability, and convergent validity. Psychological Science, 12, 163-170. doi:10.1111/1467-9280.00328

Czyzewska, M., \& Ginsburg, H. J. (2007). Explicit and implicit effects of anti-marijuana and anti-tobacco TV advertisements. Addictive Behaviors, 32, 114-127. doi:10.1016/j.addbeh.2006.03.025

Dasgupta, N., McGhee, D. E., Greenwald, A. G., \& Banaji, M. R. (2000). Automatic preference for White Americans: Eliminating the familiarity explanation. Journal of Experimental Social Psychology, 36, 316-328. doi:10.1006/jesp.1999.1418

De Houwer, J. (2001). A structural and process analysis of the Implicit Association Test. Journal of Experimental Social Psychology, 37, 443451. doi:10.1006/jesp.2000.1464

De Houwer, J. (2002). The Implicit Association Test as a tool for studying dysfunctional associations in psychopathology: Strengths and limitations. Journal of Behavior Therapy and Experimental Psychiatry, 33, 115-133. doi:10.1016/S0005-7916(02)00024-1

De Houwer, J. (2003a). A structural analysis of indirect measures of attitudes. In J. Musch \& K. C. Klauer (Eds.), The psychology of evaluation: Affective processes in cognition and emotion (pp. 219-244). Mahwah, NJ: Erlbaum.

De Houwer, J. (2003b). The extrinsic affective Simon task. Experimental Psychology, 50, 77-85. doi:10.1026//1618-3169.50.2.77

De Houwer, J. (2006). What are implicit measures and why are we using them? In R. W. Wiers \& A. W. Stacy (Eds.), The handbook of implicit cognition and addiction (pp. 11-28). Thousand Oaks, CA: Sage.

De Houwer, J. (2009). Comparing measures of attitudes at the functional and procedural level: Analysis and implications. In R. E. Petty, R. H. Fazio, \& P. Brinol (Eds.), Attitudes: Insights from the new implicit measures (pp. 361-390). New York: Erlbaum.

De Houwer, J., Crombez, G., Baeyens, F., \& Hermans, D. (2001). On the generality of the affective Simon effect. Cognition \& Emotion, 15, 189-206. doi:10.1080/0269993004200051

De Houwer, J., Crombez, G., Koster, E. H. W., \& De Beul, N. (2004). Implicit alcohol-related cognitions in a clinical sample of heavy drinkers. Journal of Behavior Therapy and Experimental Psychiatry, 35, 275-286. doi:10.1016/j.jbtep.2004.05.001

De Houwer, J., Custers, R., \& De Clercq, A. (2006). Do smokers have a negative implicit attitude towards smoking? Cognition \& Emotion, 20, 1274-1284. doi:10.1080/02699930500484506 
De Houwer, J., \& De Bruycker, E. (2007). The Identification-EAST as a valid measure of implicit attitudes toward alcohol-related stimuli. Journal of Behavior Therapy and Experimental Psychiatry, 38, 133-143. doi:10.1016/j.jbtep.2006.10.004

De Houwer, J., \& Eelen, P. (1998). An affective variant of the Simon paradigm. Cognition \& Emotion, 12, 45-61. doi:10.1080/ 026999398379772

De Houwer, J., Geldof, T., \& De Bruycker, E. (2005). The Implicit Association Test as a general measure of similarity. Canadian Journal of Experimental Psychology, 59, 228-239. doi:10.1037/h0087478

De Houwer, J., Teige-Mocigemba, S., Spruyt, A., \& Moors, A. (2009a). Implicit measures: A normative analysis and review. Psychological Bulletin, 135, 347-368. doi:10.1037/a0014211

De Houwer, J., Teige-Mocigemba, S., Spruyt, A., \& Moors, A. (2009b). Theoretical claims necessitate basic research: Reply to Gawronski, Lebel, Peters, and Banse (2009) and Nosek and Greenwald (2009). Psychological Bulletin, 135, 377-379. doi:10.1037/a0015328

de Jong, P. J. (2002). Implicit self-esteem and social anxiety: Differential self-favouring effects in high and low anxious individuals. Behaviour Research and Therapy, 40, 501-508. doi:10.1016/S0005-7967(01)00022-5

de Jong, P. J., \& Muris, P. (2002). Spider phobia: Interaction of disgust and perceived likelihood of involuntary physical contact. Journal of Anxiety Disorders, 16, 51-65. doi:10.1016/S0887-6185(01)00089-5

de Jong, P. J., Pasman, W., Kindt, M., \& van den Hout, M. A. (2001). A reaction time paradigm to assess (implicit) complaint-specific dysfunctional beliefs. Behaviour Research and Therapy, 39, 101-113. doi: 10.1016/S0005-7967(99)00180-1

de Jong, P. J., van den Hout, M. A., Rietbroek, H., \& Huijding, J. (2003). Dissociations between implicit and explicit attitudes towards phobic stimuli. Cognition \& Emotion, 17, 521-545. doi:10.1080/ 02699930302305

de Jong, P. J., \& Veenstra, E. (2007, June). Automatic approach-avoidance tendencies and dysfunctional eating patterns. Paper presented at the Fifth World Congress of Behavioural and Cognitive Therapy, Barcelona, Spain.

de Jong, P. J., Wiers, R. W., van de Braak, M., \& Huijding, J. (2007). Using the Extrinsic Affective Simon Test as a measure of implicit attitudes towards alcohol: Relationship with drinking behavior and alcohol problems. Addictive Behaviors, 32, 881-887. doi:10.1016/ j.addbeh.2006.06.017

de Liver, Y., van der Pligt, J., \& Wigboldus, D. (2007). Positive and negative associations underlying ambivalent attitudes. Journal of Experimental Social Psychology, 43, 319-326. doi:10.1016/j.jesp.2006.02.012

De Raedt, R., Schacht, R., Franck, E., \& De Houwer, J. (2006). Self-esteem and depression revisited: Implicit positive self-esteem in depressed patients? Behaviour Research and Therapy, 44, 1017-1028. doi: 10.1016/j.brat.2005.08.003

de Zwaan, M., \& Mitchell, J. E. (1992). Binge eating in the obese. Annals of Medicine, 24, 303-308. doi:10.3109/07853899209149959

Egloff, B., \& Schmukle, S. C. (2002). Predictive validity of an Implicit Association Test for assessing anxiety. Journal of Personality and Social Psychology, 83, 1441-1455. doi:10.1037/0022-3514.83.6.1441

Ellwart, T., Becker, E. S., \& Rinck, M. (2005). Activation and measurement of threat associations in fear of spiders: An application of the extrinsic affective Simon task. Journal of Behaviour Therapy and Experimental Psychiatry, 36, 281-299. doi:10.1016/j.jbtep.2004.08.008

Ellwart, T., Rinck, M., \& Becker, E. S. (2006). From fear to love: Individual differences in implicit spider associations. Emotion, 6, 18-27. doi:10.1037/1528-3542.6.1.18

Engelhard, I. M., Huijding, J., van den Hout, M., \& de Jong, P. J. (2007). Vulnerability associations and symptoms of posttraumatic stress disorder after peacekeeping duties in Iraq. Behaviour Research and Therapy, 45, 2317-2325. doi:10.1016/j.brat.2007.04.005

Fazio, R. H. (2001). On the automatic evaluation of associated evaluations:
An overview. Cognition \& Emotion, 15, 115-141. doi:10.1080/ 0269993004200024

Fazio, R. H., Jackson, J. R., Dunton, B. C., \& Williams, C. J. (1995), Variability in automatic activation as an unobtrusive measure of racial attitudes: A bona fide pipeline? Journal of Personality and Social Psychology, 69, 1013-1027. doi:10.1037/0022-3514.69.6.1013

Fazio, R. H., \& Olson, M. A. (2003). Implicit measures in social cognition research: Their meaning and use. Annual Review of Psychology, 54, 297-327.

Fazio, R. H., Sanbonmatsu, D. M., Powell, M. C., \& Kardes, F. R. (1986). On the automatic activation of attitudes. Journal of Personality and Social Psychology, 50, 229-238. doi:10.1037/0022-3514.50.2.229

Fazio, R. H., \& Towles-Schwen, T. (1999). The MODE model of attitudebehavior processes. In S. Chaiken \& Y. Trope (Eds.), Dual-process theories in social psychology (pp. 97-116). New York: Guilford Press.

Fiedler, K., Messner, C., \& Bluemke, M. (2006). Unresolved problems with the "I", the "A", and the "T": A logical and psychometric critique of the Implicit Association Test (IAT). European Review of Social Psychology, 17, 74-147. doi:10.1080/10463280600681248

Field, M., Eastwood, B., Bradley, B. P., \& Mogg, K. (2006). Selective processing of cannabis cues in regular cannabis users. Drug and Alcohol Dependence, 85, 75-82. doi:10.1016/j.drugalcdep.2006.03.018

Field, M., Kiernan, A., Eastwood, B., \& Child, R. (2008). Rapid approach responses to alcohol cues in heavy drinkers. Journal of Behavior Therapy and Experimental Psychiatry, 39, 209-218. doi:10.1016/ j.jbtep.2007.06.001

Field, M., Mogg, K., \& Bradley, B. P. (2004). Cognitive bias and drug craving in recreational cannabis users. Drug and Alcohol Dependence, 74, 105-111. doi:10.1016/j.drugalcdep.2003.12.005

Field, M., Mogg, K., \& Bradley, B. P. (2005a). Alcohol increases cognitive biases for smoking cues in smokers. Psychopharmacology, 180, 63-72. doi:10.1007/s00213-005-2251-1

Field, M., Mogg, K., \& Bradley, B. P. (2005b). Craving and cognitive biases for alcohol cues in social drinkers. Alcohol and Alcoholism, 40, 504-510. doi:10.1093/alcalc/agh213

Fishbach, A., Friedman, R. S., \& Kruglanski, A. W. (2003). Leading us not into temptation: Momentary allurements elicit overriding goal activation. Journal of Personality and Social Psychology, 84, 296-309. doi: 10.1037/0022-3514.84.2.296

Fishbach, A., \& Shah, J. Y. (2006). Self-control in action: Implicit dispositions toward goals and away from temptations. Journal of Personality and Social Psychology, 90, 820-832. doi:10.1037/0022-3514.90.5.820

Foa, E. B., \& Kozak, M. J. (1986). Emotional processing of fear: Exposure to corrective information. Psychological Bulletin, 99, 20-35. doi: 10.1037/0033-2909.99.1.20

Franck, E., De Raedt, R., \& De Houwer, J. (2008). Activation of latent self-schemas as a cognitive vulnerability factor for depression: The potential role of implicit self-esteem. Cognition \& Emotion, 22, 1588 1599. doi:10.1080/02699930801921271

Franck, E., De Raedt, R., Dereu, M., \& Van den Abbeele, D. (2007). Implicit and explicit self-esteem in currently depressed individuals with and without suicidal ideation. Journal of Behavior Therapy and Experimental Psychiatry, 38, 75-85. doi:10.1016/j.jbtep.2006.05.003

Freud, S. (1914). The psychopathology of everyday life (A. A. Brill, Trans.). New York: Macmillan. doi:10.1037/10012-000. (Original work published 1901)

Friese, M., Hofmann, W., \& Wänke, M. (2008). When impulses take over: Moderated predictive validity of explicit and implicit attitude measures in predicting food choice and consumption behaviour. British Journal of Social Psychology, 47, 397-419. doi:10.1348/014466607X241540

Gamer, J., Schmukle, S. C., Luka-Krausgrill, U., \& Egloff, B. (2008). Examining the dynamics of the implicit and the explicit self-concept in social anxiety: Changes in the implicit association test-Anxiety and the 
Social Phobia Anxiety Inventory following treatment. Journal of Personality Assessment, 90, 476-480. doi:10.1080/00223890802248786

Gatchel, R. J., Peng, Y. B., Peters, M. L., Fuchs, P. N., \& Turk, D. C. (2007). The biopsychosocial approach to chronic pain: Scientific advances and future directions. Psychological Bulletin, 133, 581-624. doi:10.1037/0033-2909.133.4.581

Gemar, M. C., Segal, Z. V., Sagrati, S., \& Kennedy, S. J. (2001). Moodinduced changes on the Implicit Association Test in recovered depressed patients. Journal of Abnormal Psychology, 110, 282-289. doi:10.1037/ 0021-843X.110.2.282

Gendall, K. A., \& Joyce, P. R. (2001). Characteristics of food cravers who binge eat. In M. M. Hetherington (Ed.), Food cravings and addiction (pp. 567-583). London: Leatherhead.

Gerding, A. L., \& Weinstein, L. (1992). Taste ratings of obese people, and taste preferences based on geographical location. Bulletin of the Psychonomic Society, 30, 509-510.

Goldman, M. S., Del Boca, F. K., \& Darkes, J. (1999). Alcohol expectancy theory: The application of cognitive neuroscience. In K. E. Leonard \& H. T. Blane (Eds.), Psychological theories of drinking and alcoholism (2nd ed., pp. 203-246). New York: Guilford Press.

Goubert, L., Crombez, G., Hermans, D., \& Vanderstraeten, G. (2003). Implicit attitude towards pictures of back-stressing activities in pain-free subjects and patients with low back pain: An affective priming study. European Journal of Pain, 7, 33-42. doi:10.1016/S10903801(02)00054-X

Gray, N. S., Brown, A. S., MacCulloch, M. J., Smith, J., \& Snowden, R. J. (2005). An implicit test of the associations between children and sex in pedophiles. Journal of Abnormal Psychology, 114, 304-308. doi: 10.1037/0021-843X.114.2.304

Greenwald, A. G., \& Farnham, S. D. (2000). Using the Implicit Association Test to measure self-esteem and self-concept. Journal of Personality and Social Psychology, 79, 1022-1038. doi:10.1037/00223514.79.6.1022

Greenwald, A. G., McGhee, D. E., \& Schwartz, J. L. K. (1998). Measuring individual differences in implicit cognition: The Implicit Association Test. Journal of Personality and Social Psychology, 74, 1464-1480. doi:10.1037/0022-3514.74.6.1464

Greenwald, A. G., Nosek, B. A., \& Siriam, N. (2006). Consequential validity of the Implicit Association Test. American Psychologist, 61, 56-61. doi:10.1037/0003-066X.61.1.56

Greenwald, A. G., Poehlman, T. A., Uhlmann, E. L., \& Banaji, M. R. (2009). Understanding and using the implicit association test: III. Metaanalysis of predictive validity. Journal of Personality and Social Psychology, 97, 17-41. doi:10.1037/a0015575

Grumm, M., Erbe, K., von Collani, G., \& Nestler, S. (2008). Automatic processing of pain: The change of implicit pain associations after psychotherapy. Behaviour Research and Therapy, 46, 701-714. doi: 10.1016/j.brat.2008.02.009

Haeffel, G. J., Abramson, L. Y., Brazy, P. C., Shah, J. Y., Teachman, B. A., \& Nosek, B. A. (2007). Explicit and implicit cognition: A preliminary test of a dual-process theory of cognitive vulnerability to depression. Behaviour Research and Therapy, 45, 1155-1167. doi:10.1016/ j.brat.2006.09.003

Harvey, A., Watkins, E., Mansell, W., \& Shafran, R. (Eds.). (2004). Cognitive behavioural processes across psychological disorders: A transdiagnostic approach to research and treatment. Oxford, England: Oxford University Press.

Heatherton, T. F., Herman, C. P., Polivy, J., King, G. A., \& McGree, S. T. (1988). The (mis)measurement of restraint: An analysis of conceptual and psychometric issues. Journal of Abnormal Psychology, 97, 19-28. doi:10.1037/0021-843X.97.1.19

Heimberg, R. G., Hope, D. A., Rapee, R. M., \& Bruch, M. A. (1988). The validity of the Social Avoidance and Distress Scale and the Fear of
Negative Evaluation Scale with social phobic patients. Behaviour Research and Therapy, 26, 407-410. doi:10.1016/0005-7967(88)90074-5

Herman, C. P., \& Polivy, J. (2004). The self-regulation of eating: Theoretical and practical problems. In R. F. Baumeister \& K. D. Vohs (Eds.), Handbook of self-regulation research (pp. 492-508). New York: Guilford Press.

Hermans, D., De Houwer, J., \& Eelen, P. (1994). The affective priming effect: Automatic activation of evaluative information in memory. Cog nition \& Emotion, 8, 515-533. doi:10.1080/02699939408408957

Hermans, D., De Houwer, J., \& Eelen, P. (2001). A time course analysis of the affective priming effect. Cognition \& Emotion, 15, 143-165. doi: $10.1080 / 0269993004200033$

Heuer, K., Rinck, M., \& Becker, E. S. (2007). Avoidance of emotional expressions in social anxiety: The approach-avoidance task. Behaviour Research and Therapy, 45, 2990-3001. doi:10.1016/j.brat.2007.08.010

Hine, D. W., Honan, C. A., Marks, A. D. G., \& Brettschneider, K. (2007). Development and validation of the Smoking Expectancy Scale for Adolescents. Psychological Assessment, 19, 347-355. doi:10.1037/ 1040-3590.19.3.347

Hoefling, A., \& Strack, F. (2008). The tempting effect of forbidden foods: High calorie content evokes conflicting implicit and explicit evaluations in restrained eaters. Appetite, 51, 681-689. doi:10.1016/j.appet .2008 .06 .004

Hofmann, W., \& Friese, M. (2008). Impulses got the better of me: Alcohol moderates the influence of the impulsive vs. reflective system on eating behavior. Journal of Abnormal Psychology, 117, 420-427. doi:10.1037/ 0021-843X.117.2.420

Hofmann, W., Friese, M., \& Roefs, A. (2009). Three ways to resist temptation: The independent contributions of executive attention, inhibitory control, and affect regulation to the impulse control of eating behavior. Journal of Experimental Social Psychology, 45, 431-435. doi:10.1016/j.jesp.2008.09.013

Hofmann, W., Gawronski, B., Gschwendner, T., Le, H., \& Schmitt, M. (2005). A meta-analysis on the correlation between the Implicit Association Test and explicit self-report measures. Personality and Social Psychology Bulletin, 31, 1369-1385. doi:10.1177/0146167205275613

Hofmann, W., Gschwendner, T., Wiers, R. W., Friese, M., \& Schmitt, M. (2008). Working memory capacity and self-regulation: Towards an individual differences perspective on behavior determination by automatic versus controlled processes. Journal of Personality and Social Psychology, 95, 962-977. doi:10.1037/a0012705

Hofmann, W., Rauch, W., \& Gawronski, B. (2007). And deplete us not into temptation: Automatic attitudes, dietary restraint, and self-regulatory resources as determinants of eating behavior. Journal of Experimental Social Psychology, 43, 497-504. doi:10.1016/j.jesp.2006.05.004

Hollon, S. D., Kendall, P. C., \& Lumry, A. (1986). Specificity of depressotypic cognitions in clinical depression. Journal of Abnormal Psychology, 95, 52-59. doi:10.1037/0021-843X.95.1.52

Houben, K., \& Wiers, R. W. (2006a). A test of the salience asymmetry interpretation of the Alcohol-IAT. Experimental Psychology, 53, 292300. doi:10.1027/1618-3169.53.4.292

Houben, K., \& Wiers, R. W. (2006b). Assessing implicit alcohol associations with the Implicit Association Test: Fact or artifact? Addictive Behaviors, 31, 1346-1362. doi:10.1016/j.addbeh.2005.10.009

Houben, K., \& Wiers, R. W. (2007a). Are drinkers implicitly positive about drinking alcohol? Personalizing the Alcohol-IAT to reduce negative extrapersonal contamination. Alcohol and Alcoholism, 42, 301-307. doi:10.1093/alcalc/agm015

Houben, K., \& Wiers, R. W. (2007b). Personalizing the Alcohol-IAT with individualized stimuli: Relationship with drinking behavior and drinking-related problems. Addictive Behaviors, 32, 2852-2864. doi: 10.1016/j.addbeh.2007.04.022

Houben, K., \& Wiers, R. W. (2008a). Implicitly positive about alcohol? 
Implicit positive associations predict drinking behavior. Addictive Behaviors, 33, 979-986. doi:10.1016/j.addbeh.2008.03.002

Houben, K., \& Wiers, R. W. (2008b). Measuring implicit alcohol associations via the Internet: Validation of web-based implicit association tests. Behavior Research Methods, 40, 1134-1143. doi:10.3758/ BRM.40.4.1134

Houben, K., \& Wiers, R. W. (2009). Beer makes the heart grow fonder: Single-target implicit attitudes toward beer but not alcohol are related to drinking behavior in regular beer drinkers. The Netherlands Journal of Psychology, 65, 10-21. doi:10.1007/BF03080123

Huijding, J., \& de Jong, P. J. (2005a). A modified Extrinsic Affective Simon Task (EAST) to assess the affective value of pictorial stimuli: No influence of age and educational level. Psychologica Belgica, 45, 241255

Huijding, J., \& de Jong, P. J. (2005b). A pictorial version of the extrinsic affective Simon task: Sensitivity to generally affective and phobiarelevant stimuli in high and low spider fearful individuals. Experimental Psychology, 52, 289-295. doi:10.1027/1618-3169.52.4.289

Huijding, J., \& de Jong, P. J. (2006a). Automatic associations with the sensory aspects of smoking: Positive in habitual smokers but negative in non-smokers. Addictive Behaviors, 31, 182-186. doi:10.1016/ j.addbeh.2005.04.014

Huijding, J., \& de Jong, P. J. (2006b). Specific predictive power of automatic spider-related affective associations for controllable and uncontrollable fear responses toward spiders. Behaviour Research and Therapy, 44, 161-176. doi:10.1016/j.brat.2005.01.007

Huijding, J., \& de Jong, P. J. (2007). Beyond fear and disgust: The role of (automatic) contamination-related associations in spider phobia. Journal of Behaviour Therapy and Experimental Psychiatry, 38, 200-211. doi: 10.1016/j.jbtep.2006.10.009

Huijding, J., \& de Jong, P. J. (2009). Implicit and explicit attitudes toward spiders: Sensitivity to treatment and predictive validity for generalization of treatment effects. Cognitive Therapy and Research, 33, 211-220. doi:10.1007/s10608-007-9167-5

Huijding, J., de Jong, P. J., Wiers, R. W., \& Verkooijen, K. (2005). Implicit and explicit attitudes toward smoking in a smoking and a nonsmoking setting. Addictive Behaviors, 30, 949-961. doi:10.1016/j.addbeh .2004 .09 .014

Jacoby, L. L. (1991). A process-dissociation framework: Separating automatic from intentional uses of memory. Journal of Memory \& Language, 30, 513-541. doi:10.1016/0749-596X(91)90025-F

Jajodia, A., \& Earleywine, M. (2003). Measuring alcohol expectancies with the Implicit Association Test. Psychology of Addictive Behaviors, 17, 126-133. doi:10.1037/0893-164X.17.2.126

Jansen, A. (1998). A learning model of binge eating: Cue reactivity and cue exposure. Behaviour Research and Therapy, 36, 257-272. doi:10.1016/ S0005-7967(98)00055-2

Jansen, A. (2001). Craving and binge eating. In M. M. Hetherington (Ed.), Food cravings and addiction (pp. 549-565). Surrey, England: Leatherhead.

Jéquier, E. (2002). Pathways to obesity. International Journal of Obesity, 26, S12-S17. doi:10.1038/sj.ijo.0802123

Jones, B. T., Corbin, W., \& Fromme, K. (2001). A review of expectancy theory and alcohol consumption. Addiction, 96, 57-72. doi:10.1046/ j.1360-0443.2001.961575.x

Kahler, C. W., Daughters, S. B., Leventhal, A. M., Gwaltney, C. J., \& Palfai, T. P. (2007). Implicit associations between smoking and social consequences among smokers in cessation treatment. Behaviour Research and Therapy, 45, 2066-2077. doi:10.1016/j.brat.2007.03.004

Karpinski, A., \& Hilton, J. L. (2001). Attitudes and the Implicit Association Test. Journal of Personality and Social Psychology, 81, 774-788. doi:10.1037/0022-3514.81.5.774

Karpinski, A., \& Steinman, R. B. (2006). The Single Category Implicit Association Test as a measure of implicit social cognition. Journal of
Personality and Social Psychology, 91, 16-32. doi:10.1037/00223514.91.1.16

Keefe, F. J., Rumble, M. E., Scipio, C. D., Giordano, L. A., \& Perri, L. M. (2004). Psychological aspects of persistent pain. The Journal of Pain, 5, 195-211. doi:10.1016/j.jpain.2004.02.576

Klauer, K. C., \& Musch, J. (2003). Affective priming: Findings and theories. In J. Musch, \& K. C. Klauer (Eds.), The psychology of evaluation (pp. 7-49). Mahwah, NJ: Erlbaum.

Leeuw, M., Peters, M. L., Wiers, R. W., \& Vlaeyen, J. W. S. (2007) Measuring fear of movement/(re)injury in chronic low back pain using implicit measures. Cognitive Behaviour Therapy, 36, 52-64. doi: 10.1080/16506070601070400

Linton, S. J. (2000). A review of psychological risk factors in back and neck pain. Spine, 25, 1148-1156. doi:10.1097/00007632-20000501000017

MacLeod, C. M. (2008). Implicit memory tests: Techniques for reducing conscious intrusion. In J. Dunlosky \& R. A. Bjork (Eds.), Handbook of metamemory and memory (pp. 245-263). New York: Psychology Press.

Maison, D., Greenwald, A. G., \& Bruin, R. (2001). The Implicit Association Test as a measure of implicit consumer attitudes. Polish Psychological Bulletin, 32, 61-69.

McCarthy, D. M., \& Thompsen, D. M. (2006). Implicit and explicit measures of alcohol and smoking cognitions. Psychology of Addictive Behaviors, 20, 436-444. doi:10.1037/0893-164X.20.4.436

McConnell, A. R., \& Leibold, J. M. (2009). Weak criticisms and selective evidence: Reply to Blanton et al. (2009). Journal of Applied Psychology, 94, 583-589. doi:10.1037/a0014649

Meites, T. M., Deveney, C. M., Steele, K. T., Holmes, A. J., \& Pizzagalli, D. A. (2008). Implicit depression and hopelessness in remitted depressed individuals. Behaviour Research and Therapy, 46, 1078-1084. doi: 10.1016/j.brat.2008.05.008

Mierke, J., \& Klauer, K. C. (2003). Method-specific variance in the implicit association test. Journal of Personality and Social Psychology, 85, 1180-1192. doi:10.1037/0022-3514.85.6.1180

Mogg, K., Bradley, B. P., Field, M., \& De Houwer, J. (2003). Eye movements to smoking-related pictures in smokers: Relationship between attentional biases and implicit and explicit measures of stimulus valence. Addiction, 98, 825-836. doi:10.1046/j.1360-0443.2003.00392.x

Mogg, K., Field, M., \& Bradley, B. P. (2005). Attentional and approach biases for smoking cues in smokers: An investigation of competing theoretical views of addiction. Psychopharmacology, 180, 333-341. doi:10.1007/s00213-005-2158-x

Monteith, M. J., Voils, C. I., \& Ashburn-Nardo, L. (2001). Taking a look underground: Detecting, interpreting, and reacting to implicit racial biases. Social Cognition, 19, 395-417. doi:10.1521/soco.19.4.395.20759

Moors, A., \& De Houwer, J. (2006). Automaticity: A theoretical and conceptual analysis. Psychological Bulletin, 132, 297-326. doi:10.1037/ 0033-2909.132.2.297

Mullens, A. B., Young, R. M., Dunne, M., \& Norton, G. (2010). The cannabis expectancy questionnaire for men who have sex with men (CEQ-MSM): A measure of substance-related beliefs. Addictive Behaviors, 35, 616-619. doi:10.1016/j.addbeh.2010.01.006

Nisbett, R. E., \& Wilson, T. D. (1977). Telling more than we can know: Verbal reports on mental processes. Psychological Review, 84, 231-259. doi:10.1037/0033-295X.84.3.231

Nock, M. K., \& Banaji, M. R. (2007). Prediction of suicide ideation and attempts among adolescents using a brief performance-based test. Journal of Consulting and Clinical Psychology, 75, 707-715. doi:10.1037/ 0022-006X.75.5.707

Nosek, B. A. (2005). Moderators of the relationship between implicit and explicit evaluation. Journal of Experimental Psychology: General, 134, 565-584. doi:10.1037/0096-3445.134.4.565

Nosek, B. A., \& Banaji, M. R. (2001). The go/no-go association task. Social Cognition, 19, 625-666. doi:10.1521/soco.19.6.625.20886 
Nosek, B. A., \& Greenwald, A. G. (2009). (Part of) the case for a pragmatic approach to validity: Comment on De Houwer, Teige-Mocigemba, Spruyt, and Moors (2009). Psychological Bulletin, 135, 373-376. doi: 10.1037/a0015047

Nosek, B. A., Greenwald, A. G., \& Banaji, M. R. (2007). The Implicit Association Test at age 7: A methodological and conceptual review. In J. A. Bargh (Ed.), Automatic processes in social thinking and behavior (pp. 265-292). New York: Psychology Press.

Nosek, B. A., \& Hansen, J. J. (2008). The associations in our heads belong to us: Searching for attitudes and knowledge in implicit evaluation. Cognition \& Emotion, 22, 553-594. doi:10.1080/02699930701438186

Nosek, B. A., \& Smyth, F. L. (2007). A multitrait-multimethod validation of the Implicit Association Test. Experimental Psychology, 54, 14-29. doi:10.1027/1618-3169.54.1.14

Obsessive Compulsive Cognitions Working Group. (2001). Development and initial validation of the Obsessive Beliefs Questionnaire and the Interpretation of Intrusions Inventory. Behaviour Research and Therapy, 39, 987-1006. doi:10.1016/S0005-7967(00)00085-1

Obsessive Compulsive Cognitions Working Group. (2003). Psychometric validation of the Obsessive Beliefs Questionnaire and the Interpretation of Intrusions Inventory: Part I. Behaviour Research and Therapy, 41, 863-878. doi:10.1016/S0005-7967(02)00099-2

Olson, M. A., \& Fazio, R. H. (2001). Implicit attitude formation through classical conditioning. Psychological Science, 12, 413-417. doi: 10.1111/1467-9280.00376

Olson, M. A., \& Fazio, R. H. (2002). Implicit acquisition and manifestation of classically conditioned attitudes. Social Cognition, 20, 89-104. doi: 10.1521/soco.20.2.89.20992

Olson, M. A., \& Fazio, R. H. (2003). Relations between implicit measures of prejudice: What are we measuring? Psychological Science, 14, 636639. doi:10.1046/j.0956-7976.2003.psci_1477.x

Olson, M. A., \& Fazio, R. H. (2004). Reducing the influence of extrapersonal associations on the Implicit Association Test: Personalizing the IAT. Journal of Personality and Social Psychology, 86, 653-667. doi: 10.1037/0022-3514.86.5.653

Olson, M. A., Fazio, R. H., \& Han, A. (2009). Conceptualizing personal and extrapersonal associations. Social and Personality Psychology Compass, 3, 152-170. doi:10.1111/j.1751-9004.2008.00164.x

Ostafin, B. D., Marlatt, G. A., \& Greenwald, A. G. (2008). Drinking without thinking: An implicit measure of alcohol motivation predicts failure to control alcohol use. Behaviour Research and Therapy, 46, 1210-1219. doi:10.1016/j.brat.2008.08.003

Ostafin, B. D., \& Palfai, T. P. (2006). Compelled to consume: The Implicit Association Test and automatic alcohol motivation. Psychology of Addictive Behaviors, 20, 322-327. doi:10.1037/0893-164X.20.3.322

Ostafin, B. D., Palfai, T. P., \& Wechsler, C. E. (2003). The accessibility of motivational tendencies toward alcohol: Approach, avoidance, and disinhibited drinking. Experimental and Clinical Psychopharmacology, 11, 294-301. doi:10.1037/1064-1297.11.4.294

Palfai, T. P., \& Ostafin, B. D. (2003a). Alcohol-related motivational tendencies in hazardous drinkers: Assessing implicit response tendencies using the modified-IAT. Behaviour Research and Therapy, 41, 11491162. doi:10.1016/S0005-7967(03)00018-4

Palfai, T. P., \& Ostafin, B. D. (2003b). The influence of alcohol on the activation of outcome expectancies: The role of evaluative expectancy activation in drinking behavior. Journal of Studies on Alcohol, 64, 111-119.

Papies, E. K., Stroebe, W., \& Aarts, H. (2008). Healthy cognition: Processes of self-regulatory success in restrained eating. Personality and Social Psychology Bulletin, 34, 1290-1300. doi:10.1177/ 0146167208320063

Payne, B. K., Burkley, M. A., \& Stokes, M. B. (2008). Why do implicit and explicit attitude tests diverge? The role of structural fit. Journal of
Experimental and Social Psychology, 94, 16-31. doi:10.1037/00223514.94.1.16

Perugini, M. (2005). Predictive models of implicit and explicit attitudes. British Journal of Social Psychology, 44, 29-45. doi:10.1348/ 014466604X23491

Perugini, M., O'Gorman, R., \& Prestwich, A. (2007). An ontological test of the IAT: Self-activation can increase predictive validity. Experimental Psychology, 54, 134-147. doi:1027/1618-3169.54.2.134

Pinel, J. P. J., Assanand, S., \& Lehman, D. R. (2000). Hunger, eating, and ill health. American Psychologist, 55, 1105-1116. doi:10.1037/0003066X.55.10.1105

Pinter, B., \& Greenwald, A. G. (2005). Clarifying the role of the "other" category in the self-esteem IAT. Experimental Psychology, 52, 74-79. doi:10.1027/1618-3169.52.1.74

Rachman, S. (1997). A cognitive theory of obsessions. Behaviour Research and Therapy, 35, 793-802. doi:10.1016/S0005-7967(97)00040-5

Rachman, S., \& De Silva, P. (1978). Abnormal and normal obsessions. Behaviour Research and Therapy, 16, 233-248. doi:10.1016/00057967(78) $90022-0$

Rapee, R. M., \& Heimberg, R. G. (1997). A cognitive-behavioral model of anxiety in social phobia. Behaviour Research and Therapy, 35, 741-756. doi:10.1016/S0005-7967(97)00022-3

Rather, B. C., Goldman, M. S., Roehrich, L., \& Brannick, M. (1992). Empirical modeling of an alcohol expectancy memory network using multidimensional scaling. Journal of Abnormal Psychology, 101, 174183. doi:10.1037/0021-843X.101.1.174

Ray, L. A., \& Hutchison, K. E. (2004). A polymorphism of the mu-opioid receptor gene (OPRM1) and sensitivity to the effects of alcohol in humans. Alcoholism: Clinical and Experimental Research, 28, 17891795. doi:10.1097/01.ALC.0000148114.34000.B9

Richetin, J., Perugini, M., Prestwich, A., \& O'Gorman, R. (2007). The IAT as a predictor of food choice: The case of fruits versus snacks. International Journal of Psychology, 42, 166-173. doi:10.1080/ 00207590601067078

Rinck, M., \& Becker, E. S. (2007). Approach and avoidance in fear of spiders. Journal of Behavior Therapy and Experimental Psychiatry, 38, 105-120. doi:10.1016/j.jbtep.2006.10.001

Rissanen, A., Hakala, P., Lissner, L., Mattlar, C. E., Koskenvuo, M., \& Ronnemaa, T. (2002). Acquired preference especially for dietary fat and obesity: A study of weight-discordant monozygotic twin pairs. International Journal of Obesity, 26, 973-977. doi:10.1038/sj.ijo.0802014

Roberts, J. E., \& Monroe, S. M. (1994). A multidimensional model of self-esteem in depression. Clinical Psychology Review, 14, 161-181. doi:10.1016/0272-7358(94)90006-X

Robinson, M. D., Meier, B. P., Zetocha, K. J., \& McCaul, K. D. (2005). Smoking and the Implicit Association Test: When the contrast category determines the theoretical conclusions. Basic and Applied Social Psychology, 27, 201-212. doi:10.1207/s15324834basp2703_2

Roefs, A., Herman, C. P., MacLeod, C. M., Smulders, F. T. Y., \& Jansen, A. (2005). At first sight: How do restrained eaters respond to high-fat palatable foods? Appetite, 44, 103-114. doi:10.1016/j.appet.2004.08.001

Roefs, A., \& Jansen, A. (2002). Implicit and explicit attitudes toward high-fat foods in obesity. Journal of Abnormal Psychology, 111, 517521. doi:10.1037/0021-843X.111.3.517

Roefs, A., Quaedackers, L., Werrij, M. Q., Wolters, G., Havermans, R., Nederkoorn, C., Van Breukelen, G., \& Jansen, A. (2006). The environment influences whether high-fat foods are associated with palatable or with unhealthy. Behaviour Research and Therapy, 44, 715-736. doi: 10.1016/j.brat.2005.05.007

Roefs, A., Stapert, D., Isabella, L. A. S., Wolters, G., Wojciechowski, F., \& Jansen, A. (2005). Early associations with food in anorexia nervosa patients and obese people assessed in the affective priming paradigm. Eating Behaviors, 6, 151-163. doi:10.1016/j.eatbeh.2004.10.001

Rosmarin, D. H., Bourque, L. M., Antony, M. M., \& McCabe, R. E. 
(2009). Interpretation bias in panic disorder: Self-referential or global? Cognitive Therapy and Research, 33, 624-632. doi:10.1007/s10608009-9249-7

Rothermund, K., \& Wentura, D. (2001). Figure-ground asymmetries in the Implicit Association Test (IAT). Zeitschrift fur Experimentelle Psychologie, 48, 94-106.

Rothermund, K., \& Wentura, D. (2004). Underlying processes in the Implicit Association Test: Dissociating salience from associations. Journal of Experimental Psychology: General, 133, 139-165. doi:10.1037/ 0096-3445.133.2.139

Rudman, L. A., Phelan, J. E., \& Heppen, J. B. (2007). Developmental sources of implicit attitudes. Personality and Social Psychology Bulletin, 33, 1700-1713. doi:10.1177/0146167207307487

Salkovskis, P. M. (1985). Obsessional-compulsive problems: A cognitivebehavioural analysis. Behaviour Research and Therapy, 23, 571-583. doi:10.1016/0005-7967(85)90105-6

Schmukle, S. C., \& Egloff, B. (2004). Does the Implicit Association Test for assessing anxiety measure trait and state variance? European Journal of Personality, 18, 483-494. doi:10.1002/per.525

Schneider, R., \& Schulte, D. (2007). Panic patients reveal idiographic associations between anxiety symptoms and catastrophes in a semantic priming task. Behaviour Research and Therapy, 45, 211-223. doi: 10.1016/j.brat.2006.02.007

Schneider, R., \& Schulte, D. (2008). Catastrophic associations predict level of change in anxiety sensitivity in response to cognitive-behavioural treatment for panic. Behaviour Research and Therapy, 46, 557-572. doi:10.1016/j.brat.2008.01.015

Schwarz, N. (1999). Self-reports: How the questions shape the answers. American Psychologist, 54, 93-105. doi:10.1037/0003-066X.54.2.93

Schwarz, N., \& Oyserman, D. (2001). Asking questions about behavior: Cognition, communication, and questionnaire construction. American Journal of Evaluation, 22, 127-160. doi:10.1177/109821400102200202

Seibt, B., Häfner, M., \& Deutsch, R. (2007). Prepared to eat: How immediate affective and motivational responses to food cues are influenced by food deprivation. European Journal of Social Psychology, 37, 359-379. doi:10.1002/ejsp.365

Sherman, S. J., Rose, J. S., Koch, K., Presson, C. C., \& Chassin, L. (2003). Implicit and explicit attitudes toward cigarette smoking: The effects of context and motivation. Journal of Social and Clinical Psychology, 22, 13-39. doi:10.1521/jscp.22.1.13.22766

Silverman, J. S., Silverman, J. A., \& Eardley, D. A. (1984). Do maladaptive attitudes cause depression? Archives of General Psychiatry, 41, $28-30$.

Smith, E. R., \& DeCoster, J. (2000). Dual-process models in social and cognitive psychology: Conceptual integration and links to underlying memory systems. Personality and Social Psychology Review, 4, 108131. doi:10.1207/S15327957PSPR0402_01

Spruyt, A., Hermans, D., De Houwer, J., Vandekerckhove, J., \& Eelen, P. (2007). On the predictive validity of indirect attitude measures: Prediction of consumer choice behavior on the basis of affective priming in the picture-picture naming task. Journal of Experimental Social Psychology, 43, 599-610. doi:10.1016/j.jesp.2006.06.009

Stacy, A. W., Bentler, P. M., \& Flay, B. R. (1994). Attitudes and health behavior in diverse populations: Drunk driving, alcohol use, binge eating, marijuana use, and cigarette use. Health Psychology, 13, 73-85. doi: $10.1037 / 0278-6133.13 .1 .73$

Stacy, A. W., Newcomb, M. D., \& Bentler, P. M. (1995). Expectancy in meditational models of cocaine use. Personality and Individual Differences, 19, 655-667. doi:10.1016/0191-8869(95)00100-K

Stafford, L. D., \& Scheffler, G. (2008). Hunger inhibits negative associations to food but not auditory biases in attention. Appetite, 51, 731-734. doi:10.1016/j.appet.2008.04.020

Steffens, M. C. (2004). Is the Implicit Association Test immune to faking?
Experimental Psychology, 51, 165-179. doi:10.1027/16183169.51.3.165

Steinberg, J. A., Karpinski, A., \& Alloy, L. B. (2007). The exploration of implicit aspects of self-esteem in vulnerability-stress models of depression. Self and Identity, 6, 101-117. doi:10.1080/15298860601118884

Stice, E. (2002). Risk and maintenance factors for eating pathology: A meta-analytic review. Psychological Bulletin, 128, 825-848. doi: 10.1037/0033-2909.128.5.825

Stoner, S. A., Fedoroff, I. C., Andersen, A. E., \& Rolls, B. J. (1996). Food preferences and desire to eat in anorexia and bulimia nervosa. International Journal of Eating Disorders, 19, 13-22. doi:10.1002/(SICI)1098108X(199601)19:1<13

Strack, F., \& Deutsch, R. (2004). Reflective and impulsive determinants of social behavior. Personality and Social Psychology Review, 8, 220-247. doi:10.1207/s15327957pspr0803_1

Stroebe, W., Mensink, W., Aarts, H., Schut, H., \& Kruglanski, A. W. (2008). Why dieters fail: Testing the goal conflict model of eating. Journal of Experimental Social Psychology, 44, 26-36. doi:10.1016/ j.jesp.2007.01.005

Swanson, J. E., Rudman, L. A., \& Greenwald, A. G. (2001). Using the Implicit Association Test to investigate attitude-behaviour consistency for stigmatized behaviour. Cognition \& Emotion, 15, 207-230. doi: 10.1080/0269993004200060.

Tanner, R. J., Stopa, L., \& De Houwer, J. (2006). Implicit views of the self in social anxiety. Behaviour Research and Therapy, 44, 1397-1409. doi:10.1016/j.brat.2005.10.007

Teachman, B. A. (2005). Information processing and anxiety sensitivity: Cognitive vulnerability to panic reflected in interpretation and memory biases. Cognitive Therapy and Research, 29, 479-499. doi:10.1007/ s10608-005-0627-5

Teachman, B. A. (2007). Evaluating implicit spider fear associations using the go/no-go association task. Journal of Behaviour Therapy and Experimental Psychiatry, 38, 156-167. doi:10.1016/j.jbtep.2006.10.006

Teachman, B. A., \& Clerkin, E. M. (2007). Obsessional beliefs and the implicit and explicit morality of intrusive thought. Cognition \& Emotion, 21, 999-1024. doi:10.1080/02699930600985576

Teachman, B. A., Gregg, A. P., \& Woody, S. R. (2001). Implicit associations for fear-relevant stimuli among individuals with snake and spider fears. Journal of Abnormal Psychology, 110, 226-235. doi:10.1037/ 0021-843X.110.2.226

Teachman, B. A., Marker, C. D., \& Smith-Janik, S. B. (2008). Automatic associations and panic disorder: Trajectories of change over the course of treatment. Journal of Consulting and Clinical Psychology, 76, 988 1002. doi:10.1037/a0013113

Teachman, B. A., Smith-Janik, S. B., \& Saporito, J. (2007). Information processing biases and panic disorder: Relationships among cognitive and symptom measures. Behaviour Research and Therapy, 45, 1791-1811. doi:10.1016/j.brat.2007.01.009

Teachman, B. A., \& Woody, S. R. (2003). Automatic processing in spider phobia: Implicit fear associations over the course of treatment. Journal of Abnormal Psychology, 112, 100-109. doi:10.1037/0021843X.112.1.100

Teachman, B. A., Woody, S. R., \& Magee, J. C. (2006). Implicit and explicit appraisals of the importance of intrusive thoughts. Behaviour Research and Therapy, 44, 785-805. doi:10.1016/j.brat.2005.05.005

Teige, S., Schnabel, K., Banse, R., \& Asendorpf, J. B. (2004). Assessment of multiple implicit self-concept dimensions using the Extrinsic Affective Simon Task (EAST). European Journal of Personality, 18, 495520. doi:10.1002/per.531

Thorpe, S. J., \& Salkovskis, P. M. (1995). Phobia beliefs: Do cognitive factors play a role in specific phobias? Behaviour Research and Therapy, 33, 805-816. doi:10.1016/0005-7967(95)00022-P

Thush, C., \& Wiers, R. W. (2007). Explicit and implicit alcohol-related 
cognitions and the prediction of future drinking in adolescents. Addictive Behaviors, 32, 1367-1383. doi:10.1016/j.addbeh.2006.09.011

Thush, C., Wiers, R. W., Ames, S. L., Grenard, J. L., Sussman, S., \& Stacy, A. W. (2007). Apples and oranges? Comparing indirect measures of alcohol-related cognition predicting alcohol use in at-risk adolescents. Psychology of Addictive Behaviors, 21, 587-591. doi:10.1037/0893164X.21.4.587

Thush, C., Wiers, R. W., Ames, S. L., Grenard, J. L., Sussman, S., \& Stacy, A. W. (2008). Interactions between implicit and explicit cognition and working memory capacity in the prediction of alcohol use in at-risk adolescents. Drug and Alcohol Dependence, 94, 116-124. doi:10.1016/ j.drugalcdep.2007.10.019

Thush, C., \& Wiers, R. W., Moerbeek, M., Ames, S. L., Grenard, J. L., Sussman, S., \& Stacy, A. W. (2009). Influence of motivational interviewing on explicit and implicit alcohol-related cognition and alcohol use in at-risk adolescents. Psychology of Addictive Behaviors, 23, 146151. doi:10.1037/a0013789

van den Wildenberg, E., Beckers, M., van Lambaart, F., Conrod, P. J., \& Wiers, R. W. (2006). Is the strength of implicit alcohol associations correlated with alcohol-induced heart-rate acceleration? Alcoholism, Clinical and Experimental Research, 30, 1336-1348. doi:10.1111/ j.1530-0277.2006.00161.x

van den Wildenberg, E., Wiers, R. W., Janssen, R. G. J. H., Lambrichs, E. H., Smeets, H. J. M., \& Van Breukelen, G. J. P. (2007). A functional polymorphism of the mu-opioid receptor gene (OPRM1) influences cue-induced craving for alcohol in male heavy drinkers. Alcoholism: Clinical and Experimental Research, 31, 1-10. doi:10.1111/j.15300277.2006.00258.x

Vancleef, L. M. G., Peters, M. L., Gilissen, S. M. P., \& de Jong, P. J. (2007). Understanding the role of injury/illness sensitivity and anxiety sensitivity in (automatic) pain processing: An examination using the Extrinsic Affective Simon Task. Journal of Pain, 8, 563-572. doi: 10.1016/j.jpain.2007.02.431

Vartanian, L. R., Polivy, J., \& Herman, C. P. (2004). Implicit cognitions and eating disorders: Their application in research and treatment. Cognitive and Behavioral Practice, 11, 160-167. doi:10.1016/S10777229(04)80027-0

Veale, D. (2004). Advances in a cognitive behavioural model of body dysmorphic disorder. Body Image, 1, 113-125. doi:10.1016/S17401445(03)00009-3

Veale, D., Boocock, A., Gournay, K., Dryden, W., Shah, F., Willson, R., \& Walburn, J. (1996). Body dysmorphic disorder: A survey of fifty cases. British Journal of Psychiatry, 169, 196-201. doi:10.1192/ bjp.169.2.196

Vlaeyen, J. W. S., Kole-Snijders, A. M. J., Boeren, R. G. B., \& van Eek, H. (1995). Fear of movement/(re)injury in chronic low back pain and its relation to behavioral performance. Pain, 62, 363-372. doi:10.1016/ 0304-3959(94)00279-N

Waters, A. J., Carter, B. L., Robinson, J. D., Wetter, D. W., Lam, C. Y., \& Cinciripini, P. M. (2007). Implicit attitudes to smoking are associated with craving and dependence. Drug and Alcohol Dependence, 91, 178186. doi:10.1016/j.drugalcdep.2007.05.024

Watts, F. N., McKenna, F. P., Sharrock, R., \& Trezise, L. (1986). Colour naming of phobia-related words. British Journal of Psychology, 77, $97-108$.

Weiner, M. B., \& White, M. T. (1982). Depression as the search for the lost self. Psychotherapy: Theory, Research and Practice, 19, 491-499. doi: 10.1037/h0088462

Werrij, M. Q., Roefs, A., Janssen, I., Stapert, D., Wolters, G., Mulkens, S., ... Jansen, A. (2009). Early associations with palatable foods in overweight and obesity are not disinhibition related but restraint related. Journal of Behavior Therapy and Experimental Psychiatry, 40, 136146. doi:10.1016/j.jbtep.2008.07.003

Westberg, P., Lundh, L. G., \& Jönsson, P. (2007). Implicit associations and social anxiety. Cognitive Behaviour Therapy, 36, 43-51. doi:10.1080/ 08037060601020401

Wiers, R. W., Houben, K., \& de Kraker, J. (2007). Implicit cocaine associations in active cocaine users and controls. Addictive Behaviors, 32, 1284-1289. doi:10.1016/j.addbeh.2006.07.009

Wiers, R. W., Rinck, M., Dictus, M., \& van den Wildenberg, E. (2009). Relatively strong automatic appetitive action-tendencies in male carriers of the OPRM1 g-Allele. Genes, Brain and Behavior, 8, 101-106. doi: 10.1111/j.1601-183X.2008.00454.x

Wiers, R. W., \& Stacy, A. W. (2010). Are alcohol expectancies associations? Comment on Moss and Albery (2009). Psychological Bulletin, 136, 12-16. doi:10.1037/a0017769

Wiers, R. W., van de Luitgaarden, J., van den Wildenberg, E., \& Smulders, F. T. (2005). Challenging implicit and explicit alcohol-related cognitions in young heavy drinkers. Addiction, 100, 806-819. doi:10.1111/j.13600443.2005.01064.x

Wiers, R. W., Van Woerden, N., Smulders, F. T. Y., \& de Jong, P. J. (2002). Implicit and explicit alcohol-related cognitions in heavy and light drinkers. Journal of Abnormal Psychology, 111, 648-658. doi: 10.1037/0021-843X.111.4.648

Williams, J. M. G., Mathews, A., \& MacLeod, C. (1996). The emotional Stroop task and psychopathology. Psychological Bulletin, 120, 3-24. doi:10.1037/0033-2909.120.1.3

Williams, J. M. G., Watts, F. N., MacLeod, C., \& Matthews, A. (1997). Cognitive psychology and the emotional disorders. New York: Wiley.

Yamaguchi, S., Greenwald, A. G., Banaji, M. R., Murakami, F., Chen, D., Shiomura, K., . . Krendl, A. (2007). Apparent universality of positive implicit self-esteem. Psychological Science, 18, 498-500. doi:10.1111/ j.1467-9280.2007.01928.x

Ziegert, J. C., \& Hanges, P. J. (2009). Strong rebuttal for weak criticisms: Reply to Blanton et al. (2009). Journal of Applied Psychology, 94 590-597. doi:10.1037/a0014661

Received January 30, 2009

Revision received September 13, 2010

Accepted September 20, 2010 